FEDERAL RESERVE BANK OF SAN FRANCISCO

WORKING PAPER SERIES

\title{
Accounting for Low Long-Term Interest Rates: Evidence from Canada
}

\author{
Jens H. E. Christensen \\ Federal Reserve Bank of San Francisco \\ Glenn D. Rudebusch \\ Federal Reserve Bank of San Francisco \\ Patrick J. Shultz \\ Wharton School of the University of Pennsylvania
}

July 2021

Working Paper 2020-35

https://www.frbsf.org/economic-research/publications/working-papers/2020/35/

\section{Suggested citation:}

Christensen, Jens H. E., Glenn D. Rudebusch, Patrick J. Shultz. 2021. “Accounting for Low Long-Term Interest Rates: Evidence from Canada," Federal Reserve Bank of San Francisco Working Paper 2020-35. https://doi.org/10.24148/wp2020-35

The views in this paper are solely the responsibility of the authors and should not be interpreted as reflecting the views of the Federal Reserve Bank of San Francisco or the Board of Governors of the Federal Reserve System. 


\title{
Accounting for Low Long-Term Interest Rates: Evidence from Canada
}

\author{
Jens H. E. Christensen ${ }^{\dagger}$ \\ Glenn D. Rudebusch ${ }^{\ddagger}$ \\ Patrick J. Shultz*
}

\begin{abstract}
In recent decades, long-term interest rates around the world have fallen to historic lows. We examine the source of this decline using a dynamic term structure model of Canadian nominal and real yields with adjustments for term, liquidity, and inflation risk premiums. Canada provides a novel perspective on this issue because of its established indexed debt market, negligible distortions from monetary quantitative easing or the zero lower bound, and absence of sovereign credit risk. We find that since 2000, the steady-state real interest rate has fallen by more than 2 percentage points, long-term inflation expectations have edged down, and real bond and inflation risk premiums have varied over time but shown little longer-run trend. Therefore, the drop in the equilibrium real rate appears largely to account for the lower new normal in interest rates.
\end{abstract}

\section{JEL Classification: C32, E43, E52, G12, G17}

Keywords: affine arbitrage-free term structure model, liquidity risk, financial market frictions, r-star

We thank conference participants at the 2nd LTI/Bank of Italy Workshop on Long-Term Investors' Trends: Theory and Practice and the 37th International Conference of the French Finance Association (AFFI) for helpful comments and suggestions, including our discussants Juan Arismendi Zambrano and Fan Dora Xia. We also thank seminar participants at the Bank of Canada for helpful comments and suggestions. Furthermore, we thank Antonio Diez de los Rios for helpful comments on an early draft of the paper. Finally, we thank Dori Wilson and Simon Zhu for outstanding research assistance. The views in this paper are solely the responsibility of the authors and should not be interpreted as reflecting the views of the Federal Reserve Bank of San Francisco or the Federal Reserve System.

${ }^{\dagger}$ Corresponding author: Federal Reserve Bank of San Francisco, 101 Market Street MS 1130, San Francisco, CA 94105, USA; phone: 1-415-974-3115; e-mail: jens.christensen@sf.frb.org.

${ }^{\ddagger}$ Federal Reserve Bank of San Francisco; e-mail: glenn.rudebusch@sf.frb.org.

*Wharton School of the University of Pennsylvania; e-mail: pshultz@wharton.upenn.edu.

This version: June 14, 2021. 


\section{Introduction}

The secular decline in global long-term nominal interest rates over the past few decades has been the subject of much discussion and research. Indeed, the possibility of a lower new normal for interest rates has been at the center of key economic, financial, and policy debates about the transformation of the economy and bond market dynamics. Still, the source and permanence of the gradual decline in interest rates remain unresolved. Therefore, in this paper, we estimate a comprehensive dynamic term structure model on an under utilized data set to provide a new perspective on the underlying nature of recent low long-term interest rates.

Accounting for the decline in long-term interest rates requires assessing the relative importance of nominal inflationary forces, real economic factors, and risk premiums in pushing down yields. In the 1980s and 1990s, falling inflation expectations played a substantial role in lowering long-term yields, but more recently, actual inflation as well as survey-based measures of longer-run inflation expectations have been relatively more stable. The source of the general decline in interest rates since 2000 appear to reflect a variety of longer-run real-side factors - such as slower productivity growth and an aging population (e.g., Rachel and Smith, 2015, Christensen and Rudebusch, 2019, and Bauer and Rudebusch, 2020). These shifts in economic fundamentals can push down nominal and real yield curves by lowering the steadystate level of the safe short-term real interest rate - the so-called equilibrium or natural or neutral rate of interest. Many researchers have used macroeconomic models and data to try to pin down the equilibrium real rate. Inspired by Christensen and Rudebusch (2019), we use a financial model that accounts for nominal and real factors. ${ }^{1}$ Declining term, inflation risk, and liquidity risk premiums could also play a role in reducing long-term yields, and one advantage of a financial modeling approach is that it allows for explicit risk premiums to account for the new lower normal in interest rates (e.g., Bauer and Rudebusch, 2020). In particular, as price inflation has become better anchored at low levels in many countries, the inflation risk premium may have declined (e.g., Wright, 2011, and Bauer et al., 2014).

Our analysis assesses the relative contribution to lower yields of each of the various components. We employ Canadian government bond prices, which provides a new - or at least, a relatively under-studied-perspective on the lower new normal for interest rates. Besides its novelty, a Canadian case study has several other advantages. First, Canada has deep and liquid markets for government debt. Also, the Bank of Canada had not engaged in unconventional monetary policies such as large-scale asset purchases (also known as quantitative easing) prior to the coronavirus crisis unlike most other major central banks. As a conse-

\footnotetext{
${ }^{1}$ Our finance-based approach has several advantages relative to macro-based estimates. Most notably, our measure does not depend on obtaining a correct, complete, and stable specification of the macroeconomic dynamics of output and inflation, as described in Christensen and Rudebusch (2019).
} 
quence, Canadian bond yields during our sample period, which ends before the onset of the global pandemic, had not been directly affected by such policies (although indirect spillover effects from QE in other countries is a possibility). ${ }^{2}$ Arguably then, the Canadian government bond market offers a cleaner, less-managed setting for analyzing these questions than the euro area, Japan, the U.K., or the U.S., where such policies have been implemented for extended periods. Also, as the underlying factors depressing long-term interest rates are likely global in nature - such as worldwide demographic shifts or disinflationary pressures - the Canadian government bond market may well be about as informative as any other major sovereign bond market. Furthermore, the Canadian government holds a AAA credit rating with a stable outlook from all major rating agencies, which also contrasts with some of its G7 peers. Therefore, there is no credit risk to account for in our Canadian bond price data, which is an additional advantage. Finally, the Canadian government has been issuing inflation-indexed debt since 1991, and Canada therefore offers a relatively long history of both nominal and real yields, only rivaled by U.K. and U.S. samples. ${ }^{3}$

We examine a sample of Canadian nominal government bond yields along with prices of Canadian government Real Return Bonds (RRBs), which have coupon and principal payments indexed to the Canadian Consumer Price Index (CPI). The indexed debt provides compensation to investors for the erosion of purchasing power due to price inflation with prices that can be expressed directly in terms of real yields. We assume that the embedded longer-term expectations in these asset prices reflect financial market participants' views about the steady state of the Canadian economy including the natural rate of interest and the long-run level of inflation (i.e., the perceived Bank of Canada inflation target). Still, the use of RRBs for measuring the steady-state short-term real interest rate and inflation level does pose empirical challenges. One problem is that despite the long history and fairly large notional amount of outstanding RRBs, these securities potentially face appreciable liquidity risk as they tend to have smaller trading volumes and wider bid-ask spreads than Canadian nominal government securities. Presumably, investors require a premium for bearing the liquidity risk associated with holding RRBs, but the extent and time variation of this liquidity premium is unknown and apparently unresearched. This contrasts with numerous studies of the liquidity risk associated with U.S. Treasury Inflation-Protected Securities (TIPS) (e.g., Campbell et al., 2009, Pflueger and Viceira, 2016, and Christensen and Rudebusch, 2019).

To estimate the natural rate of interest and long-term inflation expectations in the presence of liquidity and real and nominal term premiums, we use an arbitrage-free dynamic term

\footnotetext{
${ }^{2}$ See Kearns et al. (2020) for an analysis of monetary policy spillover effects from four major economies to 47 advanced and emerging economies, including Canada, covering the 1999-2019 period.

${ }^{3}$ A long sample allows for robust estimation of the models' objective factor dynamics, which are important for many of our conclusions. See Bauer et al. (2012) for a detailed discussion of the related finite-sample bias problem and its impact on yield curve model estimation.
} 
structure model of nominal and real yields augmented with a liquidity risk factor. The identification of the liquidity risk factor comes from its unique loading for each individual RRB security as in Andreasen et al. (2020, henceforth ACR). Similar to ACR, our analysis combines a standard sample of nominal yields with the prices of individual RRBs. The underlying mechanism for identifying liquidity risk assumes that, over time, an increasing proportion of the outstanding inventory of each RRB is locked up in buy-and-hold investors' portfolios. Given forward-looking investor behavior, this lock-up effect means that a particular bond's sensitivity to the market-wide liquidity factor will vary depending on how seasoned the bond is and how close to maturity it is. In a careful study of nominal U.S. Treasuries, Fontaine and Garcia (2012) also find a pervasive liquidity factor that affects all bond prices with loadings that vary with the maturity and age of each bond. By observing a cross section of RRB prices over time - each with a different time-since-issuance and time-to-maturitywe can identify the overall RRB liquidity factor and each bond's loading on that factor. This technique is particularly useful for analyzing inflation-indexed debt when only a limited sample of bonds may be available as in our case. ${ }^{4,5}$

As in ACR, the frictionless Canadian nominal and real yields follow the model of nominal and real yields introduced in Christensen et al. (2010, henceforth CLR), referred to throughout as the CLR model. We estimate CLR models and their liquidity-augmented extension, denoted CLR-L models. The theoretical arbitrage-free formulation of the CLR-L model also provides identification of a time-varying real term premium in the pricing of RRBs. Identifying the liquidity and term premiums allows us to estimate the underlying frictionless real rate term structure and the natural rate of interest, which we measure as the average expected real short rate over a five-year period starting five years ahead as in Christensen and Rudebusch (2019).

Our preferred estimate of the natural rate of interest, $r_{t}^{*}$, is shown in Figure 1 along with measures of the ten-year nominal and real Canadian government bond yields. Both nominal and real long-term yields have trended down together over the past two decades, and this concurrence suggests little net change in inflation expectations or the inflation risk premium, which is supported by our results as evidenced by the estimated ten-year expected inflation also shown in the figure. Instead, the estimated equilibrium real rate is identified as the primary driver of the long-term yield declines since it has fallen from above 2 percent

\footnotetext{
${ }^{4}$ Finlay and Wende (2012) examine prices from a limited number of Australian inflation-indexed bonds but do not account for their liquidity risk.

${ }^{5}$ We do not account for the liquidity risk in the Canadian nominal bond yields for two reasons. First, our focus is on the real yield aspect of our joint models of nominal and real yields, which is less sensitive to liquidity bias in nominal yields. Second and more importantly, Andreasen et al. (2019) find that pricing in the regular Canadian government bond market appears to be very efficient, which suggests that the liquidity premiums of standard fixed-coupon bonds are likely to be small. This may reflect the fact that the Bank of Canada occasionally buys back seasoned nominal bond series and replaces them with new bond series, which helps maintain liquidity in the secondary market for these bonds.
} 


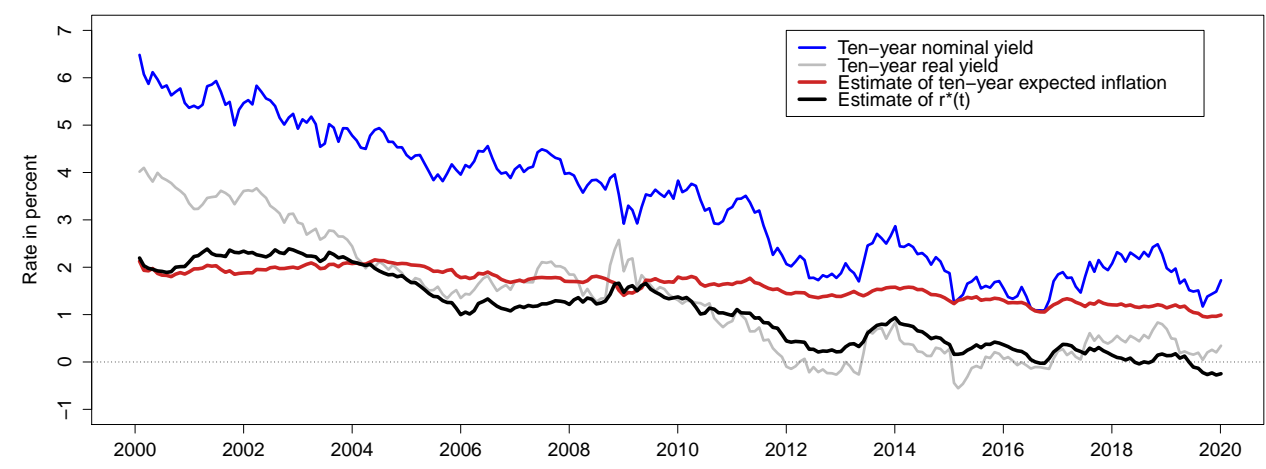

Figure 1: Long-Term Nominal and Real Yields and an Estimate of Ten-Year Expected Inflation and $\mathbf{r}^{*}$

Illustration of (i) the ten-year nominal Canadian government bond yield from the Bolder et al. (2004) database maintained by staff at the Bank of Canada, (ii) the fitted ten-year real Canadian government bond yield from the CLR model with a diagonal specification of $K^{\mathbb{P}}$ and $\Sigma$, (iii) our preferred CLR-L model estimate of the ten-year expected inflation, and (iv) our preferred CLR-L model estimate of the equilibrium real short rate, $r_{t}^{*}$, i.e., the 5 -to-10 year risk-neutral real rate.

to below -0.25 percent during this period. Accordingly, our results show that much of the 4-percentage-point decline in longer-term Canadian bond yields represents a reduction in the natural rate of interest, while ten-year inflation expectations are estimated to have declined only about 1 percentage point. Our model estimates also suggest that this situation is unlikely to reverse quickly in the years ahead.

Furthermore, we find that the average liquidity premiums embedded in the yields of RRBs exhibit notable time variation reaching highs of close to 40 basis points around the peak of the global financial crisis in the fall of 2008. However, since 2012, the average liquidity premium has been in a fairly narrow, slightly negative range. For the entire sample, the estimated RRB liquidity premiums have averaged -2.6 basis points. This can be compared to the results of ACR, who report that the average liquidity premium in U.S. TIPS is estimated at 34 basis points for the 1997-2013 period. The difference in liquidity premium levels across the TIPS and the Canadian RRB markets is likely to be due to the much greater relative liquidity of nominal versus indexed U.S. Treasury securities compared to the more modest liquidity advantage of Canadian fixed-coupon government securities over Canadian RRBs.

In line with the existing literature on TIPS, we rely on a joint modeling of the nominal and real yield curves (e.g., CLR, Abrahams et al., 2016, and D'Amico et al., 2018). Although these joint specifications can also be used to estimate the steady-state real rate similar to our analysis, this earlier work has emphasized only the measurement of inflation expectations and risk. Importantly, our methodology requires a stable dynamic relationship between the pricing 
factors of both nominal and real bonds. This assumption is particularly demanding during the period from 2009 to 2015 when the U.S. Federal Reserve kept the overnight federal funds rate at its effective zero lower bound, which drove Canadian short-term yields to historical lows as well. As a consequence, the dynamic interactions of Canadian short- and mediumterm nominal yields were likely affected (see Swanson and Williams, 2014 and Christensen and Rudebusch, 2015, for discussions). However, given that this issue lies outside the scope of this paper, we leave it for future research to explore that further. ${ }^{6}$

The analysis in this paper relates to several important literatures. Most directly, it speaks to the burgeoning literatures on measurement of both the natural rate of interest and longterm inflation expectations. Second, our estimates of the real yield curve that would prevail without trading frictions have implications for asset pricing analysis on the true slope of the real yield curve. Finally, our results relate to research on financial market liquidity. Indeed, the RRB liquidity premiums we estimate may serve as a benchmark for assessing liquidity premiums in other fixed-income markets in Canada and elsewhere.

The remainder of the paper is structured as follows. Section 2 contains the data description, while Section 3 provides a description of the no-arbitrage term structure model we use and presents the empirical results. Section 4 analyzes our market-based estimates of long-term inflation expectations and the natural rate before Section 6 concludes. An online appendix contains additional technical model details, robustness checks, estimation results, and out-of-sample forecast exercises.

\section{Canadian Government Bond Data}

This section describes the Canadian government bond data used in our model estimation. As for the size of the Canadian government bond market, at the end of December 2019, the total outstanding notional amount of marketable bonds issued by the government of Canada was CAD 580.1 billion of which CAD 65.3 billion, or 11.3 percent, represented RRBs. ${ }^{7}$ The Canadian government bond market is equivalent to about $25 \%$ of Canadian nominal GDP, and the Canadian government holds a AAA rating with a stable outlook by all major rating agencies.

\footnotetext{
${ }^{6}$ We did estimate a shadow-rate version of the CLR-L model that respects the zero lower bound for nominal yields and found that our results were generally robust.

${ }^{7}$ This information is available at http://www.bankofcanada.ca/markets/government-securitiesauctions/goc-t-bills-and-bonds-outstanding/
} 


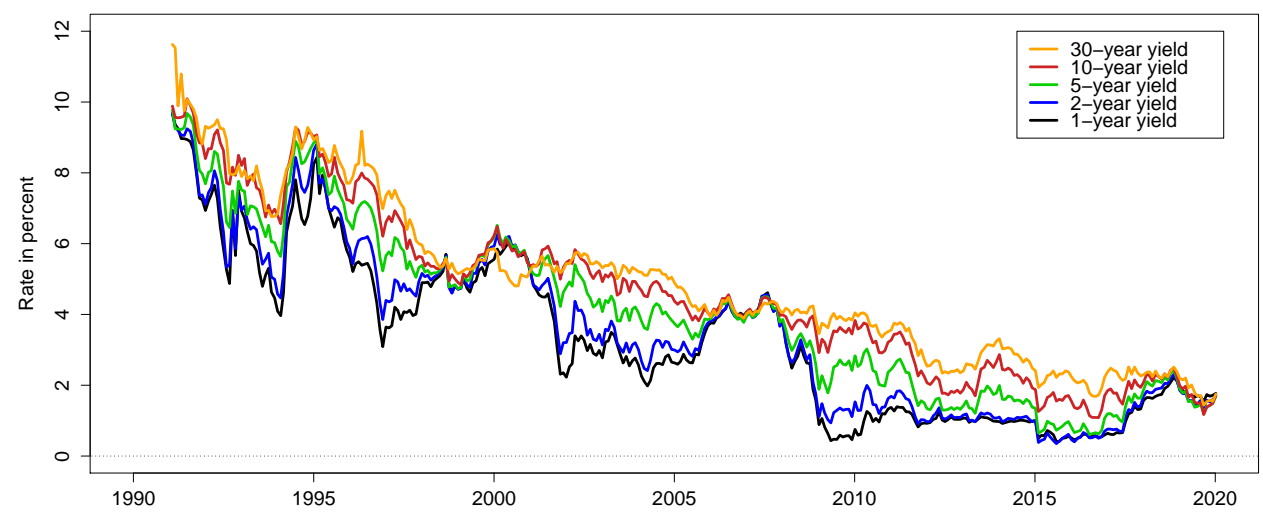

Figure 2: Canadian Nominal Government Bond Yields

Illustration of the Canadian government zero-coupon bond yields constructed by staff at the Bank of Canada with maturities of three months, two years, five years, ten years, and thirty years. The data series are monthly covering the period from January 31, 1991, to December 31, 2019.

\subsection{Nominal Bonds}

The Bank of Canada produces daily zero-coupon yield curves from a subset of the available universe of Canadian government fixed-coupon bonds using an "exponential spline model." 8 The database starts in January 1986 and is updated every Thursday with a two-week reporting lag. Note that, while the database contains the time series of maturities in quarterly increments from three months to thirty years, we limit our focus to a representative sample with the following eleven fixed maturities: $0.25,0.5,1,2,3,5,7,10,15,20$, and 30 years. Furthermore, we limit the sample to monthly data covering the period from January 31, 1991, to December 31, 2019, where the start date matches the launch of the RRB market in $1991 .^{9}$

Figure 2 shows time series of the zero-coupon yields with maturities of three months, two years, five years, ten years, and thirty years. First, we note the downward trend of the general yield level since 1991. The ten-year yield dropped from above 10 percent to below 2 percent over the shown period. Second, as in U.S. Treasury yield data, there is clear business cycle variation in the shape of the yield curve around this lower trend.

Finally, regarding the important question of a lower bound, the Bank of Canada had yet to lower its conventional policy rate to zero during our sample period, and the bond yields in the data have remained well above zero throughout. Thus, we employ an unconstrained

\footnotetext{
${ }^{8}$ See Bolder et al. (2004) for a description of these data, which can be accessed at http://www.bankofcanada.ca/rates/interest-rates/bond-yield-curves/. See Diez de los Rios (2015) for another empirical application using these data.

${ }^{9}$ Although we rely on constructed synthetic nominal zero-coupon bond yields instead of bond prices, Andreasen et al. (2019) provide evidence that this conventional approach to term structure modeling delivers satisfactory estimates of investors' expectations and risk premiums, which is the focus of our paper.
} 


\begin{tabular}{|l|c|c|c|c|}
\hline \multirow{2}{*}{ Real return bond } & \multirow{2}{*}{$\begin{array}{c}\text { No. } \\
\text { obs. }\end{array}$} & \multicolumn{2}{|c|}{ Issuance } & Total notional \\
\cline { 3 - 4 } & Damount & amount & ate & amoun \\
\hline (1) $4.25 \% 12 / 1 / 2021$ & 240 & $12 / 10 / 1991$ & n.a. & 8,508 \\
(2) $4.25 \% 12 / 1 / 2026$ & 240 & $12 / 7 / 1995$ & n.a. & 8,165 \\
(3) $4 \% 12 / 1 / 2031$ & 240 & $3 / 8 / 1999$ & 400 & 8,669 \\
(4) $3 \% 12 / 1 / 2036$ & 199 & $6 / 9 / 2003$ & 400 & 7,758 \\
(5) $2 \% 12 / 1 / 2041$ & 151 & $6 / 4 / 2007$ & 650 & 8,044 \\
(6) $1.5 \% 12 / 1 / 2044$ & 115 & $5 / 31 / 2010$ & 700 & 9,098 \\
(7) $1.25 \% 12 / 1 / 2047$ & 73 & $12 / 2 / 2013$ & 700 & 8,530 \\
(8) $0.5 \% 12 / 1 / 2050$ & 31 & $6 / 5 / 2017$ & 700 & 6,516 \\
\hline
\end{tabular}

Table 1: Sample of Canadian Government Real Return Bonds

The table reports the characteristics, first issuance date and amount, and total notional amount outstanding as of December 31, 2019 in millions of Canadian dollars for the sample of Canadian government real return bonds. Also reported are the number of monthly observation dates for each bond during the sample period from January 31, 2000, to December 31, 2019.

Gaussian model rather than models that respect the zero lower bound (e.g., Christensen and Rudebusch, 2015, and Andreasen and Meldrum, 2019).

\subsection{Real Bonds}

Since 1991, the Canadian government has issued RRBs, which have semi-annual interest payments that are adjusted for inflation using the changes in the all-items Canadian CPI without seasonal adjustment. ${ }^{10}$ These bonds have all been thirty-year bonds and are issued only once every 3-4 years. As a consequence, there is a limited universe of RRBs with a total of eight outstanding at the end of our sample. Due to the limited number of RRBs in the early years and their correspondingly narrow maturity range, we start our sample of RRB prices in 2000. Table 1 contains the contractual details of all eight RRBs as well as the number of monthly observations of each in our sample, while the time-varying maturity distribution of the eight RRBs in our sample is illustrated in Figure 3, where each security is represented by a downward-sloping line showing its remaining years to maturity at each date.

Figure 4 shows the yields to maturity for all eight RRBs. The significant persistent decline in real yields over this 20-year period is clearly visible. Canadian long-term real yields were close to 4 percent in the early 2000s and have dropped to close to zero by the end of our sample. One empirical question is to what extent this decline represents a drop in the natural real rate or is driven by other factors such as liquidity or other risk premiums.

Before turning to model estimation, we examine RRB bid-ask spreads to provide support for the ACR approach to identify liquidity premiums. Figure 5 shows two series of bid-ask

\footnotetext{
${ }^{10}$ Coté et al. (1996) and Reid et al. (2004) are early studies comparing RRB and conventional Canadian nominal bond yields.
} 


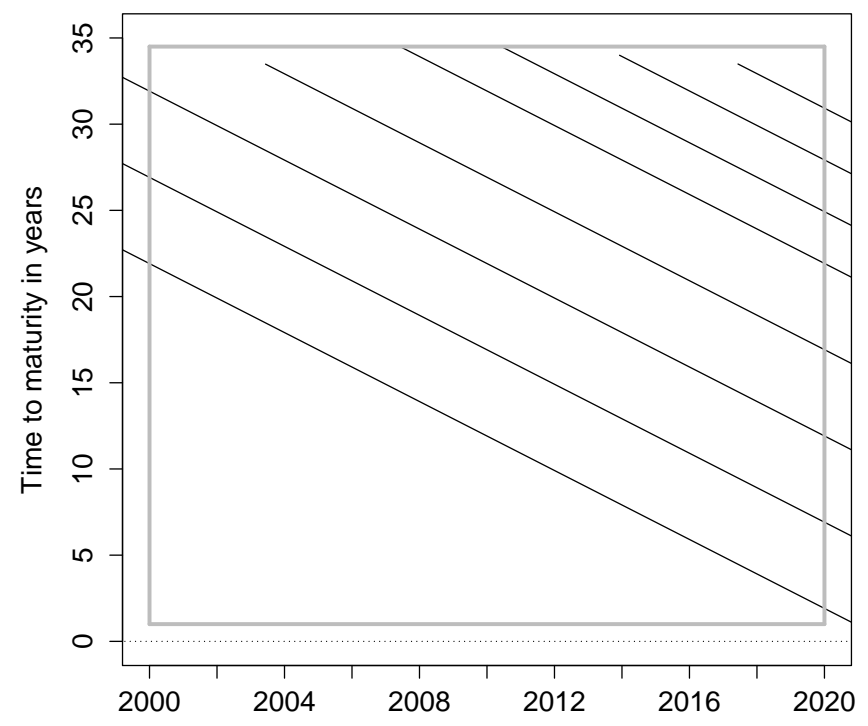

Figure 3: Maturity Distribution of Canadian Government Real Return Bonds

Illustration of the maturity distribution of the available universe of Canadian government real return bonds. The solid grey rectangle indicates the sample used in the empirical analysis, where the sample is restricted to start on January 31, 2000, and end on December 31, 2019.

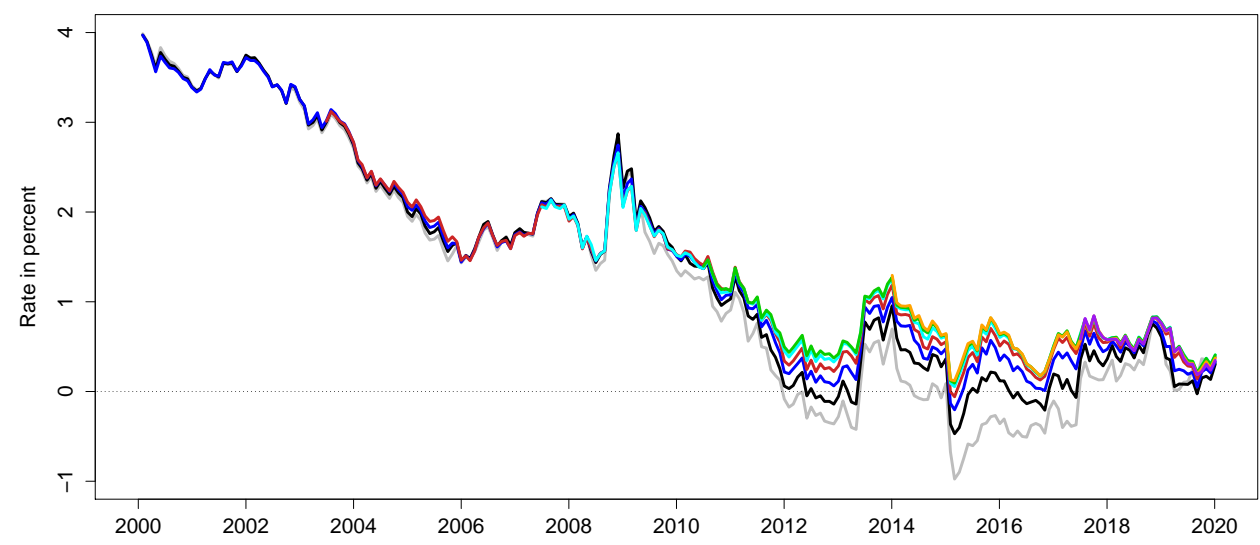

Figure 4: Yield to Maturity of Canadian Government Real Return Bonds

Illustration of the yield to maturity of the Canadian real return bonds considered in this paper covering the period from January 31, 2000, to December 31, 2019.

spreads for Canadian RRBs, one represents the bid-ask spread of the first ever RRB issued in 1991, the other tracks the bid-ask spread of the most recently issued (on-the-run) RRB - a 


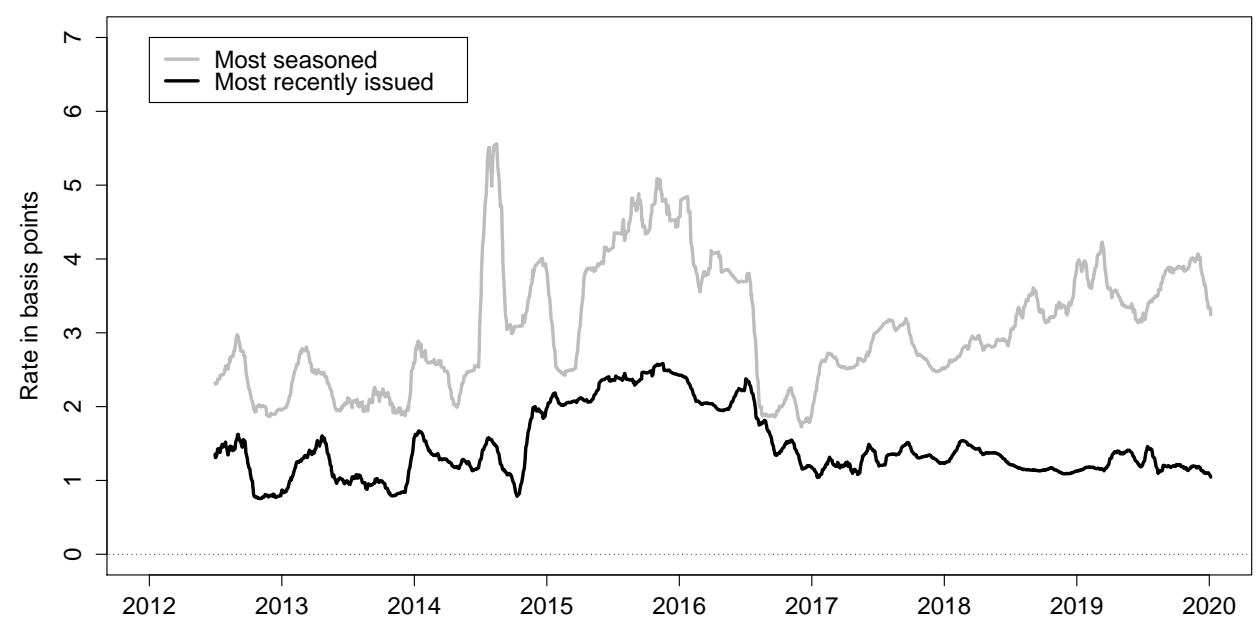

Figure 5: Bid-Ask Spreads of Canadian Real Return Bonds

Illustration of the four-week moving average of bid-ask spreads of Canadian RRBs constructed as explained in the main text. The series are daily covering the period from May 31, 2012, to December $31,2019$.

sequence of different underlying RRBs. Both series are smoothed four-week averages and measured in basis points. Similar to what ACR document for U.S. TIPS, the RRB bid-ask spreads are wider for more seasoned securities than for recently issued securities. Rational, forward-looking investors are aware of these dynamics and the fact that future market liquidity of a given security is likely to be below its current market liquidity. This gives rise to liquidity premiums in the security price that serve as compensation for assuming the risk that it may be difficult to sell the security back to the market in the future at a satisfactory price and without incurring higher transaction costs. This pattern in observed measures of current market liquidity of RRBs is consistent with the factor loading of the liquidity risk factor in our approach that is intended to model the effects on current RRB prices of expected future market liquidity conditions.

\section{Model Estimation and Results}

In this section, we first detail the CLR-L model that serves as the benchmark in our analysis before we describe the restrictions imposed to achieve econometric identification of the model. We then compare its estimates to those from the CLR model without a liquidity adjustment. Finally, we describe the RRB liquidity premium implied by the estimated CLR-L model. 


\subsection{The CLR-L Model}

To begin, let $X_{t}=\left(L_{t}^{N}, S_{t}, C_{t}, L_{t}^{R}, X_{t}^{l i q}\right)$ denote the state vector of the five-factor CLR-L model. Here, $L_{t}^{N}$ and $L_{t}^{R}$ denote the level factor unique to the nominal and real yield curve, respectively, while $S_{t}$ and $C_{t}$ represent slope and curvature factors common to both yield curves. Finally, $X_{t}^{l i q}$ represents the added liquidity factor.

The instantaneous nominal and real risk-free rates are defined as

$$
\begin{aligned}
r_{t}^{N} & =L_{t}^{N}+S_{t}, \\
r_{t}^{R} & =L_{t}^{R}+\alpha^{R} S_{t} .
\end{aligned}
$$

Note that the differential scaling of the real rates to the common slope factor is captured by the parameter $\alpha^{R}$.

The risk-neutral $\mathbb{Q}$-dynamics of the state variables used for pricing are given by

$$
\left(\begin{array}{c}
d L_{t}^{N} \\
d S_{t} \\
d C_{t} \\
d L_{t}^{R} \\
d X_{t}^{l i q}
\end{array}\right)=\left(\begin{array}{ccccc}
0 & 0 & 0 & 0 & 0 \\
0 & \lambda & -\lambda & 0 & 0 \\
0 & 0 & \lambda & 0 & 0 \\
0 & 0 & 0 & 0 & 0 \\
0 & 0 & 0 & 0 & \kappa_{l i q}^{\mathbb{Q}}
\end{array}\right)\left[\left(\begin{array}{c}
0 \\
0 \\
0 \\
0 \\
\theta_{l i q}^{\mathbb{Q}}
\end{array}\right)-\left(\begin{array}{c}
L_{t}^{N} \\
S_{t} \\
C_{t} \\
L_{t}^{R} \\
X_{t}^{l i q}
\end{array}\right)\right] d t+\Sigma\left(\begin{array}{c}
d W_{t}^{L^{N}, \mathbb{Q}} \\
d W_{t}^{S, \mathbb{Q}} \\
d W_{t}^{C, \mathbb{Q}} \\
d W_{t}^{L^{R}, \mathbb{Q}} \\
d W_{t}^{l i q, \mathbb{Q}}
\end{array}\right),
$$

where $\Sigma$ is assumed to be a diagonal matrix as per Christensen et al. (2011).

Based on the $\mathbb{Q}$-dynamics above, nominal zero-coupon bond yields preserve a Nelson and Siegel (1987) factor loading structure

$$
y_{t}^{N}(\tau)=L_{t}^{N}+\left(\frac{1-e^{-\lambda \tau}}{\lambda \tau}\right) S_{t}+\left(\frac{1-e^{-\lambda \tau}}{\lambda \tau}-e^{-\lambda \tau}\right) C_{t}-\frac{A^{N}(\tau)}{\tau},
$$

where $A^{N}(\tau)$ is a convexity term that adjusts the functional form in Nelson and Siegel (1987) to ensure absence of arbitrage (see Christensen et al., 2011).

On the other hand, due to the lower liquidity in the market for real bonds, real yields are sensitive to liquidity pressures. As a consequence, the pricing of RRBs is not performed with the standard real discount function, but rather with a discount function that accounts for the liquidity risk:

$$
\bar{r}_{t}^{R, i}=r_{t}^{R}+\beta^{i}\left(1-e^{-\lambda^{L, i}\left(t-t_{0}^{i}\right)}\right) X_{t}^{l i q}=L_{t}^{R}+\alpha^{R} S_{t}+\beta^{i}\left(1-e^{-\lambda^{L, i}\left(t-t_{0}^{i}\right)}\right) X_{t}^{l i q},
$$

where $t_{0}^{i}$ denotes the date of issuance of the specific real bond and $\beta^{i}$ is its sensitivity to the variation in the liquidity factor. Furthermore, the decay parameter $\lambda^{L, i}$ is assumed to vary across securities as well. 
ACR show that the net present value of one consumption unit paid by real bond $i$ at time $t+\tau$ has the following exponential-affine form

$$
\begin{aligned}
P_{t}\left(t_{0}^{i}, \tau\right) & =E_{t}^{\mathbb{Q}}\left[e^{-\int_{t}^{t+\tau^{i}} \bar{r}^{R, i}\left(s, t_{0}^{i}\right) d s}\right] \\
& =\exp \left(B_{1}(\tau) L_{t}^{N}+B_{2}(\tau) S_{t}+B_{3}(\tau) C_{t}+B_{4}(\tau) L_{t}^{R}+B_{5}\left(t, t_{0}^{i}, \tau\right) X_{t}^{L i q}+A\left(t, t_{0}^{i}, \tau\right)\right)
\end{aligned}
$$

which implies that the model belongs to the class of Gaussian affine term structure models. Note also that, by fixing $\beta^{i}=0$ for all $i$, we recover the CLR model.

Now, consider the whole value of the real bond $i$ issued at time $t_{0}^{i}$ with maturity at $t+\tau^{i}$ that pays an annual coupon $C^{R}$ semi-annually. Its price is given by ${ }^{11}$

$$
\begin{aligned}
\bar{P}_{t}^{R, i}\left(t_{0}^{i}, \tau^{i}, C^{R}\right)= & C^{R}\left(t_{1}-t\right) E_{t}^{\mathbb{Q}}\left[e^{-\int_{t}^{t_{1}} \bar{r}^{R, i}\left(s, t_{0}^{i}\right) d s}\right]+\sum_{j=2}^{N} \frac{C^{R}}{2} E_{t}^{\mathbb{Q}}\left[e^{-\int_{t}^{t_{j}} \bar{r}^{R, i}\left(s, t_{0}^{i}\right) d s}\right] \\
& +E_{t}^{\mathbb{Q}}\left[e^{-\int_{t}^{t+\tau^{i}} \bar{r}^{R, i}\left(s, t_{0}^{i}\right) d s}\right] .
\end{aligned}
$$

Unlike U.S. TIPS, Canadian RRBs have no embedded deflation protection option, which makes their pricing straightforward. The only minor omission in the bond price formula above is that we do not account for the lag in the inflation indexation of the real bond payoff, but the potential error should be modest in most cases, see Grishchenko and Huang (2013) and D'Amico et al. (2018) for evidence in the case of the U.S. TIPS market.

Finally, within the CLR-L model described above, nominal bonds are assumed to have a minimum of liquidity risk, which is consistent with the empirical findings of Andreasen et al. (2019). Therefore, they are valued using the standard nominal zero-coupon yield described in equation (3).

So far, the description of the CLR-L model has relied solely on the dynamics of the state variables under the $\mathbb{Q}$-measure used for pricing. However, to complete the description of the model and to implement it empirically, we will need to specify the risk premiums that connect the factor dynamics under the $\mathbb{Q}$-measure to the dynamics under the real-world (or historical) $\mathbb{P}$-measure. It is important to note that there are no restrictions on the dynamic drift components under the empirical $\mathbb{P}$-measure beyond the requirement of constant volatility. To facilitate empirical implementation, we use the essentially affine risk premium specification introduced in Duffee (2002). In the Gaussian framework, this specification implies that the risk premiums $\Gamma_{t}$ depend on the state variables; that is,

$$
\Gamma_{t}=\gamma^{0}+\gamma^{1} X_{t},
$$

\footnotetext{
${ }^{11}$ This is the clean price that does not account for any accrued interest and maps to our observed RRB prices.
} 
where $\gamma^{0} \in \mathbf{R}^{5}$ and $\gamma^{1} \in \mathbf{R}^{5 \times 5}$ contain unrestricted parameters, see online Appendix A.

Thus, the resulting unrestricted five-factor CLR-L model has $\mathbb{P}$-dynamics given by

$$
\left(\begin{array}{c}
d L_{t}^{N} \\
d S_{t} \\
d C_{t} \\
d L_{t}^{R} \\
d X_{t}^{l i q}
\end{array}\right)=\left(\begin{array}{ccccc}
\kappa_{11}^{\mathbb{P}} & \kappa_{12}^{\mathbb{P}} & \kappa_{13}^{\mathbb{P}} & \kappa_{14}^{\mathbb{P}} & \kappa_{15}^{\mathbb{P}} \\
\kappa_{21}^{\mathbb{P}} & \kappa_{22}^{\mathbb{P}} & \kappa_{23}^{\mathbb{P}} & \kappa_{24}^{\mathbb{P}} & \kappa_{25}^{\mathbb{P}} \\
\kappa_{31}^{\mathbb{P}} & \kappa_{32}^{\mathbb{P}} & \kappa_{33}^{\mathbb{P}} & \kappa_{34}^{\mathbb{P}} & \kappa_{35}^{\mathbb{P}} \\
\kappa_{41}^{\mathbb{P}} & \kappa_{42}^{\mathbb{P}} & \kappa_{43}^{\mathbb{P}} & \kappa_{44}^{\mathbb{P}} & \kappa_{45}^{\mathbb{P}} \\
\kappa_{51}^{\mathbb{P}} & \kappa_{52}^{\mathbb{P}} & \kappa_{53}^{\mathbb{P}} & \kappa_{54}^{\mathbb{P}} & \kappa_{55}^{\mathbb{P}}
\end{array}\right)\left(\left(\begin{array}{c}
\theta_{1}^{\mathbb{P}} \\
\theta_{2}^{\mathbb{P}} \\
\theta_{3}^{\mathbb{P}} \\
\theta_{4}^{\mathbb{P}} \\
\theta_{5}^{\mathbb{P}}
\end{array}\right)-\left(\begin{array}{c}
L_{t}^{N} \\
S_{t} \\
C_{t} \\
L_{t}^{R} \\
X_{t}^{l i q}
\end{array}\right)\right) d t+\Sigma\left(\begin{array}{c}
d W_{t}^{L^{N}, \mathbb{P}} \\
d W_{t}^{S, \mathbb{P}} \\
d W_{t}^{C, \mathbb{P}} \\
d W_{t}^{L^{R}, \mathbb{P}} \\
d W_{t}^{l i q, \mathbb{P}}
\end{array}\right)
$$

This is the transition equation in the extended Kalman filter estimation of the CLR-L model.

\subsection{Model Estimation and Econometric Identification}

While nominal yields have a standard affine formulation given by equation (3), RRB prices are nonlinear functions of the state variables. Due to this nonlinearity of the RRB pricing formulas, the model cannot be estimated with the standard Kalman filter. Instead, we use the extended Kalman filter as in Kim and Singleton (2012); see ACR for details. To make the fitted errors comparable across RRBs of various maturities, we follow ACR and scale each bond price by its duration. Thus, the measurement equation for the real bond prices takes the following form:

$$
\frac{\bar{P}_{t}^{R}\left(t_{0}^{i}, \tau^{i}\right)}{D_{t}^{R}\left(\tau^{i}\right)}=\frac{\widehat{P}_{t}^{R}\left(t_{0}^{i}, \tau^{i}\right)}{D_{t}^{R}\left(\tau^{i}\right)}+\varepsilon_{t}^{R, i},
$$

where $\widehat{P}_{t}^{R}\left(t_{0}^{i}, \tau^{i}\right)$ is the model-implied price of real bond $i$ and $D_{t}^{R}\left(\tau^{i}\right)$ is its duration, which is fixed and calculated before estimation. See Andreasen et al. (2019) for evidence supporting this formulation of the measurement equation.

Since the liquidity factor is a latent factor that we do not observe, its level is not identified without additional restrictions. As a consequence, we let the first Canadian government real return bond issued, that is, the thirty-year real return bond with 4.25 percent coupon issued on December 10, 1991, with maturity on December 1, 2021, have a unit loading on the liquidity factor, that is, $\beta^{i}=1$ for this security. This choice implies that the $\beta^{i}$ sensitivity parameters measure liquidity sensitivity relative to that of the thirty-year $2021 \mathrm{RRB}$.

Furthermore, we note that the $\lambda^{L, i}$ parameters can be hard to identify if their values are too large or too small. As a consequence, we impose the restriction that they fall within the range from 0.0001 to 10 , which is without practical consequences as demonstrated by ACR. Also, for numerical stability during the model optimization, we impose the restriction that the $\beta^{i}$ parameters fall within the range from 0 to 250 , which turns out not to be a binding constraint at the optimum.

Finally, we assume that all nominal yield measurement equations have i.i.d. fitted errors 


\begin{tabular}{c|cc|cc}
\hline \hline Maturity & \multicolumn{2}{|c|}{ CLR } & \multicolumn{2}{c}{ CLR-L } \\
\cline { 2 - 5 } in months & Mean & RMSE & Mean & RMSE \\
\hline 3 & -2.53 & 15.63 & -3.66 & 12.58 \\
6 & -1.97 & 6.51 & -1.98 & 4.98 \\
12 & 0.97 & 10.69 & 2.40 & 10.81 \\
24 & 3.16 & 13.66 & 5.38 & 11.71 \\
36 & 2.81 & 11.07 & 4.43 & 8.51 \\
60 & -0.47 & 8.21 & -0.92 & 5.80 \\
84 & -3.21 & 10.10 & -5.04 & 9.47 \\
120 & -4.85 & 9.60 & -7.04 & 10.37 \\
180 & 1.70 & 11.80 & 0.91 & 10.81 \\
240 & 7.99 & 21.06 & 8.53 & 20.12 \\
360 & -5.04 & 20.10 & -4.49 & 20.60 \\
\hline All maturities & -0.13 & 13.34 & -0.13 & 12.38 \\
\hline \hline
\end{tabular}

Table 2: Pricing Errors of Nominal Yields

This table reports the mean pricing errors (Mean) and the root mean-squared pricing errors (RMSE) of nominal yields in the CLR and CLR-L models estimated with a diagonal specification of $K^{\mathbb{P}}$ and $\Sigma$.

with zero mean and standard deviation $\sigma_{\varepsilon}^{N}$. Similarly, all RRB price measurement equations have fitted errors that are assumed to be i.i.d. with zero mean and standard deviation $\sigma_{\varepsilon}^{R}$.

\subsection{Estimation Results}

This section presents our benchmark estimation results. In the interest of simplicity, focus is in this section devoted to a version of the CLR-L model where $K^{\mathbb{P}}$ and $\Sigma$ are diagonal matrices. As shown in ACR, these restrictions have hardly any effects on the estimated liquidity premium for each RRB, because it is identified from the model's $\mathbb{Q}$-dynamics, which is independent of $K^{\mathbb{P}}$ and only display a weak link to $\Sigma$ through the small convexity adjustment in yields. Furthermore, we stress that we relax this assumption in Section 4 when we analyze estimates of long-term inflation expectations and $r_{t}^{*}$, which are indeed sensitive to the specification of the models' $\mathbb{P}$-dynamics.

Given that the CLR-L model includes standard nominal Canadian government zerocoupon bond yields, it seems natural to first explore how well it fits nominal yields. Table 2 documents that it provides a very satisfying fit to all nominal yields, where the overall root mean-squared error (RMSE) is just 12.38 basis points. The corresponding CLR model without a liquidity factor gives broadly a similar fit with an overall RMSE of 13.34 basis points. ${ }^{12}$ Thus, accounting for the liquidity disadvantage of RRBs does not affect the ability of the CLR-L model to match nominal yields, which is consistent with the results in ACR.

\footnotetext{
${ }^{12}$ Unreported results further show that omitting RRB prices in the estimation gives basically the same satisfying fit of nominal yields.
} 


\begin{tabular}{l|cc|cc|cc|cc}
\hline \hline \multirow{2}{*}{ RRB security } & \multicolumn{4}{|c|}{ Pricing errors } & \multicolumn{4}{c}{ Estimated parameters } \\
\cline { 2 - 9 } & \multicolumn{2}{|c|}{ CLR } & \multicolumn{2}{c|}{ CLR-L } & \multicolumn{4}{c}{ CLR-L } \\
\cline { 2 - 9 } & Mean & RMSE & Mean & RMSE & $\beta^{i}$ & SE & $\lambda^{L, i}$ & SE \\
\hline$(1) 4.25 \% 12 / 1 / 2021$ & 2.06 & 5.71 & 0.07 & 2.32 & 1.00 & n.a. & 5.02 & 0.76 \\
$(2) 4.25 \% 12 / 1 / 2026$ & 0.02 & 3.56 & 0.58 & 2.16 & 1.12 & 0.02 & 0.37 & 0.17 \\
$(3) 4 \% 12 / 1 / 2031$ & -0.77 & 3.09 & -0.15 & 2.10 & 0.88 & 0.05 & 9.97 & 0.36 \\
$(4) 3 \% 12 / 1 / 2036$ & -0.79 & 3.89 & 0.14 & 1.63 & 0.63 & 0.07 & 9.97 & 0.35 \\
$(5) 2 \% 12 / 1 / 2041$ & -0.64 & 4.00 & 0.41 & 1.95 & 0.44 & 0.12 & 9.99 & 0.37 \\
$(6) 1.5 \% 12 / 1 / 2044$ & 1.32 & 3.21 & 0.28 & 2.04 & 0.34 & 0.17 & 0.16 & 0.27 \\
$(7) 1.25 \% 12 / 1 / 2047$ & 0.30 & 2.72 & 0.25 & 2.38 & 0.35 & 0.14 & 9.97 & 0.45 \\
$(8) 0.5 \% 12 / 1 / 2050$ & 2.74 & 4.05 & 0.20 & 2.01 & 0.08 & 0.22 & 4.26 & 0.70 \\
\hline All RRB yields & 0.25 & 4.02 & 0.21 & 2.08 & - & - & - & - \\
Max $\mathcal{L}^{E K F}$ & $25,747.17$ & $26,376.85$ & & - & & - \\
\hline \hline
\end{tabular}

Table 3: Pricing Errors of RRBs and Estimated Parameters for Liquidity Risk

This table reports the mean pricing errors (Mean) and the root mean-squared pricing errors (RMSE) of RRBs in the CLR and CLR-L models estimated with a diagonal specification of $K^{\mathbb{P}}$ and $\Sigma$. The errors are computed as the difference between the RRB market price expressed as yield to maturity and the corresponding model-implied yield. All errors are reported in basis points. Standard errors (SE) are not available (n.a.) for the normalized value of $\beta^{1}$.

The impact of accounting for liquidity risk is, however, more apparent in the RRB market. The first two columns in Table 3 show that the RRB pricing errors produced by the CLR model indicate a good fit, with an overall RMSE of 4.02 basis points. The following two columns reveal a substantial improvement in the pricing errors when correcting for liquidity risk, as the CLR-L model has a very low overall RMSE of just 2.08 basis points. Hence, accounting for liquidity risk leads to a notable improvement in the ability of our model to explain RRB market prices.

The final columns of Table 3 report the estimates of the specific parameters attached to each RRB. We note that all RRBs in our sample are exposed to liquidity risk, as the $\beta^{i}$ s are significantly different from zero at the conventional 5 percent level except for the most recently issued RRB thanks to its low number of observations. Although the estimated values of $\lambda^{L, i}$ vary notably across securities, this does not imply major differences in the sensitivity of the RRBs to the liquidity factor as shown in Figure 6. The liquidity adjustment for all RRBs is increasing in $t$ due to the strong mean-reversion in $X_{t}^{\text {liq }}$ under the $\mathbb{Q}$-measure $\left(\kappa_{\text {liq }}^{\mathbb{Q}}=2.39\right.$ according to Table 4). Thus, liquidity risk operates as a traditional slope factor within the CLR-L model, although its steepness varies across the universe of RRBs.

The remaining estimated model parameters are provided in Table 4, which shows that the dynamics of the four frictionless factors are very similar across the CLR and CLR-L models, both under the $\mathbb{P}$ - and the $\mathbb{Q}$-measure. We draw the same conclusion from Figure 7, which plots the estimated factors in the two models. The differences tend to be short-lived and 


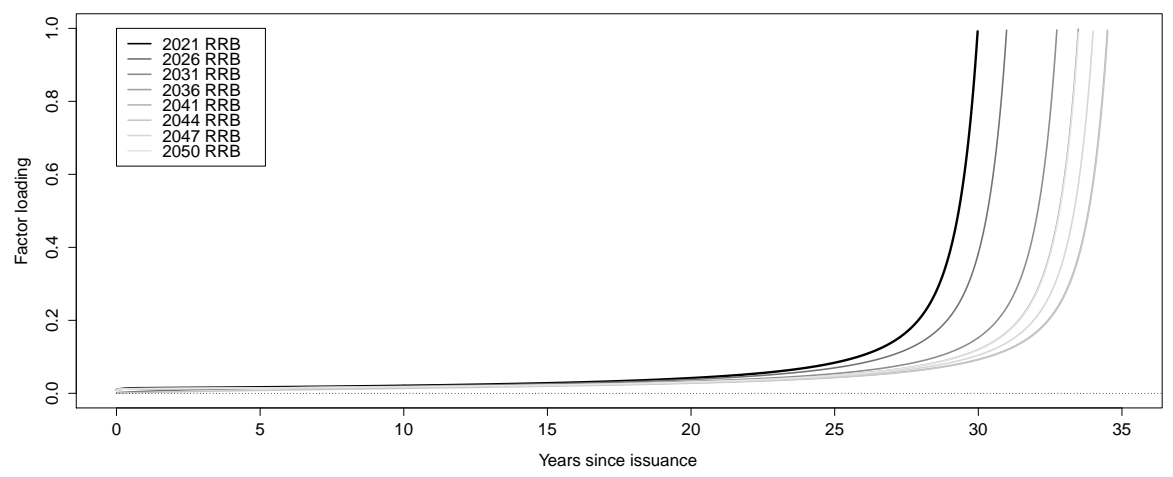

Figure 6: The Term Structure of Liquidity Risk

This figure shows the term structure of liquidity risk, where $\beta^{i}$ is omitted to facilitate the comparison. That is, we report $\frac{\left(1-\exp \left\{-\kappa_{\text {liq }}^{Q}(T-t)\right\}\right)}{\kappa_{\text {liq }}^{Q}(T-t)}-\exp \left\{-\lambda^{L, i}\left(t-t_{0}\right)\right\} \frac{1-\exp \left\{-\left(\kappa_{\text {liq }}^{Q}+\lambda^{L, i}\right)(T-t)\right\}}{\left(\kappa_{\text {liq }}^{Q}+\lambda^{L, i}\right)(T-t)}$ for the yield related to the $i$ th RRB as implied by the estimated version of the CLR-L model with a diagonal specification of $K^{\mathbb{P}}$ and $\Sigma$.

barely noticeable. For that reason it is also the case that the frictionless instantaneous real rates $r_{t}^{R}=L_{t}^{R}+\alpha^{R} S_{t}$ are almost indistinguishable across the two models as documented in panel (f) of Figure 7. Finally, panel (e) shows the estimated liquidity factor $X_{t}^{l i q}$, which is unique to the CLR-L model.

\subsection{The Estimated RRB Liquidity Premium}

We now use the estimated CLR-L model to extract the liquidity premium in the RRB market. To compute this premium we first use the estimated parameters and the filtered states $\left\{X_{t \mid t}\right\}_{t=1}^{T}$ to calculate the fitted RRB prices $\left\{\hat{P}_{t}^{R R B, i}\right\}_{t=1}^{T}$ for all outstanding securities in our sample. These bond prices are then converted into yields to maturity $\left\{\hat{y}_{t}^{c, i}\right\}_{t=1}^{T}$ by solving the fixed-point problem

$$
\begin{aligned}
\hat{P}_{t}^{R R B, i}= & C\left(t_{1}-t\right) \exp \left\{-\left(t_{1}-t\right) \hat{y}_{t}^{c, i}\right\}+\sum_{k=2}^{n} \frac{C}{2} \exp \left\{-\left(t_{k}-t\right) \hat{y}_{t}^{c, i}\right\} \\
& +\exp \left\{-(T-t) \hat{y}_{t}^{c, i}\right\}
\end{aligned}
$$

for $i=1,2, \ldots, n_{R R B}$, meaning that $\left\{\hat{y}_{t}^{c, i}\right\}_{t=1}^{T}$ is approximately the real rate of return on the $i$ th RRB if held until maturity (see Sack and Elsasser 2004). To obtain the corresponding yields without correcting for liquidity risk, a new set of model-implied bond prices are computed from the estimated CLR-L model but using only its frictionless part, i.e., using the constraints that $X_{t \mid t}^{l i q}=0$ for all $t$ as well as $\sigma_{55}=0$ and $\theta_{\text {liq }}^{Q}=0$. These prices are denoted $\left\{\tilde{P}_{t}^{R R B, i}\right\}_{t=1}^{T}$ 


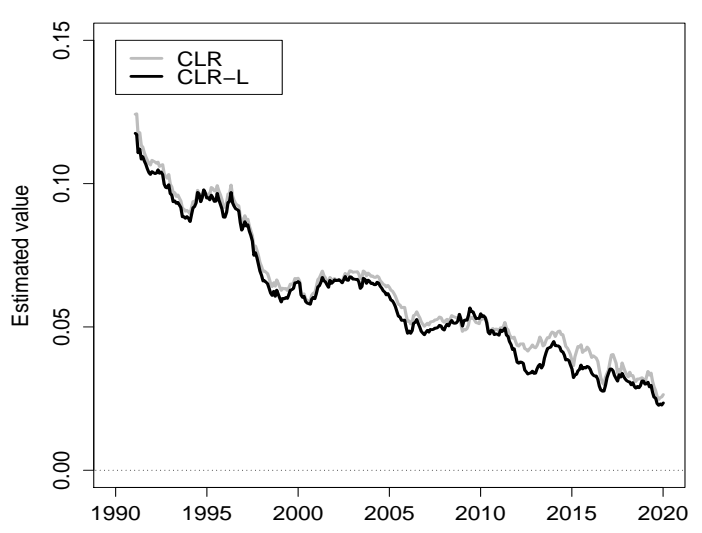

(a) $L_{t}^{N}$

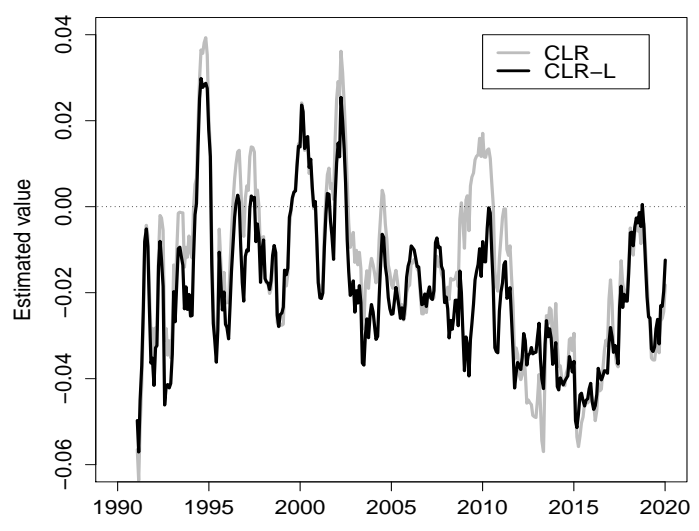

(c) $C_{t}$

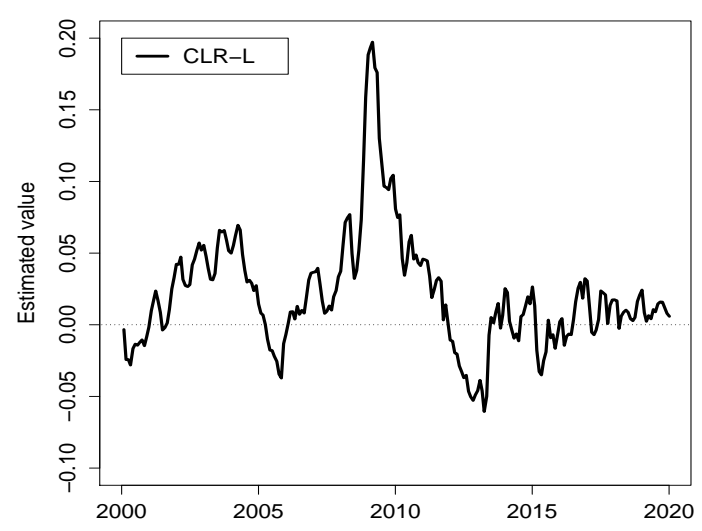

(e) $X_{t}^{l i q}$

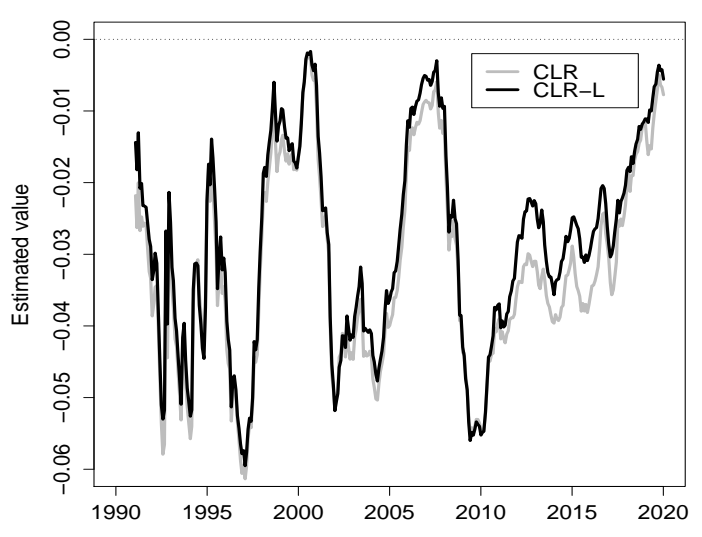

(b) $S_{t}$

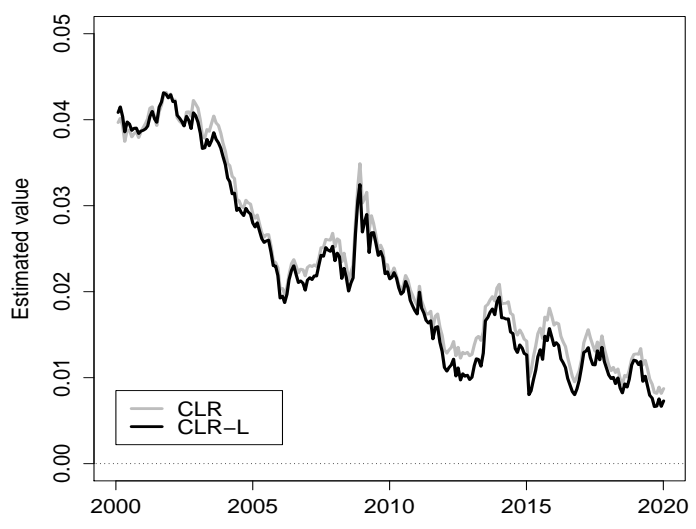

(d) $L_{t}^{R}$

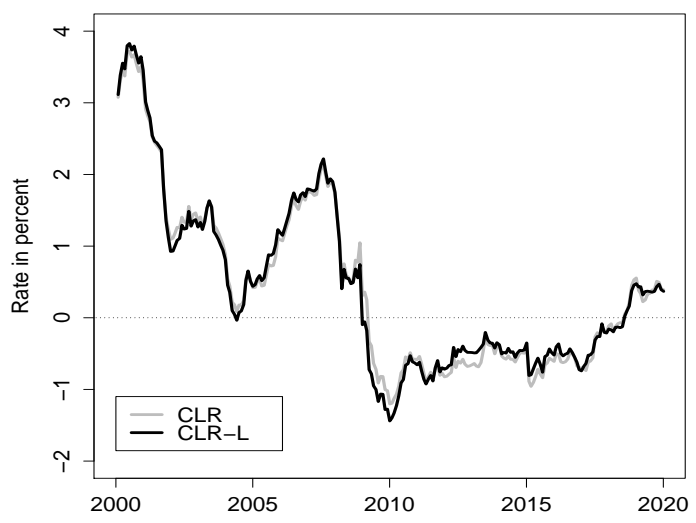

(f) The instantaneous real rate

Figure 7: Estimated State Variables

Illustration of the estimated state variables and instantaneous real rate from the CLR and CLR-L models estimated with a diagonal specification of $K^{\mathbb{P}}$ and $\Sigma$. 


\begin{tabular}{c|cc|cc}
\hline \hline \multirow{2}{*}{ Parameter } & \multicolumn{2}{|c|}{ CLR } & \multicolumn{2}{c}{ CLR-L } \\
\cline { 2 - 5 } & Est. & SE & Est. & SE \\
\hline$\kappa_{11}^{\mathbb{P}}$ & 0.0088 & 0.0477 & 0.0082 & 0.0508 \\
$\kappa_{22}^{\mathbb{P}}$ & 0.3158 & 0.1927 & 0.3350 & 0.1890 \\
$\kappa_{33}^{\mathbb{P}}$ & 0.5497 & 0.2001 & 0.8521 & 0.2353 \\
$\kappa_{44}^{\mathbb{P}}$ & 0.0392 & 0.0758 & 0.0199 & 0.0407 \\
$\kappa_{55}^{\mathbb{P}}$ & - & - & 0.5822 & 0.2068 \\
$\sigma_{11}$ & 0.0059 & 0.0001 & 0.0055 & 0.0001 \\
$\sigma_{22}$ & 0.0116 & 0.0003 & 0.0122 & 0.0003 \\
$\sigma_{33}$ & 0.0213 & 0.0008 & 0.0223 & 0.0009 \\
$\sigma_{44}$ & 0.0040 & 0.0000 & 0.0036 & 0.0001 \\
$\sigma_{55}$ & - & - & 0.0460 & 0.0071 \\
$\theta_{1}^{\mathbb{P}}$ & 0.0732 & 0.0596 & 0.0695 & 0.0521 \\
$\theta_{2}^{\mathbb{P}}$ & -0.0286 & 0.0086 & -0.0255 & 0.0087 \\
$\theta_{3}^{\mathbb{P}}$ & -0.0163 & 0.0071 & -0.0200 & 0.0052 \\
$\theta_{4}^{\mathbb{P}}$ & 0.0302 & 0.0066 & 0.0321 & 0.0063 \\
$\theta_{5}^{\mathbb{P}}$ & - & - & 0.0190 & 0.0241 \\
$\lambda$ & 0.2900 & 0.0029 & 0.4001 & 0.0054 \\
$\alpha^{R}$ & 0.6223 & 0.0069 & 0.6495 & 0.0188 \\
$\kappa_{l i q}^{\mathbb{Q}}$ & - & - & 2.3916 & 0.3490 \\
$\theta_{l i q}^{\mathbb{Q}}$ & - & - & -0.0009 & 0.0001 \\
$\sigma_{y}$ & 0.0015 & $6.90 \times 10^{-6}$ & 0.0014 & $5.60 \times 10^{-6}$ \\
$\sigma_{T I P S}$ & 0.0006 & $7.39 \times 10^{-6}$ & 0.0003 & $4.95 \times 10^{-6}$ \\
\hline \hline
\end{tabular}

Table 4: Estimated Dynamic Parameters

The table shows the estimated dynamic parameters for the CLR and CLR-L models estimated with a diagonal specification of $K^{\mathbb{P}}$ and $\Sigma$.

and converted into yields to maturity $\tilde{y}_{t}^{c, i}$ using (4). They represent estimates of the prices that would prevail in a world without any financial frictions. The liquidity premium for the $i$ th RRB is then defined as

$$
\Psi_{t}^{i} \equiv \hat{y}_{t}^{c, i}-\tilde{y}_{t}^{c, i}
$$

Figure 8 shows the average RRB liquidity premium $\bar{\Psi}_{t}$ across the outstanding RRB at a given point in time. The average estimated RRB liquidity premium clearly varies notably over time with a maximum of 39 basis points achieved at the peak of the financial crisis and a low of -22 basis points in the spring of 2013. For the entire period it has an average of -2.60 basis points with a standard deviation of 9.66 basis points.

Finally, in online Appendix $\mathrm{C}$, we demonstrate that the RRB liquidity premiums are robustly estimated based on the ACR approach, positively correlated with other measures of financial market frictions, and insensitive to the specification of the mean-reversion matrix $K^{\mathbb{P}}$.

In summary, these results allow us to conclude with great confidence that changes in 


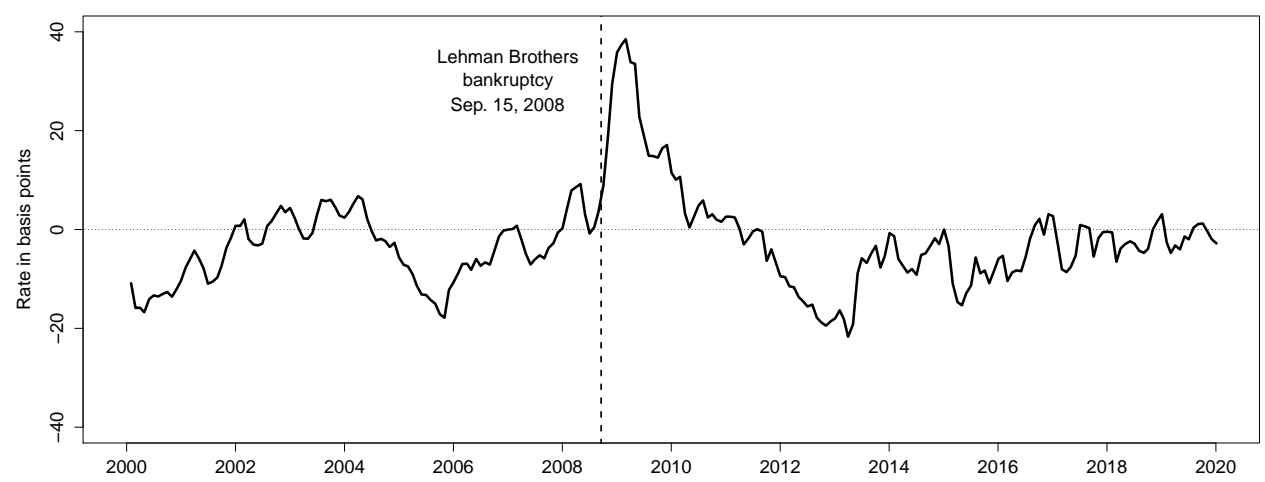

Figure 8: Average Estimated Real Bond Liquidity Premium

Illustration of the average estimated real return bond liquidity premium for each observation date implied by the CLR-L model. The real return bond liquidity premiums are measured as the estimated yield difference between the fitted yield-to-maturity of individual real return bonds and the corresponding frictionless yield-to-maturity with the liquidity risk factor turned off. The average real return liquidity premium is shown with a solid black horizontal line. The data cover the period from January 31, 2000, to December 31, 2019.

RRB liquidity premiums are not a factor behind the persistent decline in Canadian longterm interest rates observed in Figure 1. Still, thanks to their significant time variation, it is important to account for the liquidity premiums in our analysis as we show in Section 5 .

\section{A Lower New Normal for Canadian Interest Rates?}

After first defining breakeven inflation (BEI) and the natural real rate, we select a specification of the CLR-L model's objective $\mathbb{P}$-dynamics consistent with the data. We use this preferred CLR-L model to account for liquidity and term premiums in RRB prices and obtain estimates of investors' long-term inflation expectations and an associated measure of the equilibrium real rate, which we compare to other market-based and macro-based estimates from the literature.

\subsection{Definition of BEI and the Natural Rate}

To begin the analysis in this section, we note that BEI is defined as

$$
B E I_{t}(\tau) \equiv y_{t}^{N}(\tau)-y_{t}^{R}(\tau)=\pi_{t}^{e}(\tau)+\phi_{t}(\tau)
$$

that is, the difference between nominal and real yields of the same maturity, which can then be decomposed into the sum of expected inflation $\pi_{t}^{e}(\tau)$ and the inflation risk premium $\phi_{t}(\tau)$.

CLR show that the market-implied average rate of inflation expected at time $t$ for the 
period from $t$ to $t+\tau$ is

$$
\pi_{t}^{e}(\tau)=-\frac{1}{\tau} \ln E_{t}^{\mathbb{P}}\left[\frac{\Pi_{t}}{\Pi_{t+\tau}}\right]=-\frac{1}{\tau} \ln E_{t}^{\mathbb{P}}\left[e^{-\int_{t}^{t+\tau}\left(r_{s}^{N}-r_{s}^{R}\right) d s}\right]
$$

and the associated inflation risk premium for the same time period is

$$
\phi_{t}(\tau)=-\frac{1}{\tau} \ln \left(1+\frac{\operatorname{cov}_{t}^{\mathbb{P}}\left[\frac{M_{t+\tau}^{R}}{M_{t}^{R}}, \frac{\Pi_{t}}{\Pi_{t+\tau}}\right]}{E_{t}^{\mathbb{P}}\left[\frac{M_{t+\tau}^{R}}{M_{t}^{R}}\right] \times E_{t}^{\mathbb{P}}\left[\frac{\Pi_{t}}{\Pi_{t+\tau}}\right]}\right),
$$

where $\Pi_{t}$ is the price level and $M_{t}^{R}$ is the real stochastic discount factor.

This last equation highlights that the inflation risk premium can be positive or negative. It is positive if and only if

$$
\operatorname{cov}_{t}^{\mathbb{P}}\left[\frac{M_{t+\tau}^{R}}{M_{t}^{R}}, \frac{\Pi_{t}}{\Pi_{t+\tau}}\right]<0 .
$$

That is, the riskiness of nominal bonds relative to real bonds depends on the covariance between the real stochastic discount factor and inflation, and is ultimately determined by investor preferences.

Furthermore, following Christensen and Rudebusch (2019), our definition of the equilibrium real rate of interest $r_{t}^{*}$ is

$$
r_{t}^{*}=\frac{1}{5} \int_{t+5}^{t+10} E_{t}^{\mathbb{P}}\left[r_{t+s}^{R}\right] d s
$$

that is, the average expected real short rate over a five-year period starting five years ahead where the expectation is with respect to the objective $\mathbb{P}$-probability measure. As noted in the introduction, this 5yr5yr forward average expected real short rate should be little affected by short-term transitory shocks. ${ }^{13}$ Alternatively, $r_{t}^{*}$ could be defined as the expected real short rate at an infinite horizon as discussed in Bauer and Rudebusch (2020). However, this quantity will depend crucially on whether the factor dynamics exhibit a unit root. As is well known, the typical spans of time series data that are available do not distinguish strongly between highly persistent stationary processes and non-stationary ones. Our model follows the finance literature and adopts the former structure, so strictly speaking, our infinite-horizon steady state expected real rate is constant. However, our data sample likely has insufficient information in the ten-year to infinite horizon to definitively pin down that steady state. 


\begin{tabular}{|c|c|c|c|c|}
\hline \multirow{2}{*}{$\begin{array}{l}\text { Alternative } \\
\text { specifications }\end{array}$} & \multicolumn{4}{|c|}{ Goodness of fit statistics } \\
\hline & $\log L$ & $k$ & $p$-value & $\mathrm{BIC}$ \\
\hline (1) Unrestricted $I$ & $26,429.97$ & 56 & n.a. & $-52,532.22$ \\
\hline$(2) \kappa_{43}^{\mathbb{P}}=0$ & $26,429.70$ & 55 & 0.46 & $-52,537.53$ \\
\hline (3) $\kappa_{43}^{\mathbb{P}}=\kappa_{13}^{\mathbb{P}}=0$ & $26,429.05$ & 54 & 0.25 & $-52,542.08$ \\
\hline (4) $\kappa_{43}^{\mathbb{P}}=\kappa_{13}^{\mathbb{P}}=\kappa_{53}^{\mathbb{P}}=0$ & $26,428.93$ & 53 & 0.62 & $-52,547.69$ \\
\hline (5) $\kappa_{43}^{\mathbb{P}}=\ldots=\kappa_{15}^{\mathbb{P}}=0$ & $26,428.16$ & 52 & 0.21 & $-52,552.01$ \\
\hline (6) $\kappa_{43}^{\mathbb{P}}=\ldots=\kappa_{12}^{\mathbb{P}}=0$ & $26,427.48$ & 51 & 0.24 & $-52,556.50$ \\
\hline (7) $\kappa_{43}^{\mathbb{P}}=\ldots=\kappa_{32}^{\mathbb{P}}=0$ & $26,427.20$ & 50 & 0.45 & $-52,561.79$ \\
\hline (8) $\kappa_{43}^{\mathbb{P}}=\ldots=\kappa_{35}^{\mathbb{P}}=0$ & $26,426.18$ & 49 & 0.15 & $-52,565.60$ \\
\hline$(9) \kappa_{43}^{\mathbb{P}}=\ldots=\kappa_{31}^{\mathbb{P}}=0$ & $26,425.76$ & 48 & 0.36 & $-52,570.61$ \\
\hline (10) $\kappa_{43}^{\mathbb{P}}=\ldots=\kappa_{34}^{\mathbb{P}}=0$ & $26,425.69$ & 47 & 0.71 & $-52,576.33$ \\
\hline (11) $\kappa_{43}^{\mathbb{P}}=\ldots=\kappa_{24}^{\mathbb{P}}=0$ & $26,422.06$ & 46 & $<0.01$ & $-52,574.92$ \\
\hline (12) $\kappa_{43}^{\mathbb{P}}=\ldots=\kappa_{21}^{\mathbb{P}}=0$ & $26,420.45$ & 45 & 0.07 & $-52,577.55$ \\
\hline (13) $\kappa_{43}^{\mathbb{P}}=\ldots=\kappa_{52}^{\mathbb{P}}=0$ & $26,418.89$ & 44 & 0.08 & $-52,580.28$ \\
\hline (14) $\kappa_{43}^{\mathbb{P}}=\ldots=\kappa_{45}^{\mathbb{P}}=0$ & $26,412.75$ & 43 & $<0.01$ & $-52,573.86$ \\
\hline (15) $\kappa_{43}^{\mathbb{P}}=\ldots=\kappa_{14}^{\mathbb{P}}=0$ & $26,405.65$ & 42 & $<0.01$ & $-52,565.51$ \\
\hline (16) $\kappa_{43}^{\mathbb{P}}=\ldots=\kappa_{25}^{\mathbb{P}}=0$ & $26,395.39$ & 41 & $<0.01$ & $-52,550.84$ \\
\hline (17) $\kappa_{43}^{\mathbb{P}}=\ldots=\kappa_{23}^{\mathbb{P}}=0$ & $26,394.22$ & 40 & 0.13 & $-52,554.35$ \\
\hline (18) $\kappa_{43}^{\mathbb{P}}=\ldots=\kappa_{42}^{\mathbb{P}}=0$ & $26,389.94$ & 39 & $<0.01$ & $-52,551.64$ \\
\hline$=\kappa_{41}^{\mathbb{P}}=0$ & $26,383.43$ & 38 & $<0.01$ & $-52,544.48$ \\
\hline$(20) \kappa_{43}^{\mathbb{P}}=\ldots=\kappa_{51}^{\mathbb{P}}=0$ & $26,378.05$ & 37 & $<0.01$ & $-52,539.57$ \\
\hline$(21) \kappa_{43}^{\mathbb{P}}=\ldots=\kappa_{54}^{\mathbb{P}}=0$ & $26,376.85$ & 36 & 0.12 & $-52,543.02$ \\
\hline
\end{tabular}

Table 5: Evaluation of Alternative Specifications of the CLR-L Model

There are twenty-one alternative estimated specifications of the CLR-L model. Each specification is listed with its maximum $\log$ likelihood $(\log L)$, number of parameters $(k)$, the $p$-value from a likelihood ratio test of the hypothesis that it differs from the specification above with one more free parameter, and the Bayesian information criterion (BIC). The period analyzed covers monthly data from January 31, 1991, to December 31, 2019.

\subsection{Model Selection}

For decompositions of BEI and estimation of the natural real rate and associated inflation, nominal, and real risk premiums, the specification of the mean-reversion matrix $K^{\mathbb{P}}$ is critical as noted earlier. To select the best fitting specification of the model's real-world dynamics, we use a general-to-specific modeling strategy in which the least significant off-diagonal parameter of $K^{\mathbb{P}}$ is restricted to zero and the model is re-estimated. This strategy of eliminating the least significant coefficient is carried out down to the most parsimonious specification, which has a diagonal $K^{\mathbb{P}}$ matrix. The final specification choice is based on the value of the Bayesian information criterion (BIC) as in Christensen et al. (2014). ${ }^{14}$

\footnotetext{
${ }^{13}$ In online Appendix D, we show that the reported results are robust to using an alternative definition of $r_{t}^{*}$ based on the 9yr1yr forward average expected real short rate.

${ }^{14}$ The Bayesian information criterion is defined as BIC $=-2 \log L+k \log T$, where $k$ is the number of model parameters and $T$ is the number of data observations. We have 348 nominal yield and 240 real yield monthly
} 


\begin{tabular}{|c|ccccc||c||c|c|}
\hline$K^{\mathbb{P}}$ & $K_{\cdot, 1}^{\mathbb{P}}$ & $K_{\cdot, 2}^{\mathbb{P}}$ & $K_{\cdot, 3}^{\mathbb{P}}$ & $K_{\cdot, 4}^{\mathbb{P}}$ & $K_{\cdot, 5}^{\mathbb{P}}$ & $\theta^{\mathbb{P}}$ & & $\Sigma$ \\
\hline$K_{1, \cdot}^{\mathbb{P}}$ & 0.2975 & 0 & 0 & -0.4498 & 0 & 0.0683 & $\sigma_{11}$ & 0.0056 \\
& $(0.1124)$ & & & $(0.1671)$ & & $(0.0101)$ & & $(0.0001)$ \\
$K_{2, \cdot}^{\mathbb{P}}$ & 0 & 0.4178 & -0.5924 & 0 & 0.2092 & -0.0230 & $\sigma_{22}$ & 0.0116 \\
& & $(0.1890)$ & $(0.1184)$ & & $(0.0837)$ & $(0.0070)$ & & $(0.0003)$ \\
$K_{3, \cdot}^{\mathbb{P}}$ & 0 & 0 & 0.8260 & 0 & 0 & -0.0142 & $\sigma_{33}$ & 0.0226 \\
& & & $(0.2387)$ & & & $(0.0049)$ & & $(0.0010)$ \\
$K_{4, \cdot}^{\mathbb{P}}$ & -1.6112 & -0.3190 & 0 & 2.4960 & -0.0879 & 0.0351 & $\sigma_{44}$ & 0.0037 \\
& $(0.1968)$ & $(0.0833)$ & & $(0.3040)$ & $(0.0258)$ & $(0.0065)$ & & $(0.0001)$ \\
$K_{5, \cdot}^{\mathbb{P}}$ & 13.1560 & 0 & 0 & -20.7164 & 0.8814 & 0.0582 & $\sigma_{55}$ & 0.0494 \\
& $(0.3865)$ & & & $(0.4127)$ & $(0.2359)$ & $(0.0284)$ & & $(0.0104)$ \\
\hline
\end{tabular}

Table 6: Estimated Dynamic Parameters of the Preferred CLR-L Model

The table shows the estimated parameters of the $K^{\mathbb{P}}$ matrix, $\theta^{\mathbb{P}}$ vector, and diagonal $\Sigma$ matrix for the preferred CLR-L model according to the BIC. The estimated value of $\lambda$ is $0.3900(0.0056)$, while $\alpha^{R}=$ $0.5416(0.0206), \kappa_{\text {liq }}^{\mathbb{Q}}=1.8097(0.3765)$, and $\theta_{\text {liq }}^{\mathbb{Q}}=-0.0018$ (0.0003). The maximum log likelihood value is $26,418.89$. The numbers in parentheses are the estimated parameter standard deviations.

The summary statistics of the model selection process are reported in Table 5. The BIC is minimized by specification (13), which has a $K^{\mathbb{P}}$ matrix given by

$$
K_{B I C}^{\mathbb{P}}=\left(\begin{array}{ccccc}
\kappa_{11}^{\mathbb{P}} & 0 & 0 & \kappa_{14}^{\mathbb{P}} & 0 \\
0 & \kappa_{22}^{\mathbb{P}} & \kappa_{23}^{\mathbb{P}} & 0 & \kappa_{25}^{\mathbb{P}} \\
0 & 0 & \kappa_{33}^{\mathbb{P}} & 0 & 0 \\
\kappa_{41}^{\mathbb{P}} & \kappa_{42}^{\mathbb{P}} & 0 & \kappa_{44}^{\mathbb{P}} & \kappa_{45}^{\mathbb{P}} \\
\kappa_{51}^{\mathbb{P}} & 0 & 0 & \kappa_{54}^{\mathbb{P}} & \kappa_{55}^{\mathbb{P}}
\end{array}\right)
$$

The estimated parameters of the preferred specification are reported in Table 6 . The estimated $\mathbb{Q}$-dynamics used for pricing and determined by $\left(\Sigma, \lambda, \alpha^{R}, \kappa_{\text {liq }}^{\mathbb{Q}}, \theta_{\text {liq }}^{\mathbb{Q}}\right)$ are close to those reported in Table 4 for the CLR-L model with diagonal $K^{\mathbb{P}}$. This implies that both model fit and the estimated RRB liquidity premiums from the preferred CLR-L model are similar to those already reported and therefore not shown. Furthermore, the estimated objective $\mathbb{P}$-dynamics in terms of $\theta^{\mathbb{P}}$ and $\Sigma$ are also qualitatively similar to those reported in Table 4. Finally, we note that the liquidity factor matters for the expected excess return of nominal bonds through $\kappa_{25}^{\mathbb{P}}$ in addition to its effect on RRB pricing, while the slope factor is important for the expected return of both nominal bonds and RRBs. This comes about both through its own direct effect on their pricing and through its dynamic interactions with the other state variables.

observations. We follow CLR and interpret $T$ as referring to the longest data series and fix it at 348 . 


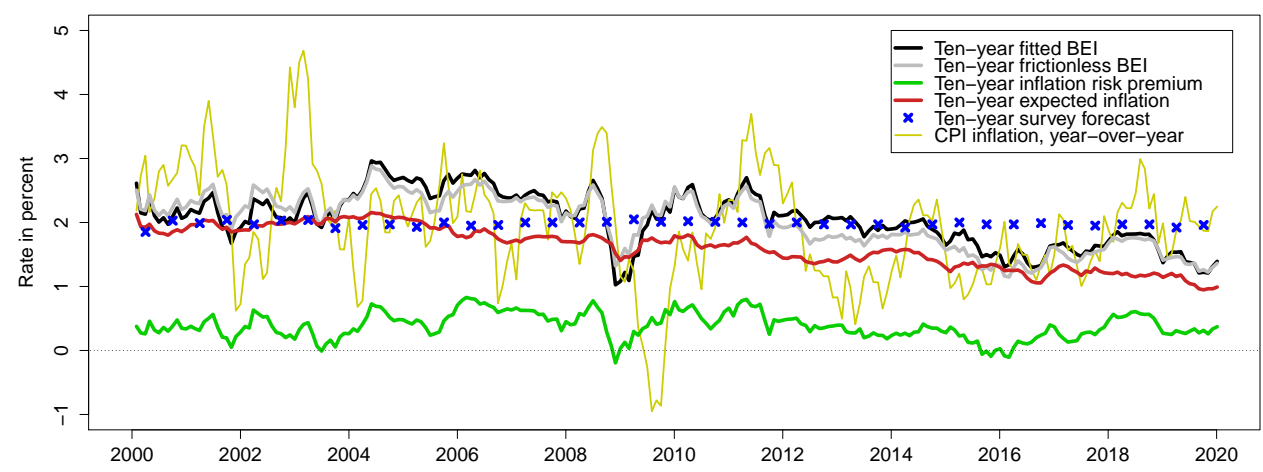

Figure 9: Ten-Year BEI Decomposition

Illustration of the ten-year fitted BEI implied by the CLR model, i.e. the model without adjustment for the RRB liquidity premium, and its decomposition into (1) the fitted frictionless BEI, (2) the tenyear expected inflation, and (3) the residual ten-year inflation risk premium based on the preferred CLR-L model. Also shown is the ten-year inflation forecasts from the Consensus Forecasts.

\subsection{Empirical BEI Decomposition}

In this section, we describe the decomposition of the ten-year BEI implied by our estimation results.

The starting point for the decomposition is the fitted ten-year BEI rate from the CLR model, which offers the cleanest and most straightforward fit of the raw bond data without any adjustments. This measure of ten-year BEI is shown with a solid black line in Figure 9 . Now, the estimated ten-year frictionless BEI from the CLR-L model, which does not contain any RRB liquidity risk premiums, is shown with a solid grey line. It fluctuates above and below the ten-year fitted BEI as the estimated RRB liquidity premiums switch sign. Hence, the difference between these two series represent an alternative measure of the RRB liquidity premiums, which is different from the estimate in Figure 8 as the former has a constant maturity.

As explained in Section 4.1, the CLR-L model also provides a decomposition of the estimated ten-year frictionless BEI into an expected CPI inflation component and the associated inflation risk premium shown with a solid red and green line, respectively.

The ten-year inflation risk premium is variable and mostly positive, but it did turn negative briefly in late 2015 and early 2016 when global energy and commodity prices fell sharply. ${ }^{15}$ In addition, it experienced a temporary softening around the peak of the financial crisis in late 2008, when CPI inflation in Canada and elsewhere started to fall, see Christensen et al. (2012)

\footnotetext{
${ }^{15}$ Note that, due to the model's Gaussian dynamics, the conditional variance of expected inflation is constant. As a result, changes in the inflation risk premium reflect changes in the risk premiums within the model.
} 
for a U.S. analysis of this episode. Many studies have found inflation risk premiums to be positive on average and relatively stable, see Ang et al. (2008), Buraschi and Jiltsov (2005), and Hördahl and Tristani (2014), among many others. Thus, we consider the estimated inflation risk premium from the CLR-L model to be reasonable in terms of both its level and time-series variation.

In comparison, the estimated ten-year inflation expectations are less variable, but characterized by a persistent gradual decline since the mid-2000s when bond investors' long-term inflation expectations were close to the Bank of Canada's two percent inflation target. By the end of our sample, these expectations had declined to 0.99 percent, or about a 1 percentage point drop. This contrasts with the responses to the Consensus Forecasts survey of professional forecasters, who twice a year are asked about their expectations for inflation over the following ten years. The mean responses in each survey since 2000 are shown with blue crosses in Figure 9 and have remained very close to two percent throughout this period. As a consequence, the forecasters view the decline in Canadian long-term BEI rates to be caused by declines in the inflation risk premiums rather than declines in the expected inflation as implied by the CLR-L model. In a robustness exercise in Section 5.2, we confirm this interpretation when we include the Consensus Forecasts above in the CLR-L model estimation.

We see a few potential explanations for the persistent difference between the estimated ten-year expected inflation and the corresponding projections from the professional forecasters participating in the Consensus Forecasts surveys. First, professional forecasters can be biased in their predictions. For example, Cieslak (2018) documents that professional forecasters systematically fail to predict recessions. As a result, they tend to underestimate the related spikes in the unemployment rate and associated declines in the stance of monetary policy. Second, they can be inattentive as noted by Andrade and Le Bihan (2013), who find that professional forecasters can fail to update their forecasts even when new information has arrived. A third possibility is that the investors trading in the Canadian bond markets represent a larger and more diverse group of people than the fairly limited number of professional forecasters included in the surveys, in particular foreigners would seem to be underrepresented in the latter. This could allow for a sustained wedge in the long-term inflation expectations of the kind we find, which seems to be less well supported by the first two explanations. Lastly, in support of our model estimate, we note that the year-over-year change in the Canadian CPI averaged 2.30 percent from January 2000 to June 2008, while it only averaged 1.66 percent, or 0.64 percent lower, over the period from July 2008 to December 2019. Thus, the decline in the long-term inflation expectations implied by our preferred CLR-L model since 2000 is close to the decline in actual CPI outcomes during that same period.

A few potential caveats are worth keeping in mind regarding these results. First, the presented results are obtained assuming stationary dynamics, which is the standard in the 


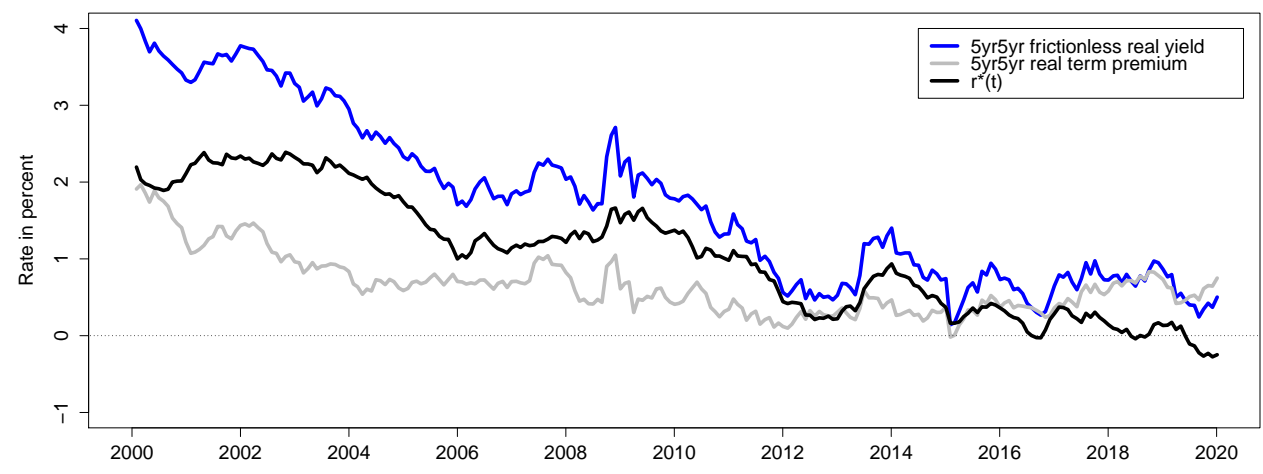

Figure 10: CLR-L Model 5yr5yr Real Yield Decomposition

finance literature. Thus, there is no consideration of nonstationary unit-root dynamics as in Christensen and Rudebusch (2012) or shifting end-point formulations as in Bauer and Rudebusch (2020). Second, unlike survey forecasts that reflect real-time expectations, the model-based measure of long-term inflation expectations represents a full-sample "look-back" estimate, which may affect the model's view of inflation expectations in the past, although our real-time exercise in Section 5.1.3 suggests that this only plays a minor role in our case.

\subsection{Estimates of the Natural Rate}

Our market-based measure of the natural rate is the average expected real short rate over a five-year period starting five years ahead. This 5yr5yr forward average expected real short rate should capture the persistent trends in the natural real rate.

Figure 10 shows the preferred CLR-L model decomposition of the 5yr5yr forward frictionless real yield based on the standard definition of the real term premium

$$
T P_{t}^{R}(\tau)=y_{t}^{R}(\tau)-\frac{1}{\tau} \int_{t}^{t+\tau} E_{t}^{\mathbb{P}}\left[r_{s}^{R}\right] d s
$$

where $y_{t}^{R}(\tau)$ is the fitted frictionless real zero-coupon yield with maturity in $\tau$ years, see online Appendix A for details. The solid grey line is the 5yr5yr forward real term premium, which has fluctuated around a fairly stable level since 2000. In contrast, the estimate of the natural real rate of interest implied by the CLR-L model - the black line - shows a gradual decline from above 2 percent in the early 2000s to below -0.25 percent by the end of the sample. Thus, much of the downward trend in the 5yr5yr forward real yield is driven by declines in this measure of $r_{t}^{*}$, while the corresponding real term premium has declined much less on net during this period. This is consistent with the results of Bauer and Rudebusch (2020). 


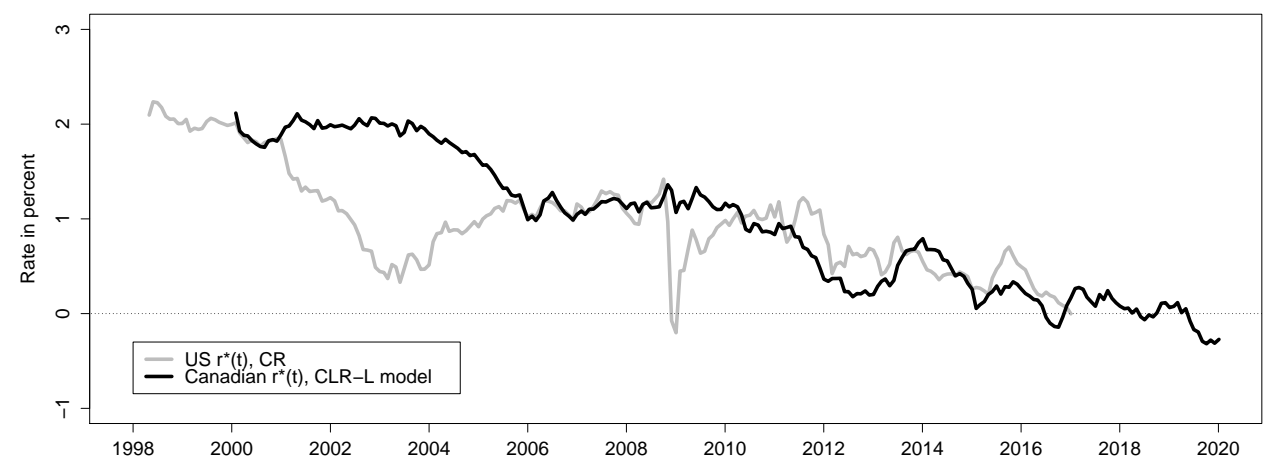

Figure 11: Comparison with a U.S. Market-Based Estimate of $\mathbf{r}^{*}$

\subsection{Comparison of Estimates of the Natural Rate}

In this section, we compare other existing estimates of the equilibrium or natural interest rate in the literature to our Canadian estimate. To start, we compare the Canadian $r_{t}^{*}$ estimate from the CLR-L model to the U.S. finance-based estimate obtained by Christensen and Rudebusch (2019) using solely the prices of U.S. TIPS. These two market-based estimates of the natural rate are shown in Figure 11. Their high positive correlation and similar downward trend are both evident. Also, they share the feature that their most pronounced common declines during the past two decades happened during the long slow recovery after the global financial crisis rather than coincident to the crisis. This suggests that the factors depressing both Canadian and U.S. interest rates are likely to be global in nature and do not just reflect the immediate financial market dislocations during the crisis.

Now, we turn to a comparison of our finance-based estimate of a Canadian $r_{t}^{*}$ with other Canadian estimates in the literature. Figure 12 shows the $r_{t}^{*}$ estimate from our preferred CLR-L model along with the pure macro-based estimate of $r^{*}$ from HLW, which is the filtered estimate generated by applying the approach described in Laubach and Williams (2003) to Canadian macroeconomic series. The macro-based estimate shown in the figure starts in 1985 - 15 years earlier than the CLR-L model estimate. However, in the 1980s and 1990s, the macro-based estimate appears to be stationary and remains close to 3 percent the whole time. This is consistent with the received wisdom of that era in monetary economics that viewed the natural rate as effectively constant - for example, as assumed in the large Taylor rule literature. It is only in the early 2000s that a decided downtrend begins in the macro-based $r_{t}^{*}$ estimate. This decline starts about the same time as we start our sample of RRBs which is quite a fortuitous coincidence for our purposes. Accordingly, even though our estimation sample is limited to the period since 2000, the evidence suggests that this is the precise sample 


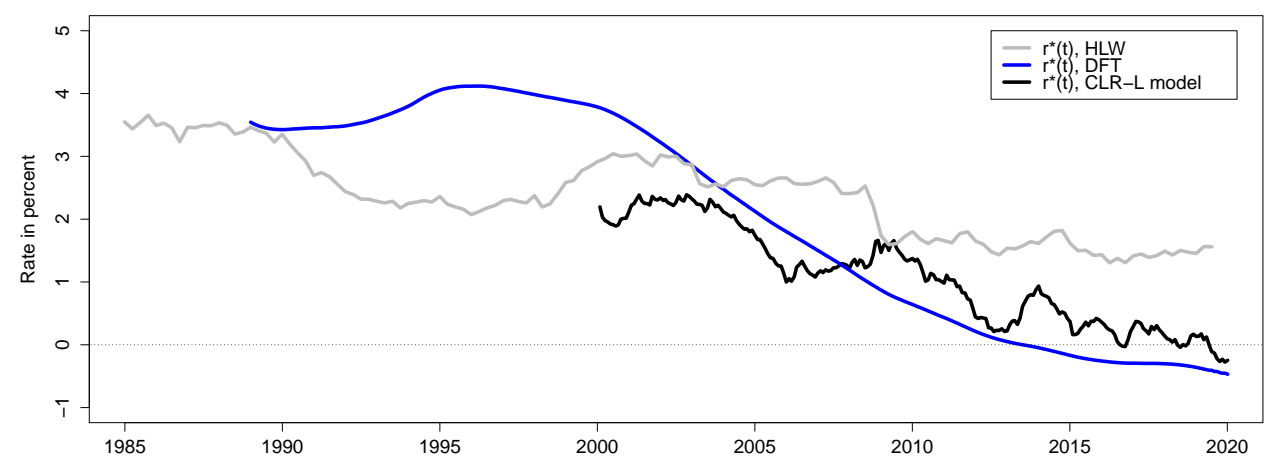

Figure 12: Comparison with Macro-Based Estimates of $\mathbf{r}^{*}$

of most relevance for discerning shifts in the equilibrium real rate.

The second estimate is taken from Davis et al. (2021, henceforth DFT), which extends the analysis of Bauer and Rudebusch (2020) to an international data set. Their Canadian macrofinance estimate starts in the late 1980s near 3.5 percent - close to the HLW estimate-but then moves higher during the 1990s. In the 2000s, it drops precipitously by more than 4 percentage points and ends the 2010s close to -0.50 percent. By contrast, our finance-based estimate declines much less, with a cumulative decrease of about 2.25 percentage points during the past two decades, and the macro-based estimate from HLW declines only about 1 percentage point during that same period.

DFT provides the most extreme estimates of $r_{t}^{*}$ for the Canadian economy taking on both the highest and lowest values for $r_{t}^{*}$ in our sample. In addition, it is extremely smooth and shows little immediate response to the important macro-finance events of the past 30 years. In contrast, our finance-based $r_{t}^{*}$ estimate derived solely from the information in Canadian government bond prices naturally fluctuates with the level and shape of the Canadian nominal and real yield curves and mostly lies in between the two other estimates. Furthermore, as noted above, our model-implied inflation expectations are reasonable, so there is no inconsistency between longer-term real rate and inflation expectations.

Finally, we note that the Bank of Canada publishes an annual analysis of the level of the neutral rate in Canada. The most recent release of this analysis described in Matveev et al. (2020) indicates an estimate between 1.75 and 2.75 percent for the neutral rate using four different macro-based approaches. Assuming inflation at 2 percent in the long run consistent with the Bank of Canada's inflation target, this would translate into a range between -0.25 and 0.75 percent for the natural real rate. This puts our $r_{t}^{*}$ estimate of -0.25 percent at the end of our sample within the range considered relevant by staff at the Bank of Canada. 
Thus, also from this perspective, our $r_{t}^{*}$ estimate appears reasonable and consistent with those implied by standard macroeconomic models.

\subsection{Projections of Expected Inflation and the Natural Rate}

Given the debate among researchers, investors, and policymakers about the persistence of low interest rates, we analyze the outlook for long-term inflation expectations and the natural rate based on the preferred CLR-L model. We follow the approach of Christensen et al. (2015) and simulate 10,000 factor paths over a ten-year horizon conditioned on the shapes of the nominal and real yield curves and investors' embedded forward-looking expectations as of the end of our sample (that is, using estimated state variables and factor dynamics as of December 31, 2019). The simulated factor paths are then converted into forecasts of ten-year expected inflation and $r_{t}^{*}$. Figure 13 shows the median projection and the 5 th and 95th percentile values for the simulated ten-year expected inflation and natural rate over a ten-year forecast horizon. ${ }^{16}$

The median projections of both ten-year expected inflation and $r_{t}^{*}$ show only a very gradual modest reversal of the declines the past two decades, and in the case of $r_{t}^{*}$ the median projection remains negative until after 2028. The upper 95th percentile rises more rapidly while the lower 5 th percentile represents outcomes with the natural rate trending persistently lower into ever deeper negative territory and remaining there over the entire forecast horizon. The underlying stationarity of the CLR-L model is clear in these conditional forecasts. Of course, like most estimates of persistent dynamics, the model will likely suffer from some finite-sample bias in the estimated parameters of its mean-reversion matrix $K^{\mathbb{P}}$, which would imply that it does not exhibit a sufficient amount of persistence - as described in Bauer et al. (2012). In turn, this would suggest (all else equal) that the outcomes below the median in each panel are more likely than a straight read of the simulated probabilities indicate, and correspondingly those above the median are less likely than indicated. As a consequence, we view the projections in Figure 13 as upper bound estimates of the true probability distribution of the future path for ten-year expected inflation and the natural real rate. As a result, we consider it even more likely that both measures will remain at or near their current new lows for the foreseeable future.

Finally, our market-based estimate of $r_{t}^{*}$ appears relevant to the debate about the source of the decline in the equilibrium real rate. In particular, although our measure of the real rate fluctuated a bit at the start of the global financial crisis, our average $r_{t}^{*}$ estimate in 2010 is not much different than in 2007. This relative stability before and after the financial crisis suggests that flight-to-safety and safety premium explanations of the lower equilibrium real

\footnotetext{
${ }^{16}$ Note that the lines do not represent paths from a single simulation run over the forecast horizon; instead, they delineate the distribution of all simulation outcomes at a given point in time.
} 


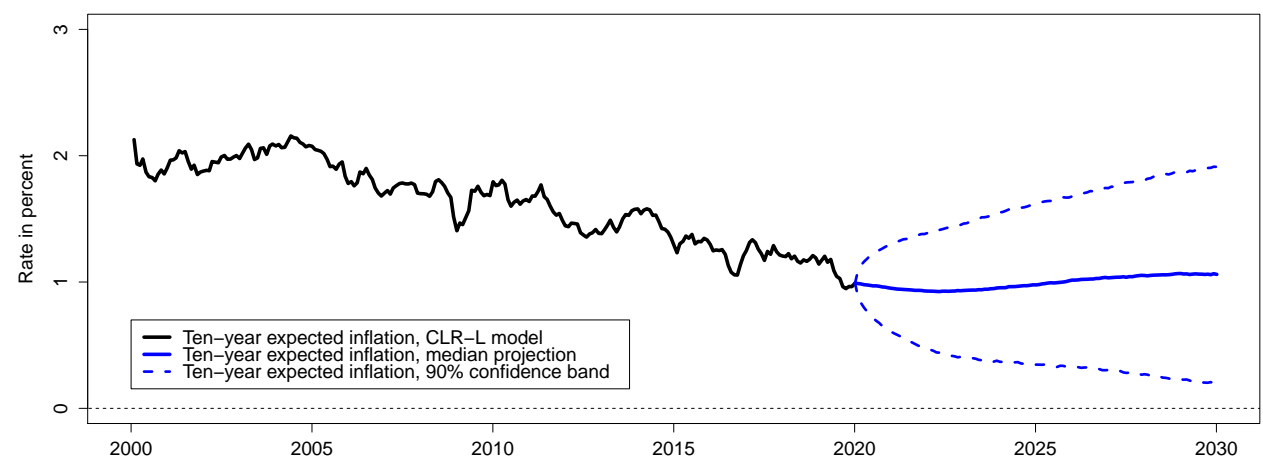

(a) Ten-year expected inflation

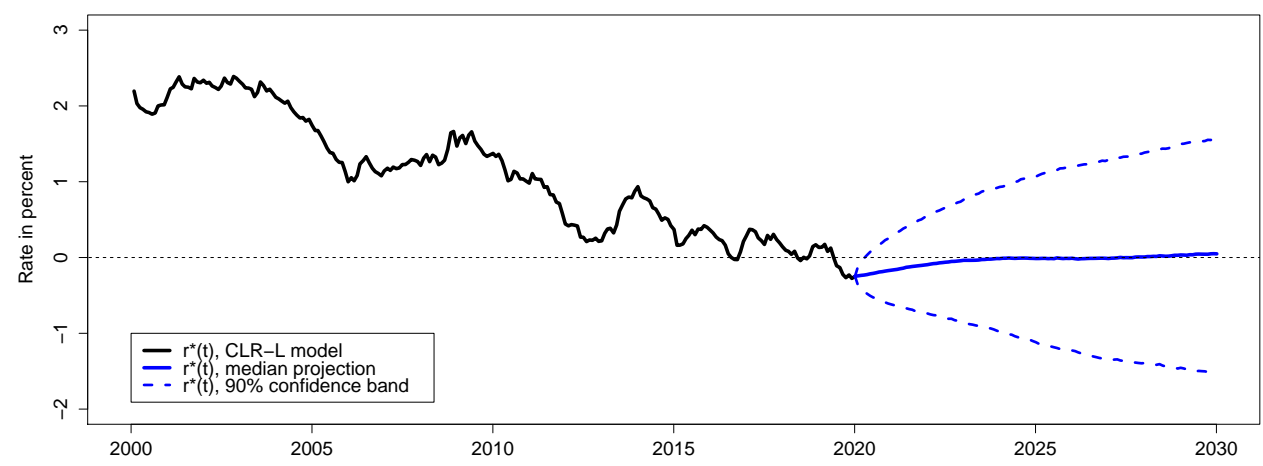

(b) $r_{t}^{*}$

Figure 13: Ten-Year Projections

rate are unlikely to be key drivers of the downtrend in global interest rates (as proposed by Hall, 2016, among others). Instead, our estimates appear more broadly consistent with many of the explanations that attribute the decline in the natural rate to real-side fundamentals such as changing demographics (e.g., Carvalho et al., 2016, Favero et al., 2016, and Gagnon et al., 2016).

\section{Robustness}

In this section, we provide details on some of the robustness checks we have performed. In the first set of exercises, we examine the effects of altering various model assumptions, including a comparison with the results from a real-time implementation of our preferred CLR-L model. In the second set of exercises, we evaluate the effects of including survey inflation forecasts in the model estimation. 


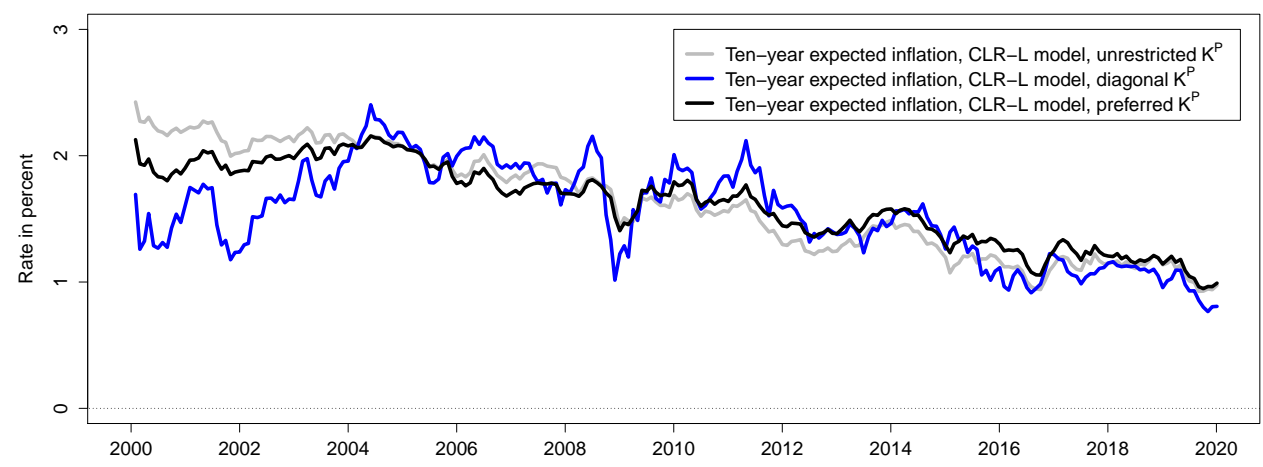

(a) Ten-year expected inflation

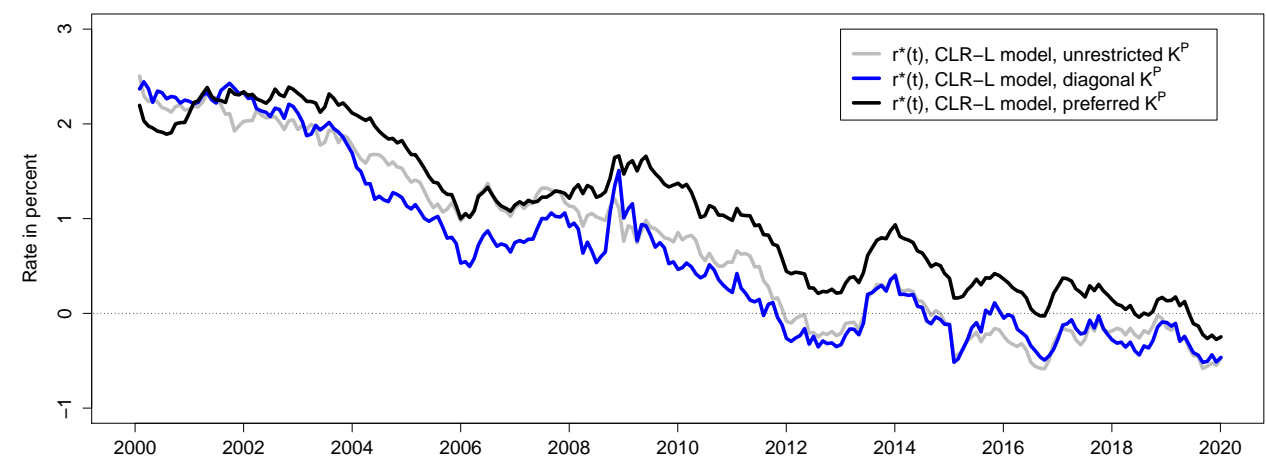

(b) $r_{t}^{*}$

Figure 14: Sensitivity of Ten-Year Expected Inflation and $\mathbf{r}^{*}$ Estimates to $K^{\mathbb{P}}$ Specification

\subsection{Model Assumptions and Implementation}

\subsubsection{Sensitivity to $\mathbb{P}$-Dynamics}

To assess the sensitivity of our ten-year expected inflation and $r_{t}^{*}$ estimates to the specification of the mean-reversion matrix $K^{\mathbb{P}}$, we compare them in Figure 14 to the corresponding estimates from the CLR-L models with unrestricted and diagonal $K^{\mathbb{P}}$ matrix. In panel (a) of the figure, we note some sensitivity of the ten-year expected inflation to the choice of $K^{\mathbb{P}}$ specification. Importantly, both of the alternative estimates suggest that long-term expected inflation is even lower at the end of our sample than estimated by the preferred CLR-L model. Thus, we view our results regarding the decline in long-term inflation expectations to be conservative based on this evidence. Furthermore, as can be seen from panel (b), our $r_{t}^{*}$ estimate is not overly sensitive to this model choice given that all three series are very close to each other throughout the sample. 


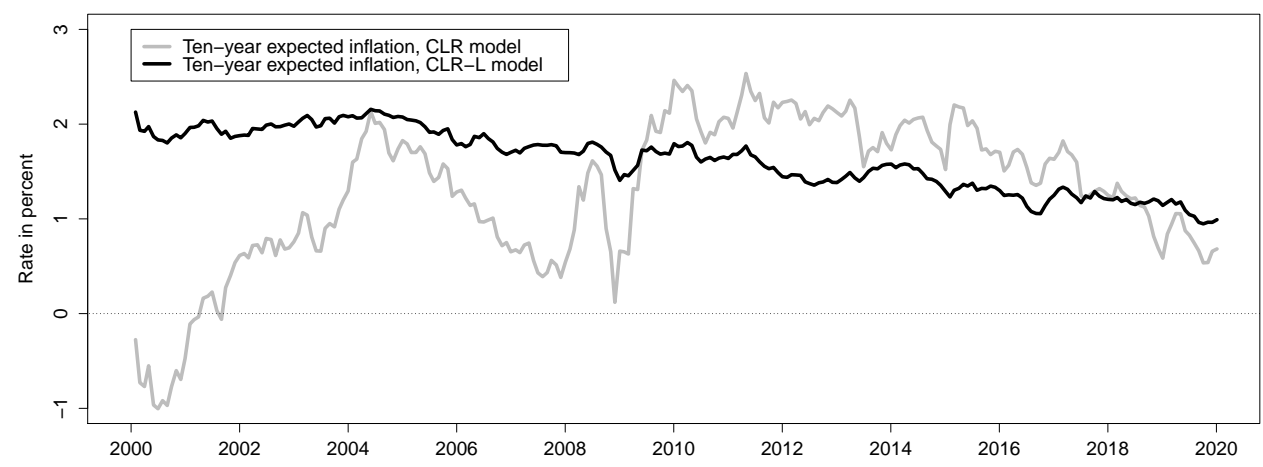

(a) Ten-year expected inflation

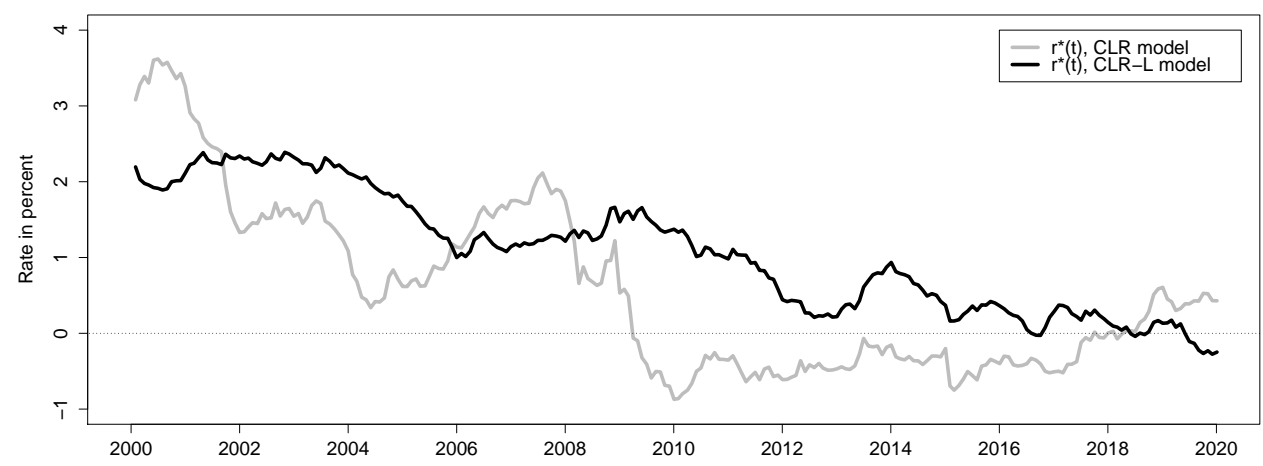

(b) $r_{t}^{*}$

Figure 15: Effect of Liquidity Adjustment on Estimates of Ten-Year Expected Inflation and $\mathrm{r}^{*}$

\subsubsection{Effect of Liquidity Adjustment}

The effect on our estimates from accounting for liquidity premiums in RRB prices is the subject of Figure 15. In panel (a), the black line is the estimate of the ten-year expected inflation from the preferred CLR-L model, and the grey line is the estimate from the CLR model, which does not account for time-varying liquidity effects in RRB prices. ${ }^{17}$ While the estimate from the CLR-L model indicates a persistent gradual decline in investors' longterm inflation expectations from an original level close to two percent in the early 2000s, the estimate from the CLR model is very erratic starting from a level below zero in 2000 and moving above two percent in the early 2010s. In panel (b), the black line is the estimate of $r_{t}^{*}$ from the preferred CLR-L model, and the grey line is the estimate from the CLR model. Accounting for the liquidity premiums in RRB prices leads to notable differences in the natural

\footnotetext{
${ }^{17}$ For the CLR model, we also go through a careful model selection process and use the BIC to determine a preferred specification as described in online Appendix E.
} 
rate estimate at times, and the mean absolute difference between the two estimates is 84 basis points over the sample. Still, the general magnitude of the overall downtrend in the natural interest rate is similar across the two specifications.

Overall, we find the differences in the estimates from the two models to be sizable. More importantly, we consider the estimates from the CLR model to be unconvincing thanks to their high volatility and unusual time-series pattern. This underscores the importance of the RRB liquidity premium adjustment provided within the CLR-L model.

\subsubsection{Real-Time Analysis}

A well-known criticism of macro-based estimates of both expected inflation and the natural real rate is that they can exhibit significant variation as additional and revised data become available, although Laubach and Williams (2016) demonstrate that the Laubach and Williams (2003) estimate of the natural real rate has been robust in real time at least since 2005.

All else equal, finance-based estimates should be less subject to this line of criticism as the key model input, namely the observed bond prices, are available in real time and not subject to any revisions. However, finance-based estimates could still vary as the sample length increases, for example the estimated persistence of the state variables may change, and this could be particularly relevant in the current environment where the general level of interest rates has been declining for the past two decades. To dispel such concerns, we estimate the preferred CLR-L model in real time starting in 2011 through December 2019. This allows us to generate real-time estimates of the ten-year expected inflation and $r_{t}^{*}$ and compare them to the corresponding full sample "look back" estimates, which is done in Figure 16. Although we do see some discrepancies between the estimates as we go back through time, these results show that both the ten-year expected inflation and the $r_{t}^{*}$ estimates from our preferred CLR-L model are reliable in real time and can be used for policy analysis, which is indeed very encouraging.

In addition to a tight fit to the data, these results show that real-time output from the CLR-L model is relatively stable. To explore whether these desirable properties allow the model to forecast out of sample, we examine its ability to project future inflation. ${ }^{18}$ We structure the forecast exercise to match the Consensus Forecasts survey already considered, but now at monthly frequency. At the start of each month, the professional forecasters are asked about their expectations for the change in the CPI for the coming calendar year in addition to their expectations about the change for the current calendar year. To have a series of pure forecasts not distorted by incoming realizations, we focus on the monthly survey forecasts of CPI inflation over the coming calendar year. We then use the real-time

\footnotetext{
${ }^{18}$ In online Appendix F, we evaluate the ability of our preferred CLR-L model to forecast nominal bond yields in real time.
} 


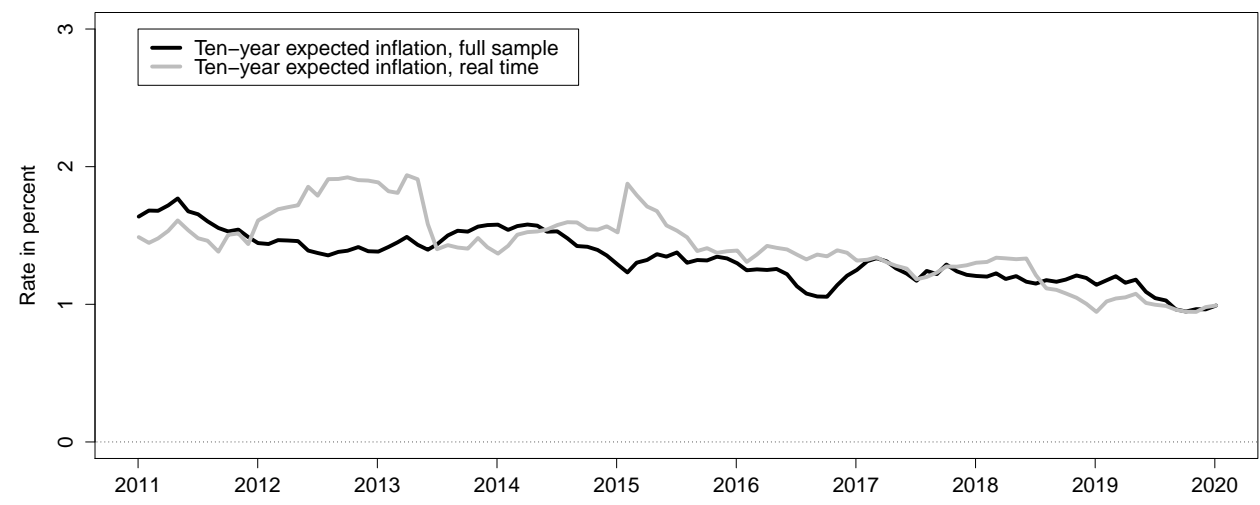

(a) Ten-year expected inflation

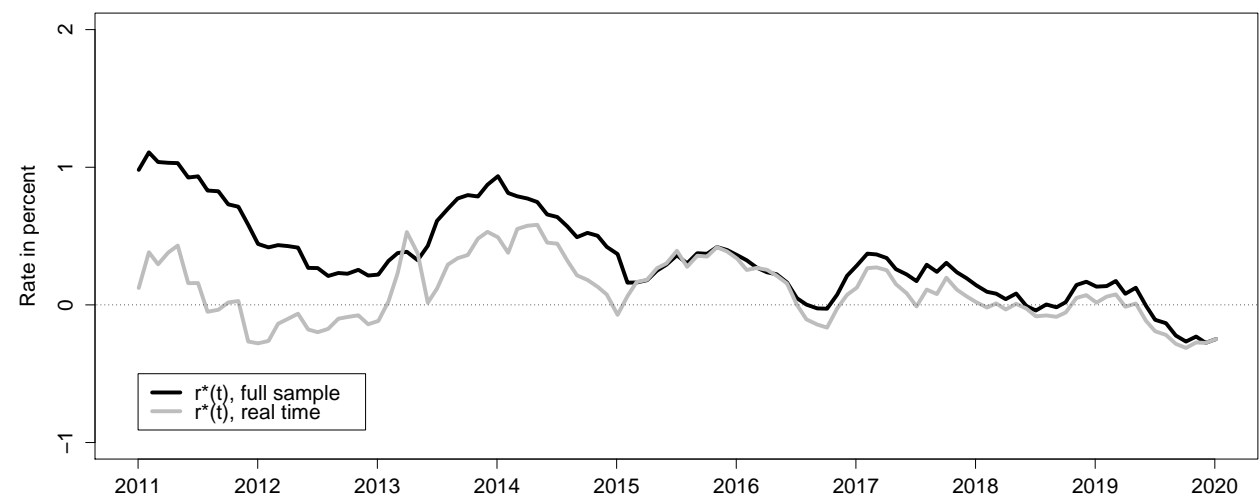

(b) $r_{t}^{*}$

Figure 16: Accuracy of Real-Time Estimates of Ten-Year Expected Inflation and $\mathbf{r}^{*}$

model estimation results from the end of December 2010 to the end of November 2019 to generate the matching model-implied CPI inflation forecast. This has the advantage that the model-implied forecasts reflect information available at the end of each month and therefore lag the official survey dates by between one and two weeks. Thus, this exercise is by design conservative and not favorable to the model.

The summary statistics of the 108 monthly forecast errors from this exercise are reported in Table 7. Note that the CLR-L model has a smaller mean forecast error and a marginally lower root mean squared forecasting error than the Consensus Forecasts. It is only in terms of mean absolute forecast errors that the survey forecasts are competitive.

In comparing the forecast series, Figure 17 shows that the survey forecasts are very stable, even at the short calendar-year-ahead horizon examined here. In contrast, the CLR-L model- 


\begin{tabular}{lccc}
\hline \hline Model & Mean & RMSE & MAE \\
\hline Consensus Forecasts & -47.59 & 68.39 & 53.91 \\
CLR-L model & 11.32 & 67.47 & 62.12 \\
\hline \hline
\end{tabular}

\section{Table 7: Summary Statistics of CPI Inflation Forecast Errors}

This table reports the mean forecasting errors (Mean), the root mean squared forecasting errors (RMSE), and the mean absolute forecasting errors (MAE). The CLR-L model forecasts are computed from monthly recursive estimations. The forecast errors are reported as the true value minus the model-implied prediction, and all numbers are reported in annual basis points.

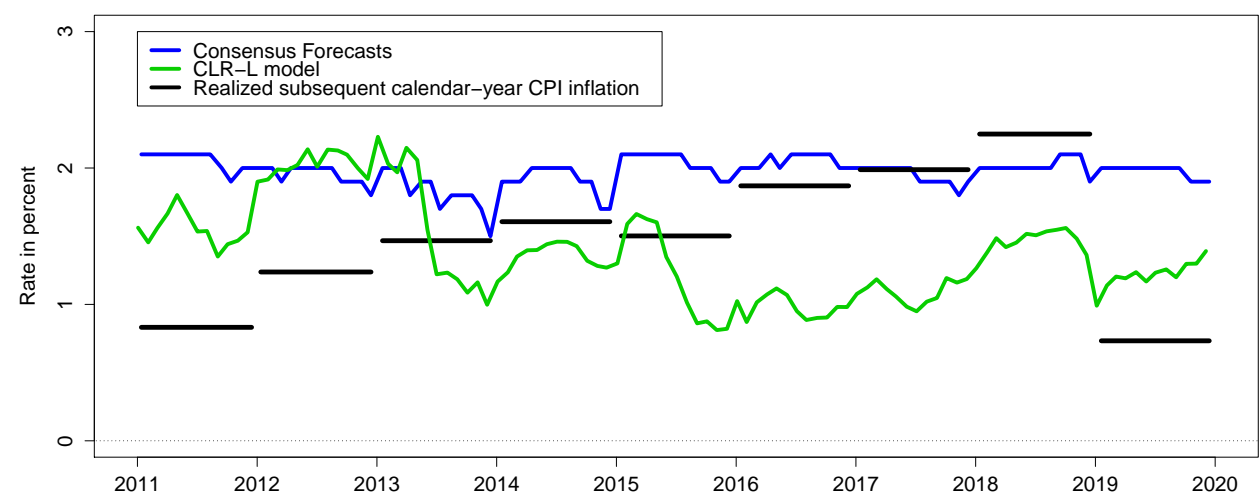

Figure 17: CPI Inflation Forecasts and Realizations

implied forecasts exhibit a level of variation similar to that reflected in the subsequent CPI inflation realizations also shown in the figure with solid black lines.

Overall, these observations lead us to conclude that the CLR-L model is able to generate realistic inflation dynamics with properties that match those of the actual CPI series, even though we stress that no inflation data is included in the model estimation.

To summarize, based on the outcomes from the presented set of robustness checks, we consider the output from our preferred CLR-L model to be robust and representative. As a consequence, we feel comfortable relying on the output from this model in our main analysis.

\subsection{Including Inflation Forecasts from Surveys}

Many studies advocate the use of survey information as a key input into the estimation of dynamic term structure models, see Chun (2011) and Kim and Orphanides (2012), amongst many others, for detailed discussions. As noted by ACR, the CLR-L model framework is sufficiently flexible to accommodate such augmentations in the information set. Therefore, in 


\begin{tabular}{|c|ccccc||c||c|c|}
\hline$K^{\mathbb{P}}$ & $K_{\cdot, 1}^{\mathbb{P}}$ & $K_{\cdot, 2}^{\mathbb{P}}$ & $K_{\cdot, 3}^{\mathbb{P}}$ & $K_{\cdot, 4}^{\mathbb{P}}$ & $K_{\cdot, 5}^{\mathbb{P}}$ & $\theta^{\mathbb{P}}$ & & $\Sigma$ \\
\hline$K_{1, \cdot}^{\mathbb{P}}$ & 0.2530 & 0 & 0 & -0.3848 & 0 & 0.0672 & $\sigma_{11}$ & 0.0056 \\
& $(0.1086)$ & & & $(0.1585)$ & & $(0.0110)$ & & $(0.0001)$ \\
$K_{2, \cdot}^{\mathbb{P}}$ & 0 & 0.1483 & -0.3756 & 0 & 0.2185 & -0.0293 & $\sigma_{22}$ & 0.0115 \\
& & $(0.1282)$ & $(0.1024)$ & & $(0.0437)$ & $(0.0090)$ & & $(0.0002)$ \\
$K_{3, \cdot}^{\mathbb{P}}$ & 0 & 0 & 1.2209 & 0 & 0 & -0.0188 & $\sigma_{33}$ & 0.0231 \\
& & & $(0.2372)$ & & & $(0.0037)$ & & $(0.0010)$ \\
$K_{4, \cdot}^{\mathbb{P}}$ & -1.5148 & -0.2763 & 0 & 2.1156 & -0.0711 & 0.0341 & $\sigma_{44}$ & 0.0036 \\
& $(0.1998)$ & $(0.0598)$ & & $(0.2921)$ & $(0.0212)$ & $(0.0071)$ & & $(0.0001)$ \\
$K_{5, \cdot}^{\mathbb{P}}$ & 12.9359 & 0 & 0 & -20.9615 & 0.6440 & 0.0442 & $\sigma_{55}$ & 0.0467 \\
& $(0.3898)$ & & & $(0.3804)$ & $(0.1902)$ & $(0.0247)$ & & $(0.0091)$ \\
\hline
\end{tabular}

Table 8: Estimated Dynamic Parameters of the Preferred CLR-L Model with Survey Forecasts

The table shows the estimated parameters of the $K^{\mathbb{P}}$ matrix, $\theta^{\mathbb{P}}$ vector, and diagonal $\Sigma$ matrix for the preferred CLR-L model according to the BIC with survey forecasts included in the data sample. The estimated value of $\lambda$ is $0.3901(0.0056)$, while $\alpha^{R}=0.5518(0.0207), \kappa_{\text {liq }}^{\mathbb{Q}}=1.7923(0.3414)$, and $\theta_{\text {liq }}^{\mathbb{Q}}=$ $-0.0016(0.0003)$. The maximum log likelihood value is $26,662.38$. The numbers in parentheses are the estimated parameter standard deviations.

this section, we explore the impact on our estimates of using the long-term inflation forecasts from the Consensus Forecasts survey in our model estimations, and to keep the exposition simple, we focus on the preferred CLR-L model studied in the previous sections.

We use the Consensus Forecasts survey for this exercise for three reasons. First and most importantly, it offers a long history of forecasts of Canadian CPI inflation. Second, the fixed structure of its survey questions is particularly suitable for model estimations like ours as we explain below. Finally, we note that it tracks a panel of very qualified economic forecasters with typically around 15 participating institutions. Thus, we consider these forecasts to be reliable and of high quality despite the potential weaknesses noted in Section 4.3.

Given that our sample of RRBs is dominated by long-term bonds and given that our definition of $r_{t}^{*}$ is centered around expectations at the five- to ten-year horizon, we focus on the long-term CPI inflation forecasts that the participants are asked about twice a year (in April and October) and convert them into ten-year inflation forecasts, denoted $\pi^{C F}(10)$. In the model estimation, we compare them to the model-implied ten-year expected inflation by adding an extra measurement equation:

$$
\pi^{C F}(10)=\widehat{\pi}_{t}^{e}(10)+\varepsilon_{t}^{C F}
$$

where $\varepsilon_{t}^{C F}$ represents a measurement error that is assumed to be i.i.d. with zero mean and standard deviation $\sigma_{\varepsilon}^{C F}$.

Table 8 reports the estimated dynamic parameters from this exercise. In comparing them 


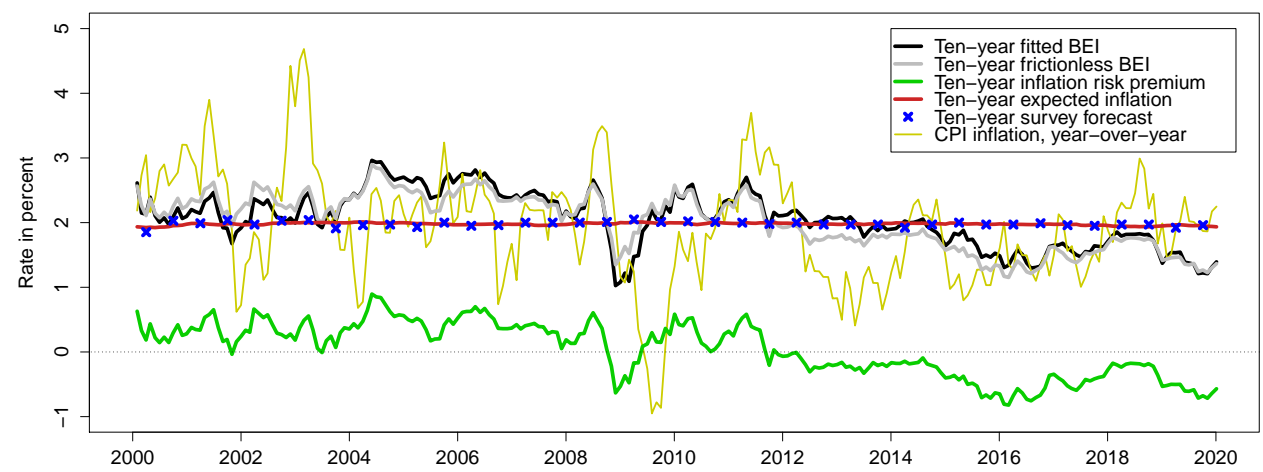

(a) Ten-year BEI decomposition

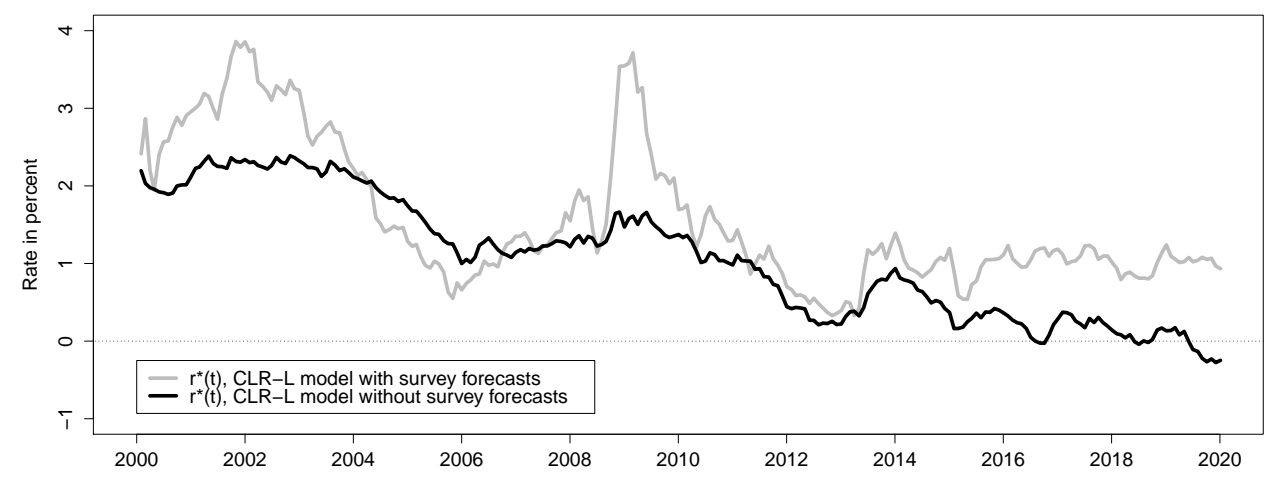

(b) $r_{t}^{*}$

Figure 18: Sensitivity of Ten-Year BEI Decomposition and $\mathbf{r}^{*}$ Estimate to Including Survey Forecasts

In panel (a) the ten-year fitted BEI implied by the CLR model, i.e. the model without adjustment for the RRB liquidity premium, is decomposed into (1) the fitted frictionless BEI, (2) the ten-year expected inflation, and (3) the residual ten-year inflation risk premium based on the preferred CLR$\mathrm{L}$ estimated with the ten-year Consensus inflation forecasts also shown in the figure along with the realizations of the year-over-year Canadian CPI inflation. Panel (b) shows the sensitivity of the $r_{t}^{*}$ estimate to the inclusion of the ten-year Consensus inflation forecasts. In both panels, the data cover the period from January 31, 2000, to December 31, 2019.

to those reported in Table 6 for the benchmark model using financial market information only, we note that the estimated $\mathbb{Q}$-dynamics are practically indistinguishable. This implies that the fit of the model including the survey information is practically identical to that reported in Tables 2 and 3 and therefore not shown.

Figure 18 shows the results for the ten-year BEI decomposition and the $r_{t}^{*}$ estimate. First, for the ten-year expected inflation derived from the ten-year BEI decomposition and illustrated in panel (a) of the figure, we note that the preferred CLR-L model has sufficient 
flexibility that it is able to fit the survey forecasts almost perfectly once they are included in the model estimation, while producing essentially the same fit to the bond data. This implies that the ten-year frictionless BEI is almost indistinguishable from the corresponding series shown in Figure 9. One important consequence of this result is that the decline in long-term BEI rates is now explained by declines in the inflation risk premium given that long-term inflation expectations under this model assumption have remained stable as in the surveys.

To assess the sensitivity of our $r_{t}^{*}$ estimate to the inclusion of the survey information, we compare our benchmark $r_{t}^{*}$ estimate to that from the augmented model, both of which are shown in Figure 18(b). As can be seen from the figure, our $r_{t}^{*}$ estimate is slightly higher with survey forecasts included in the model estimation, but remains highly positively correlated with our preferred benchmark estimate.

At this point, we find it relevant to discuss a potential drawback from including survey inflation forecasts in the model estimation. The starting point for our critique is provided in Figure 19, which compares the model-implied five-year and 5yr5yr expected inflation from the preferred CLR-L model with and without survey forecasts used in the model estimation.

First and most importantly, the contrast between the stability of the ten-year expected inflation and the outsized variance of the five-year and 5yr5yr expected inflation is unconvincing. It is inconceivable that the unobserved true process for the term structure of investors' inflation expectations would exhibit this dynamic behavior. In comparison, the term structure of investors' inflation expectations implied by our preferred CLR-L model estimated without survey forecast is characterized by a consistent mild upward slope. Furthermore and equally important, in the model estimation without the survey forecasts, we see a consistent declining pattern in the time series across all medium- to long-term forecast horizons. This is a point not emphasized in the papers advocating the use of survey forecasts in the estimation of dynamic term structure models, including Kim and Orphanides (2012) and DKW.

Lastly, as for the survey inflation forecasts, they are practically identical at the five-year, ten-year, and 5yr5yr horizons and essentially constant at two percent without any notable changes the past twenty years despite a number of unprecedented economic developments during this period, including the global financial crisis. Thus, their extremely stable pattern also comes across as somewhat suspicious and unconvincing. As a consequence, we view the CLR-L model estimated with the survey data as biased and overly influenced by the survey information. In contrast, we consider the CLR-L model without the survey data to offer a neutral way to decompose the variation in the bond data and provide readings on bond investors' inflation expectations that may differ from those reported in the surveys for the reasons listed earlier. 


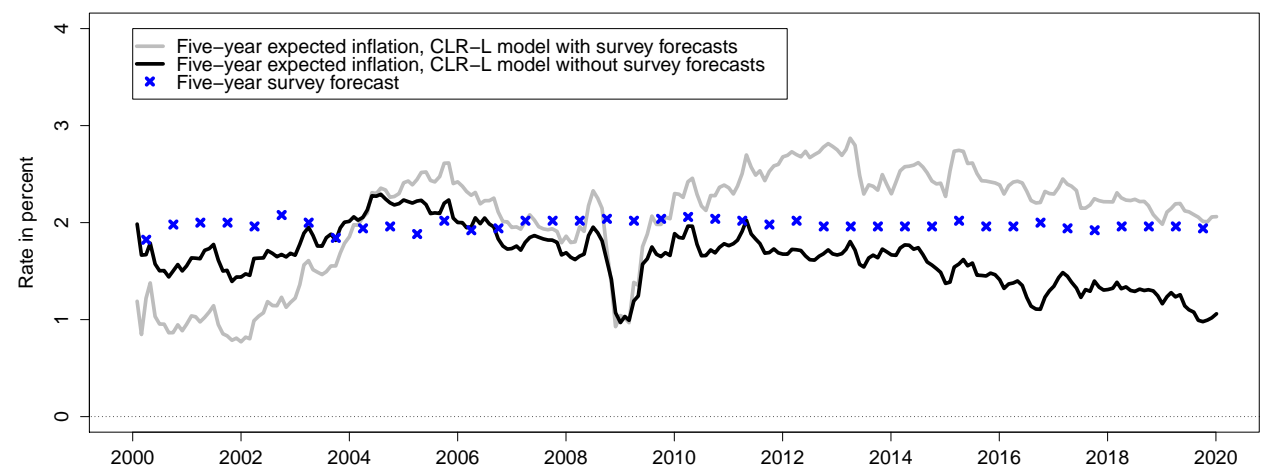

(a) Five-year expected inflation

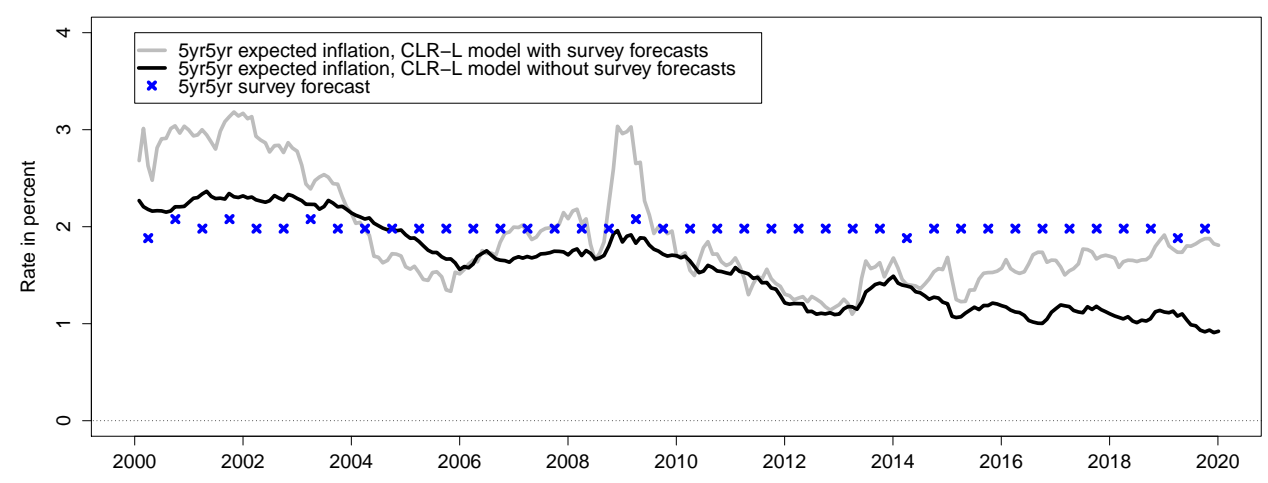

(b) 5yr5yr expected inflation

Figure 19: Five- and Ten-Year Expected Inflation Sensitivity to Including Survey Forecasts

In panel (a) the ten-year fitted BEI implied by the CLR model, i.e. the model without adjustment for the RRB liquidity premium, is decomposed into (1) the fitted frictionless BEI, (2) the ten-year expected inflation, and (3) the residual ten-year inflation risk premium based on the preferred CLR$\mathrm{L}$ estimated with the ten-year Consensus inflation forecasts also shown in the figure along with the realizations of the year-over-year Canadian CPI inflation. Panel (b) shows the sensitivity of the $r_{t}^{*}$ estimate to the inclusion of the ten-year Consensus inflation forecasts. In both panels, the data cover the period from January 31, 2000, to December 31, 2019.

\subsubsection{Evidence from the U.S.}

As for established term structure models that include survey information, we are only aware of one, namely the DKW model maintained at the Federal Reserve Board. It is estimated using nominal and real yields from the Gürkaynak et al. (2007, 2010) databases (also maintained by staff at the Federal Reserve Board). Importantly, it includes the median one- and ten-year CPI inflation forecasts from the quarterly Survey of Professional Forecasters (SPF) administered 


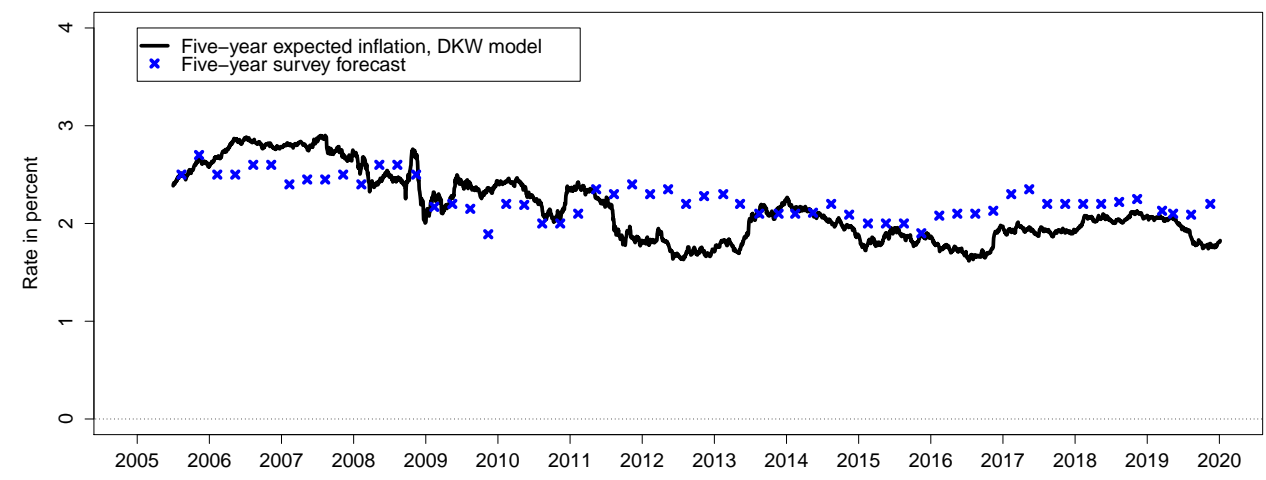

(a) Five-year expected inflation

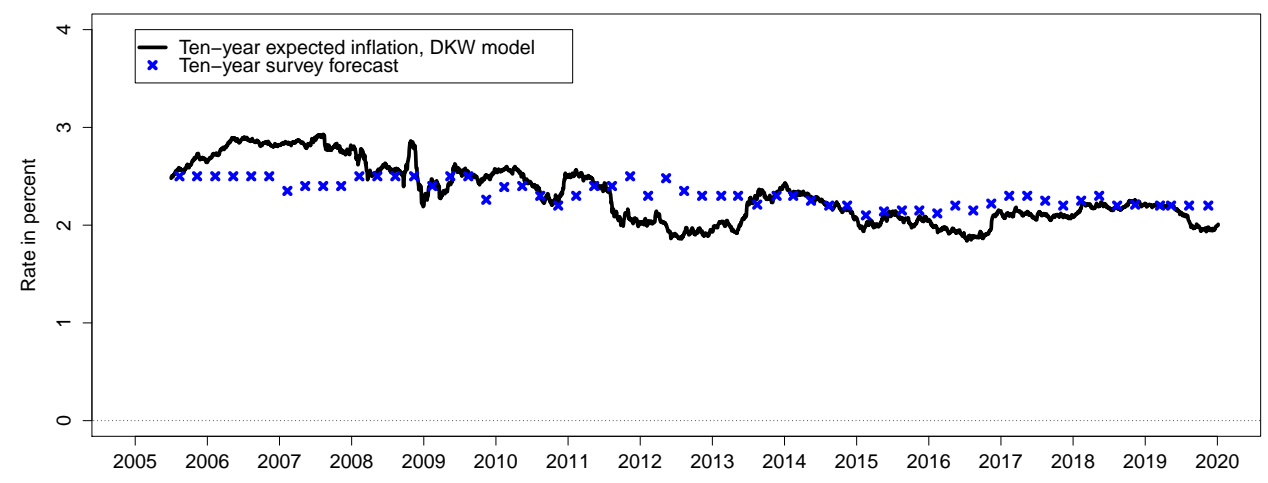

(b) Ten-year expected inflation

Figure 20: Five- and Ten-Year Expected Inflation from a U.S. Model

Panel (a) shows the five-year expected inflation from the DKW model with a comparison to the median five-year CPI inflation forecasts from the Survey of Professional Forecasters. Panel (b) shows the corresponding series at the ten-year horizon. The data from the DKW model is daily covering the period from June 30, 2005 to December 31, 2019, while the SPF forecasts are quarterly from August 11, 2005 to November 11, 2019.

by the Federal Reserve Bank of Philadelphia. ${ }^{19}$

Figure 20 shows the five- and ten-year CPI inflation forecasts from the DKW model and the SPF. There are a few takeaways from these figures. First, despite including relatively stable survey forecasts there is a notable softening in the model-implied long-term inflation expectations, and this softening is particularly surprising at the ten-year horizon given the fact that the ten-year survey forecasts are actually included in the model estimation.

Equally importantly, the softening of the model-implied inflation expectations relative to the SPF forecasts started to become notable and persistent at some point during 2011,

\footnotetext{
${ }^{19}$ The data is from an update provided at the website of Kim et al. (2019) and pulled as of April 6, 2020.
} 
which coincides with the time when our preferred CLR-L model-implied inflation expectations started to trend lower relative to the Canadian survey forecasts.

Finally, at the five-year forecast horizon, which is not included in the model estimation, we do see larger deviations between the model and survey forecasts similar to what we report for the Canadian data.

At a minimum, these results further highlight that the inclusion of survey information in the model estimation is not innocent and merits justification as well as a comprehensive examination of its implications for all relevant model output.

\section{Conclusion}

Given the historic downtrend in yields in recent decades, many researchers have investigated the factors pushing down interest rates. Much of this work has focused on the steady-state level of the safe short-term real interest rate based on macroeconomic models and U.S. data. Instead, we consider a finance-based decomposition of interest rates from empirical dynamic term structure models estimated on a sample of standard Canadian nominal bond yields combined with the prices of Canadian inflation-indexed bonds. By adjusting for both RRB liquidity premiums and nominal and real term premiums, we uncover investors' expectations for the underlying frictionless real short rate for the five-year period starting five years ahead. This measure of the natural rate of interest exhibits a gradual decline over the past two decades that accounts for about two thirds of the general decline in Canadian yields. Specifically, as of the end of December 2019, the CLR-L model estimate of $r_{t}^{*}$ is -0.25 percent, a decline of almost 2 and a half percentage points since the beginning of 2000. Furthermore, model projections that exploit the estimated factor dynamics suggest that this measure of the natural rate is more likely than not to remain near its current low level for the foreseeable future.

Equally important, our joint model of nominal and real yields also produces estimates of investors' inflation expectations and associated inflation risk premiums. Here, we find that a decline in investors' long-term inflation expectations of about a full percentage point has further contributed to the decline in Canadian long-term nominal bond yields. Again, our model-based projections indicate that this trend is unlikely to reverse in the foreseeable future, which may be a concern for the Bank of Canada in terms of achieving its price stability goal in the long run.

For monetary policy analysis, the proposed finance-based approach to estimate both inflation expectations and the natural real rate also offers notable advantages as they are available in real-time and not subject to data revision unlike estimates based on macroeconomic data. Since our measures are based on the forward-looking information priced into the active RRB market and can be updated at daily frequency, they could serve as an important input for 
real-time monetary policy analysis.

For future research, our methods can be further expanded along an international dimension. With a significant degree of capital mobility, the natural rate will depend on global saving and investment, so the joint modeling of inflation-indexed bonds in several countries could be informative similar to HLW. Finally, our measure could be incorporated into an expanded joint macroeconomic and finance analysis - particularly with an eye towards further understanding the determinants of the lower new normal for interest rates. In this regard, Bauer and Rudebusch (2020) show that accounting for fluctuations in the natural rate substantially improves long-range interest rate forecasts and helps predict excess bond returns. 


\section{References}

Abrahams, Michael, Tobias Adrian, Richard K. Crump, Emanuel Moench, and Rui Yu, 2016, "Decomposing Real and Nominal Yield Curves," Journal of Monetary Economics, Vol. $84,182-200$.

Andrade, Philippe and Hervé Le Bihan, 2013, "Inattentive Professional Forecasters," Journal of Monetary Economics, Vol. 60, 967-982.

Andreasen, Martin M., Jens H. E. Christensen, and Simon Riddell, 2020, "The TIPS Liquidity Premium," Working Paper 2017-11, Federal Reserve Bank of San Francisco.

Andreasen, Martin M., Jens H. E. Christensen, and Glenn D. Rudebusch, 2019, "Term Structure Analysis with Big Data: One-Step Estimation Using Bond Prices," Journal of Econometrics, Vol. 212, 26-46.

Andreasen, Martin M. and Andrew Meldrum, 2019, "A Shadow Rate or a Quadratic Policy Rule? The Best Way to Enforce the Zero Lower Bound in the United States," Journal of Financial and Quantitative Analysis, Vol. 54, No. 5, 2261-2292.

Ang, Andrew, Geert Bekaert, and Min Wei, 2008, "The Term Structure of Real Rates and Expected Inflation," Journal of Finance, Vol. 63, No. 2, 797-849.

Bauer, Michael D., and Glenn D. Rudebusch, 2020, "Interest Rates Under Falling Stars," American Economic Review, Vol. 110, No. 5, 1316-1354.

Bauer, Michael D., Glenn D. Rudebusch, and Jing (Cynthia) Wu, 2012, "Correcting Estimation Bias in Dynamic Term Structure Models," Journal of Business and Economic Statistics, Vol. 30, No. 3, 454-467.

Bauer, Michael D., Glenn D. Rudebusch, and Jing (Cynthia) Wu, 2014, "Term Premia and Inflation Uncertainty: Empirical Evidence from an International Panel Dataset: Comment," American Economic Review, Vol. 104, No. 1, 323-337.

Bolder, David J., Grahame Johnson, and Adam Metzler, 2004, "An Empirical Analysis of the Canadian Term Structure of Zero-Coupon Interest Rates," Bank of Canada Working Paper No. 2004-48.

Buraschi, Andrea and A. Jiltsov, 2005, "Inflation Risk Premia and the Expectations Hypothesis," Journal of Financial Economics, Vol. 75, 429-490.

Campbell, John Y., Robert J. Shiller, and Luis M. Viceira, 2009, "Understanding InflationIndexed Bond Markets," Brookings Papers on Economic Activity, Spring, 79-120. 
Carvalho, Carlos, Andrea Ferrero, and Fernanda Nechio, 2016, "Demographics and Real Interest Rates: Inspecting the Mechanism," European Economic Review, Vol. 88, 208226.

Christensen, Jens H. E., Francis X. Diebold, and Glenn D. Rudebusch, 2011, "The Affine Arbitrage-Free Class of Nelson-Siegel Term Structure Models," Journal of Econometrics, Vol. 164, No. 1, 4-20.

Christensen, Jens H. E., Jose A. Lopez, and Glenn D. Rudebusch, 2010, "Inflation Expectations and Risk Premiums in an Arbitrage-Free Model of Nominal and Real Bond Yields," Journal of Money, Credit and Banking, Supplement to Vol. 42, No. 6, 143-178.

Christensen, Jens H. E., Jose A. Lopez, and Glenn D. Rudebusch, 2012, "Extracting Deflation Probability Forecasts from Treasury Yields," International Journal of Central Banking, Vol. 8, No. 4, 21-60.

Christensen, Jens H. E., Jose A. Lopez, and Glenn D. Rudebusch, 2014, "Do Central Bank Liquidity Facilities Affect Interbank Lending Rates?," Journal of Business and Economic Statistics, Vol. 32, No. 1, 136-151.

Christensen, Jens H. E., Jose A. Lopez, and Glenn D. Rudebusch, 2015, "A ProbabilityBased Stress Test of Federal Reserve Assets and Income," Journal of Monetary Economics, Vol. 73, 26-43.

Christensen, Jens H. E. and Glenn D. Rudebusch, 2012, "The Response of Interest Rates to U.S. and U.K. Quantitative Easing," Economic Journal, Vol. 122, F385-F414.

Christensen, Jens H. E. and Glenn D. Rudebusch, 2015, "Estimating Shadow-Rate Term Structure Models with Near-Zero Yields," Journal of Financial Econometrics, Vol. 13, No. 2, 226-259.

Christensen, Jens H. E. and Glenn D. Rudebusch, 2019, “A New Normal for Interest Rates? Evidence from Inflation-Indexed Debt," Review of Economics and Statistics, Vol. 101, No. 5, 933-949.

Chun, Albert Lee, 2011, "Expectations, Bond Yields, and Monetary Policy," The Review of Financial Studies, Vol. 24, No. 1, 208-247.

Cieslak, Anna, 2018, "Short-Rate Expectations and Unexpected Returns in Treasury Bonds," The Review of Financial Studies, Vol. 31, No. 9, 3265-3306.

Coté, Agathe, Jocelyn Jacob, John Nelmes, and Miles Whittingham, 1996, "Inflation Expectations and Real Return Bonds," Bank of Canada Review (Summer), 40-53. 
D'Amico, Stefania, Don H. Kim, and Min Wei, 2018, "Tips from TIPS: The Informational Content of Treasury Inflation-Protected Security Prices," Journal of Financial and Quantitative Analysis, Vol. 53, No. 1, 243-268.

Davis, Josh, Cristian Fuenzalida, and Alan M. Taylor, 2021, "The Natural Rate Puzzle: Global Macro trends and the Market-Implied R*," NBER Working Paper 26560.

Diez de los Rios, Antonio, 2015, "A New Linear Estimator for Gaussian Dynamic Term Sructure Models," Journal of Business and Economic Statistics, Vol. 33, No. 1, 282295.

Duffee, Gregory R., 2002, "Term Premia and Interest Rate Forecasts in Affine Models," Journal of Finance, Vol. 57, No. 1, 405-443.

Favero, Carlo A., Arie E. Gozluklu, and Haoxi Yang, 2016, "Demographics and the Behavior of Interest Rates " IMF Economic Review Vol. 64, No. 4, 732-776.

Finlay, Richard and Sebastian Wende, 2012, "Estimating Inflation Expectations with a Limited Number of Inflation-Indexed Bonds," International Journal of Central Banking, Vol. 8, No. 2, 111-142.

Fontaine, Jean-Sébastien and René Garcia, 2012, "Bond Liquidity Premia," Review of Financial Studies, Vol. 25, No. 4, 1207-1254.

Gagnon, Etienne, Benjamin K. Johannsen, and David Lopez-Salido, 2016, "Understanding the New Normal: The Role of Demographics," Finance and Economics Discussion Series 2016-080. Washington: Board of Governors of the Federal Reserve System, http://dx.doi.org/10.17016/FEDS.2016.080.

Grishchenko, Olesya V. and Jing-Zhi Huang, 2013, "Inflation Risk Premium: Evidence from the TIPS Market," Journal of Fixed Income, Vol. 22, No. 4, 5-30.

Gürkaynak, Refet S., Brian Sack, and Jonathan H. Wright, 2007, "The U.S. Treasury Yield Curve: 1961 to the Present," Journal of Monetary Economics, Vol. 54, No. 8, 22912304 .

Gürkaynak, Refet S., Brian Sack, and Jonathan H. Wright, 2010, "The TIPS Yield Curve and Inflation Compensation," American Economic Journal: Macroeconomics, Vol. 2, No. 1, 70-92.

Hall, Robert E., 2016, "The Role of the Growth of Risk-Averse Wealth in the Decline of the Safe Real Interest Rate," Manuscript, Stanford University. 
Holston, Kathryn, Thomas Laubach, and John C. Williams, 2017, "Measuring the Natural Rate of Interest: International Trends and Determinants," Journal of International Economics, Vol. 108, 559-575.

Hördahl, Peter and Oreste Tristani, 2014, "Inflation Risk Premia in the Euro Area and the United States," International Journal of Central Banking, Vol. 10, No. 3, 1-47.

Kearns, Jonathan, Andreas Schrimpf, and Fan Dora Xia, 2020, "Explaining Monetary Spillovers: The Matrix Reloaded," CEPR Discussion Paper No. 15006.

Kim, Don H. and Athanasios Orphanides, 2012, "Term Structure Estimation with Survey Data on Interest Rate Forecasts," Journal of Financial and Quantitative Analysis, Vol. 47, No. 1, 241-272.

Kim, Don H. and Kenneth J. Singleton, 2012, "Term Structure Models and the Zero Bound: An Empirical Investigation of Japanese Yields," Journal of Econometrics, Vol. 170, No. $1,32-49$.

Kim, Don H., Cait Walsh, and Min Wei, 2019, "Tips from TIPS: An Update and Further Discussions," FEDS Notes.

Laubach, Thomas and John C. Williams, 2003, "Measuring the Natural Rate of Interest," Review of Economics and Statistics, Vol. 85, No. 4, 1063-1070.

Laubach, Thomas and John C. Williams, 2016, "Measuring the Natural Rate of Interest Redux," Business Economics, Vol. 51, No. 2, 57-67.

Matveev, Dmitry, Julien McDonald-Guimond, and Rodrigo Sekkel, 2020, "The Neutral Rate in Canada: 2020 Update," Bank of Canada Staff Discussion Paper No. 2020-24.

Nelson, Charles R. and Andrew F. Siegel, 1987, "Parsimonious Modeling of Yield Curves," Journal of Business, Vol. 60, No. 4, 473-489.

Pflueger, Carolin E. and Luis M. Viceira, 2016, "Return Predictability in the Treasury Market: Real Rates, Inflation, and Liquidity," in Handbook of Fixed-Income Securities, edited by P. Veronesi, Wiley, Hoboken, N.J., pp. 191-209 (Chapter 10).

Rachel, Lukasz, and Thomas D Smith, 2015, "Secular Drivers of the Global Real Interest Rate," Staff working paper 571, Bank of England.

Reid, Christopher, Frédéric Dion, and Ian Christensen, 2004, "Real Return Bonds: Monetary Policy Credibility and Short-Term Inflation Forecasting," Bank of Canada Review (Autumn), 15-26. 
Sack, Brian and Robert Elsasser, 2004, "Treasury Inflation-Indexed Debt: A Review of the U.S. Experience," Federal Reserve Bank of New York Economic Policy Review, Vol. 10, No. 1, 47-63.

Swanson, Eric T. and John C. Williams, 2014, "Measuring the Effect of the Zero Lower Bound on Medium- and Longer-Term Interest Rates," American Economic Review, Vol. 104, No. 10, 3154-3185.

Wright, Jonathan H., 2011, "Term Premia and Inflation Uncertainty: Empirical Evidence from an International Panel Dataset," American Economic Review, Vol. 101, No. 4, 1514-1534. 


\title{
Online Appendix
}

\section{Accounting for Low Long-Term Interest Rates: Evidence from Canada}

\author{
Jens H. E. Christensen \\ Federal Reserve Bank of San Francisco \\ jens.christensen@sf.frb.org \\ Glenn D. Rudebusch \\ Federal Reserve Bank of San Francisco \\ glenn.rudebusch@sf.frb.org \\ Patrick J. Shultz \\ Wharton School of the University of Pennsylvania \\ pshultz@wharton.upenn.edu
}

The views in this paper are solely the responsibility of the authors and should not be interpreted as reflecting the views of the Federal Reserve Bank of San Francisco or the Board of Governors of the Federal Reserve System.

This version: June 14, 2021. 


\section{Contents}

A Identifying the Natural Rate of Interest with Bonds $\quad 2$

A.1 Decomposing Nominal and Real Yields with Frictionless Models . . . . . . . 2

A.2 A Frictionless Arbitrage-Free Model of Nominal and Real Yields . . . . . . . 5

B Mapping from the Canonical $A_{0}(4)$ Model to the CLR Model $\quad 7$

$\begin{array}{ll}\text { C The RRB Liquidity Premium } & 13\end{array}$

C.1 The Estimated RRB Liquidity Premium . . . . . . . . . . . . . . . . 13

C.2 Liquidity Premium Comparisons . . . . . . . . . . . . . . . . . 14

C.3 Observable Proxies for Liquidity Risk . . . . . . . . . . . . . . . . 16

C.4 Sensitivity of the RRB Liquidity Premium to Model Specifications . . . . . . 19

$\begin{array}{ll}\text { D Alternative Definitions of } r^{*}(t) & \mathbf{2 0}\end{array}$

$\begin{array}{ll}\text { E Model Selection in the CLR Model } & 21\end{array}$

$\begin{array}{ll}\text { F Nominal Yield Forecast Exercise } & 24\end{array}$

F.1 Models . . . . . . . . . . . . . . . . . . . . . . . . 25

F.1.1 The Three-Factor Model . . . . . . . . . . . . . . 25

F.1.2 The Shadow-Rate Model . . . . . . . . . . . . . . . . . 26

F.1.3 The Five-Factor Model . . . . . . . . . . . . . . . . . . 26

F.2 The Consensus Forecasts . . . . . . . . . . . . . . . . . . . 27

F.3 Yield Forecast Generation . . . . . . . . . . . . . . . . . . . . . . . 28

F.4 Yield Realizations . . . . . . . . . . . . . . . . . . . . . . . 30

F.5 Results . . . . . . . . . . . . . . . . . . . . . 32 


\section{A Identifying the Natural Rate of Interest with Bonds}

In this appendix, we first describe how nominal and real bond yields can be decomposed into underlying nominal and real short-rate expectations components and residual nominal and real term premiums in a world without any frictions to trading. The model of frictionless dynamics is fundamental to our empirical analysis in the paper.

\section{A.1 Decomposing Nominal and Real Yields with Frictionless Models}

We begin our analysis assuming a world in which there are no frictions to the trading of financial claims, i.e., there are no bid-ask spreads and any financial claim can be traded in arbitrarily small or large amounts without affecting its price. As a consequence, financial market prices contain no liquidity premiums as there is no liquidity risk to be rewarded. Under such ideal conditions, nominal and real yields vary either because fundamental factors in the economy have changed or because investors have altered their perceptions of, or aversions to, the risks that those economic fundamentals represent.

An arbitrage-free term structure model of nominal and real yields can be used to decompose nominal and real yields into the sum of the corresponding short-rate expectations and associated term premiums. We follow Merton (1974) and assume a continuum of nominal and real zero-coupon bonds exists with no frictions to their continuous trading. To begin the model description, define the nominal and real stochastic discount factors, denoted $M_{t}^{N}$ and $M_{t}^{R}$, respectively. The no-arbitrage condition enforces a consistency of pricing for any security over time. Specifically, the price of a nominal bond that pays one dollar in $\tau$ years and the price of a real bond that pays one consumption unit in $\tau$ years must satisfy the conditions that

$$
P_{t}^{N}(\tau)=E_{t}^{\mathbb{P}}\left[\frac{M_{t+\tau}^{N}}{M_{t}^{N}}\right] \quad \text { and } \quad P_{t}^{R}(\tau)=E_{t}^{\mathbb{P}}\left[\frac{M_{t+\tau}^{R}}{M_{t}^{R}}\right]
$$

where $P_{t}^{N}(\tau)$ and $P_{t}^{R}(\tau)$ are the observed prices of the zero-coupon, nominal and real bonds for maturity $\tau$ at time $t$ and $E_{t}^{\mathbb{P}}$ [.] is the conditional expectations operator under the real-world (or $\mathbb{P}_{-}$) probability measure.

Our working definition of the equilibrium real rate of interest $r_{t}^{*}$ is

$$
r_{t}^{*}=\frac{1}{5} \int_{t+5}^{t+10} E_{t}^{\mathbb{P}}\left[r_{t+s}^{R}\right] d s,
$$


that is, the average expected real short rate over a five-year period starting five years ahead where the expectation is with respect to the objective $\mathbb{P}$-probability measure. As noted in the paper, this 5yr5yr forward average expected real short rate should be little affected by short-term transitory shocks.

In the empirical analysis, we rely on the market prices of nominal and real bonds to construct this market-based measure of the natural rate. In doing so, it is important to acknowledge that financial market prices do not reflect objective $\mathbb{P}$-expectations as in equation (1). Instead, they reflect expectations adjusted with the premiums investors demand for being exposed to the underlying risks. We follow the usual empirical finance approach that models bond prices with latent factors, here denoted as $X_{t}$, and the assumption of no residual arbitrage opportunities. ${ }^{1}$ We assume that $X_{t}$ follows an affine Gaussian process with constant volatility, with dynamics in continuous time given by the solution to the following stochastic differential equation (SDE):

$$
d X_{t}=K^{\mathbb{P}}\left(\theta^{\mathbb{P}}-X_{t}\right)+\Sigma d W_{t}^{\mathbb{P}}
$$

where $K^{\mathbb{P}}$ is an $n \times n$ mean-reversion matrix, $\theta^{\mathbb{P}}$ is an $n \times 1$ vector of mean levels, $\Sigma$ is an $n \times n$ volatility matrix, and $W_{t}^{\mathbb{P}}$ is an $n$-dimensional Brownian motion. The dynamics of the nominal and real stochastic discount factors are given by

$$
\begin{aligned}
d M_{t}^{N} / M_{t}^{N} & =-r_{t}^{N} d t-\Gamma_{t}^{\prime} d W_{t}^{\mathbb{P}}, \\
d M_{t}^{R} / M_{t}^{R} & =-r_{t}^{R} d t-\Gamma_{t}^{\prime} d W_{t}^{\mathbb{P}},
\end{aligned}
$$

and the instantaneous, risk-free nominal and real short rates, $r_{t}^{N}$ and $r_{t}^{R}$, are assumed affine in the state variables

$$
\begin{aligned}
& r_{t}^{N}=\delta_{0}^{N}+\delta_{1}^{N} X_{t}, \\
& r_{t}^{R}=\delta_{0}^{R}+\delta_{1}^{R} X_{t},
\end{aligned}
$$

where $\delta_{0}^{N} \in \mathbf{R}, \delta_{0}^{R} \in \mathbf{R}, \delta_{1}^{N} \in \mathbf{R}^{n}$ and $\delta_{1}^{R} \in \mathbf{R}^{n}$. The risk premiums, $\Gamma_{t}$, are also affine

$$
\Gamma_{t}=\gamma_{0}+\gamma_{1} X_{t},
$$

\footnotetext{
${ }^{1}$ Ultimately, of course, the behavior of the stochastic discount factor is determined by the preferences of the agents in the economy, as in, for example, Rudebusch and Swanson (2011).
} 
where $\gamma_{0} \in \mathbf{R}^{n}$ and $\gamma_{1} \in \mathbf{R}^{n \times n}$.

Duffie and Kan (1996) show that these assumptions imply that zero-coupon nominal and real yields are also affine in $X_{t}$ :

$$
\begin{aligned}
y_{t}^{N}(\tau) & =-\frac{1}{\tau} A^{N}(\tau)-\frac{1}{\tau} B^{N}(\tau)^{\prime} X_{t}, \\
y_{t}^{R}(\tau) & =-\frac{1}{\tau} A^{R}(\tau)-\frac{1}{\tau} B^{R}(\tau)^{\prime} X_{t},
\end{aligned}
$$

where $A^{N}(\tau), A^{R}(\tau), B^{N}(\tau)$, and $B^{R}(\tau)$ are given as solutions to the following system of ordinary differential equations

$$
\begin{aligned}
& \frac{d B^{N}(\tau)}{d \tau}=-\delta_{1}^{N}-\left(K^{\mathbb{P}}+\Sigma \gamma_{1}\right)^{\prime} B^{N}(\tau), \quad B^{N}(0)=0, \\
& \frac{d A^{N}(\tau)}{d \tau}=-\delta_{0}^{N}+B^{N}(\tau)^{\prime}\left(K^{\mathbb{P}} \theta^{\mathbb{P}}-\Sigma \gamma_{0}\right)+\frac{1}{2} \sum_{j=1}^{n}\left(\Sigma^{\prime} B^{N}(\tau) B^{N}(\tau)^{\prime} \Sigma\right)_{j, j}, \quad A^{N}(0)=0 \\
& \frac{d B^{R}(\tau)}{d \tau}=-\delta_{1}^{R}-\left(K^{\mathbb{P}}+\Sigma \gamma_{1}\right)^{\prime} B^{R}(\tau), \quad B^{R}(0)=0, \\
& \frac{d A^{R}(\tau)}{d \tau}=-\delta_{0}^{R}+B^{N}(\tau)^{\prime}\left(K^{\mathbb{P}} \theta^{\mathbb{P}}-\Sigma \gamma_{0}\right)+\frac{1}{2} \sum_{j=1}^{n}\left(\Sigma^{\prime} B^{R}(\tau) B^{R}(\tau)^{\prime} \Sigma\right)_{j, j}, \quad A^{R}(0)=0 .
\end{aligned}
$$

Thus, the $A^{N}(\tau), A^{R}(\tau), B^{N}(\tau)$, and $B^{R}(\tau)$ functions are calculated as if the dynamics of the state variables had a constant drift term equal to $K^{\mathbb{P}} \theta^{\mathbb{P}}-\Sigma \gamma_{0}$ instead of the actual $K^{\mathbb{P}} \theta^{\mathbb{P}}$ and a mean-reversion matrix equal to $K^{\mathbb{P}}+\Sigma \gamma_{1}$ as opposed to the actual $K^{\mathbb{P}}{ }^{2}$ The difference is determined by the risk premium $\Gamma_{t}$ and reflects investors' aversion to the risks embodied in $X_{t}$.

Finally, we define the nominal and real term premiums as

$$
\begin{aligned}
T P_{t}^{N}(\tau) & =y_{t}^{N}(\tau)-\frac{1}{\tau} \int_{t}^{t+\tau} E_{t}^{\mathbb{P}}\left[r_{s}^{N}\right] d s \\
T P_{t}^{R}(\tau) & =y_{t}^{R}(\tau)-\frac{1}{\tau} \int_{t}^{t+\tau} E_{t}^{\mathbb{P}}\left[r_{s}^{R}\right] d s .
\end{aligned}
$$

That is, the nominal term premium is the difference in expected nominal return between a buy and hold strategy for a $\tau$-year nominal bond and an instantaneous rollover strategy at the risk-free nominal rate $r_{t}^{N}$. The real term premium has a similar interpretation, but in real

\footnotetext{
${ }^{2}$ The probability measure with these alternative dynamics is frequently referred to as the risk-neutral, or $\mathbb{Q}$, probability measure since the expected return on any asset under this measure is equal to the risk-free real rate $r_{t}$ that a risk-neutral investor would demand.
} 
terms. This model thus allows us to decompose nominal and real yields into their respective term premium and short-rate expectations components.

\section{A.2 A Frictionless Arbitrage-Free Model of Nominal and Real Yields}

Building on the insights from the general theoretical discussion in the previous section, we need an accurate model of the instantaneous nominal and real rate, $r_{t}^{N}$ and $r_{t}^{R}$, in order to precisely measure nominal and real term premiums. With that goal in mind we choose to focus on the tractable affine dynamic term structure model of nominal and real yields introduced in Christensen et al. (2010, henceforth CLR) and briefly summarized below. We emphasize that even though the model is not formulated using the canonical form of affine term structure models introduced by Dai and Singleton (2000), it can be viewed as a restricted version of the canonical Gaussian model. ${ }^{3}$

The CLR model of nominal and real yields represents an extension of the three-factor, arbitrage-free Nelson-Siegel (AFNS) model developed by Christensen et al. (2011, henceforth CDR) for nominal yields. In the CLR model, the state vector is denoted by $X_{t}=$ $\left(L_{t}^{N}, S_{t}, C_{t}, L_{t}^{R}\right)$, where $L_{t}^{N}$ is the level factor for nominal yields, $S_{t}$ and $C_{t}$ represent slope and curvature factors common to both nominal and real yields, and $L_{t}^{R}$ is the level factor for real yields. ${ }^{4}$ The instantaneous nominal and real risk-free rates are defined as

$$
\begin{aligned}
& r_{t}^{N}=L_{t}^{N}+S_{t}, \\
& r_{t}^{R}=L_{t}^{R}+\alpha^{R} S_{t} .
\end{aligned}
$$

Note that the differential scaling of the real rates to the common slope factor is captured by the parameter $\alpha^{R}$. To preserve the Nelson and Siegel (1987) factor loading structure in the yield functions, the risk-neutral (or $\mathbb{Q}$-) dynamics of the state variables are given by the

\footnotetext{
${ }^{3}$ These restrictions can be derived explicitly, see online Appendix B for details.

${ }^{4}$ Chernov and Mueller (2012) provide evidence of a hidden factor in the nominal yield curve that is observable from real yields and inflation expectations. The CLR model accommodates this stylized fact via the $L_{t}^{R}$ factor.
} 
stochastic differential equations: ${ }^{5}$

$$
\left(\begin{array}{c}
d L_{t}^{N} \\
d S_{t} \\
d C_{t} \\
d L_{t}^{R}
\end{array}\right)=\left(\begin{array}{cccc}
0 & 0 & 0 & 0 \\
0 & -\lambda & \lambda & 0 \\
0 & 0 & -\lambda & 0 \\
0 & 0 & 0 & 0
\end{array}\right)\left(\begin{array}{c}
L_{t}^{N} \\
S_{t} \\
C_{t} \\
L_{t}^{R}
\end{array}\right) d t+\Sigma\left(\begin{array}{c}
d W_{t}^{L^{N}, \mathbb{Q}} \\
d W_{t}^{S, \mathbb{Q}} \\
d W_{t}^{C, \mathbb{Q}} \\
d W_{t}^{L^{R}, \mathbb{Q}}
\end{array}\right)
$$

where $\Sigma$ is the constant covariance (or volatility) matrix. ${ }^{6}$ Based on this specification of the $\mathbb{Q}$-dynamics, nominal zero-coupon bond yields preserve the Nelson-Siegel factor loading structure as

$$
y_{t}^{N}(\tau)=L_{t}^{N}+\left(\frac{1-e^{-\lambda \tau}}{\lambda \tau}\right) S_{t}+\left(\frac{1-e^{-\lambda \tau}}{\lambda \tau}-e^{-\lambda \tau}\right) C_{t}-\frac{A^{N}(\tau)}{\tau},
$$

where the nominal yield-adjustment term is given by

$$
\begin{aligned}
\frac{A^{N}(\tau)}{\tau}= & \frac{\sigma_{11}^{2}}{6} \tau^{2}+\sigma_{22}^{2}\left[\frac{1}{2 \lambda^{2}}-\frac{1}{\lambda^{3}} \frac{1-e^{-\lambda \tau}}{\tau}+\frac{1}{4 \lambda^{3}} \frac{1-e^{-2 \lambda \tau}}{\tau}\right] \\
& +\sigma_{33}^{2}\left[\frac{1}{2 \lambda^{2}}+\frac{1}{\lambda^{2}} e^{-\lambda \tau}-\frac{1}{4 \lambda} \tau e^{-2 \lambda \tau}-\frac{3}{4 \lambda^{2}} e^{-2 \lambda \tau}+\frac{5}{8 \lambda^{3}} \frac{1-e^{-2 \lambda \tau}}{\tau}-\frac{2}{\lambda^{3}} \frac{1-e^{-\lambda \tau}}{\tau}\right] .
\end{aligned}
$$

Similarly, real zero-coupon bond yields have a Nelson-Siegel factor loading structure expressed as

$$
y_{t}^{R}(\tau)=L_{t}^{R}+\alpha^{R}\left(\frac{1-e^{-\lambda \tau}}{\lambda \tau}\right) S_{t}+\alpha^{R}\left(\frac{1-e^{-\lambda \tau}}{\lambda \tau}-e^{-\lambda \tau}\right) C_{t}-\frac{A^{R}(\tau)}{\tau}
$$

where the real yield-adjustment term is given by

$$
\begin{aligned}
\frac{A^{R}(\tau)}{\tau}= & \frac{\sigma_{44}^{2}}{6} \tau^{2}+\sigma_{22}^{2}\left(\alpha_{S}^{R}\right)^{2}\left[\frac{1}{2 \lambda^{2}}-\frac{1}{\lambda^{3}} \frac{1-e^{-\lambda \tau}}{\tau}+\frac{1}{4 \lambda^{3}} \frac{1-e^{-2 \lambda \tau}}{\tau}\right] \\
& +\sigma_{33}^{2}\left(\alpha_{S}^{R}\right)^{2}\left[\frac{1}{2 \lambda^{2}}+\frac{1}{\lambda^{2}} e^{-\lambda \tau}-\frac{1}{4 \lambda} \tau e^{-2 \lambda \tau}-\frac{3}{4 \lambda^{2}} e^{-2 \lambda \tau}+\frac{5}{8 \lambda^{3}} \frac{1-e^{-2 \lambda \tau}}{\tau}-\frac{2}{\lambda^{3}} \frac{1-e^{-\lambda \tau}}{\tau}\right] .
\end{aligned}
$$

To complete the description of the model and to implement it empirically, we will need to specify the risk premiums that connect these factor dynamics under the $\mathbb{Q}$-measure to the dynamics under the real-world (or physical) $\mathbb{P}$-measure. It is important to note that there are no restrictions on the dynamic drift components under the empirical $\mathbb{P}$-measure beyond

\footnotetext{
${ }^{5}$ As discussed in CDR, with unit roots in the two level factors, the model is not arbitrage-free with an unbounded horizon; therefore, as is often done in theoretical discussions, we impose an arbitrary maximum horizon.

${ }^{6}$ As per CDR, $\Sigma$ is a diagonal matrix, and $\theta^{\mathbb{Q}}$ is set to zero without loss of generality.
} 
the requirement of constant volatility. To facilitate empirical implementation, we use the essentially affine risk premium specification introduced in Duffee (2002). In the Gaussian framework, this specification implies that the risk premiums $\Gamma_{t}$ depend on the state variables; that is,

$$
\Gamma_{t}=\gamma^{0}+\gamma^{1} X_{t}
$$

where $\gamma^{0} \in \mathbf{R}^{4}$ and $\gamma^{1} \in \mathbf{R}^{4 \times 4}$ contain unrestricted parameters.

Thus, the resulting unrestricted four-factor CLR model has $\mathbb{P}$-dynamics given by

$$
\left(\begin{array}{c}
d L_{t}^{N} \\
d S_{t} \\
d C_{t} \\
L_{t}^{R}
\end{array}\right)=\left(\begin{array}{cccc}
\kappa_{11}^{\mathbb{P}} & \kappa_{12}^{\mathbb{P}} & \kappa_{13}^{\mathbb{P}} & \kappa_{14}^{\mathbb{P}} \\
\kappa_{21}^{\mathbb{P}} & \kappa_{22}^{\mathbb{P}} & \kappa_{23}^{\mathbb{P}} & \kappa_{24}^{\mathbb{P}} \\
\kappa_{31}^{\mathbb{P}} & \kappa_{32}^{\mathbb{P}} & \kappa_{33}^{\mathbb{P}} & \kappa_{34}^{\mathbb{P}} \\
\kappa_{41}^{\mathbb{P}} & \kappa_{42}^{\mathbb{P}} & \kappa_{43}^{\mathbb{P}} & \kappa_{44}^{\mathbb{P}}
\end{array}\right)\left(\left(\begin{array}{c}
\theta_{1}^{\mathbb{P}} \\
\theta_{2}^{\mathbb{P}} \\
\theta_{3}^{\mathbb{P}} \\
\theta_{4}^{\mathbb{P}}
\end{array}\right)-\left(\begin{array}{c}
L_{t}^{N} \\
S_{t} \\
C_{t} \\
L_{t}^{R}
\end{array}\right)\right) d t+\Sigma\left(\begin{array}{c}
d W_{t}^{L^{N}, \mathbb{P}} \\
d W_{t}^{S, \mathbb{P}} \\
d W_{t}^{C, \mathbb{P}} \\
d W_{t}^{L^{R}, \mathbb{P}}
\end{array}\right) .
$$

This is the transition equation in the Kalman filter estimation of the CLR model.

\section{B Mapping from the Canonical $A_{0}(4)$ Model to the CLR Model}

In this appendix, we build on the classification of ATSMs introduced in Dai and Singleton (2000) and detail the connection between the canonical $A_{0}(4)$ model of nominal and real yields and its counterpart CLR model. It should be noted that implicit in the description is the usage of the extended affine risk premium specification of Cheridito et al. (2007), which for Gaussian $A_{0}(N)$ models is equivalent to the essentially affine risk premium specification introduced in Duffee (2002). By limiting the focus to affine risk premium specifications, the models preserve affine factor dynamics under both probability measures and the invariant affine transformations of Dai and Singleton (2000) apply.

Derivation of the restrictions imposed on the canonical representation of the $A_{0}(4)$ model needed to get to a specification that has a distribution identical to the CLR model considered in the paper starts from a general affine diffusion process represented by

$$
d Y_{t}=K_{Y}^{\mathbb{Q}}\left[\theta_{Y}^{\mathbb{Q}}-Y_{t}\right] d t+\Sigma_{Y} d W_{t}^{\mathbb{Q}}
$$

Now, consider the affine transformation $\mathcal{T}_{A}: A Y_{t}+\eta$, where $A$ is a nonsingular square matrix of the same dimension as $Y_{t}$ and $\eta$ is a vector of constants of the same dimension as $Y_{t}$. Denote 
the transformed process by $X_{t}=A Y_{t}+\eta$. By Ito's lemma, it follows that

$$
\begin{aligned}
d X_{t} & =A d Y_{t}=\left[A K_{Y}^{\mathbb{Q}} \theta_{Y}^{\mathbb{Q}}-A K_{Y}^{\mathbb{Q}} Y_{t}\right] d t+A \Sigma_{Y} d W_{t}^{\mathbb{Q}} \\
& =A K_{Y}^{\mathbb{Q}} A^{-1}\left[A \theta_{Y}^{\mathbb{Q}}-A Y_{t}-\eta+\eta\right] d t+A \Sigma_{Y} d W_{t}^{\mathbb{Q}} \\
& =A K_{Y}^{\mathbb{Q}} A^{-1}\left[A \theta_{Y}^{\mathbb{Q}}+\eta-X_{t}\right] d t+A \Sigma_{Y} d W_{t}^{\mathbb{Q}}=K_{X}^{\mathbb{Q}}\left[\theta_{X}^{\mathbb{Q}}-X_{t}\right] d t+\Sigma_{X} d W_{t}^{\mathbb{Q}}
\end{aligned}
$$

Thus, $X_{t}$ is itself an affine diffusion process with parameter specification:

$$
K_{X}^{\mathbb{Q}}=A K_{Y}^{\mathbb{Q}} A^{-1}, \quad \theta_{X}^{\mathbb{Q}}=A \theta_{Y}^{\mathbb{Q}}+\eta, \quad \text { and } \quad \Sigma_{X}=A \Sigma_{Y}
$$

A similar result holds for the dynamics under the $\mathbb{P}$-measure.

As for the short rate process, there exists the following relationship:

$$
\begin{aligned}
r_{t} & =\delta_{0}^{Y}+\left(\delta_{1}^{Y}\right)^{\prime} Y_{t}=\delta_{0}^{Y}+\left(\delta_{1}^{Y}\right)^{\prime} A^{-1} A Y_{t}=\delta_{0}^{Y}+\left(\delta_{1}^{Y}\right)^{\prime} A^{-1}\left[A Y_{t}+\eta-\eta\right] \\
& =\delta_{0}^{Y}-\left(\delta_{1}^{Y}\right)^{\prime} A^{-1} \eta+\left(\delta_{1}^{Y}\right)^{\prime} A^{-1} X_{t}
\end{aligned}
$$

Thus, defining $\delta_{0}^{X}=\delta_{0}^{Y}-\left(\delta_{1}^{Y}\right)^{\prime} A^{-1} \eta$ and $\delta_{1}^{X}=\left(\delta_{1}^{Y}\right)^{\prime} A^{-1}$, the short rate process is left unchanged and may be represented in either way

$$
r_{t}=\delta_{0}^{Y}+\left(\delta_{1}^{Y}\right)^{\prime} Y_{t}=\delta_{0}^{X}+\left(\delta_{1}^{X}\right)^{\prime} X_{t}
$$

Because both $Y_{t}$ and $X_{t}$ are affine latent factor processes that deliver the same distribution for the short rate process $r_{t}$, they are equivalent representations of the same fundamental model; hence, $\mathcal{T}_{A}$ is called an affine invariant transformation.

In the canonical representation of the subset of $A_{0}(4)$ affine term structure models considered here, the $\mathbb{Q}$-dynamics are $^{7}$

$$
\left(\begin{array}{c}
d Y_{t}^{1} \\
d Y_{t}^{2} \\
d Y_{t}^{3} \\
d Y_{t}^{4}
\end{array}\right)=-\left(\begin{array}{cccc}
\kappa_{11}^{Y, \mathbb{Q}} & \kappa_{12}^{Y, \mathbb{Q}} & \kappa_{13}^{Y, \mathbb{Q}} & \kappa_{14}^{Y, \mathbb{Q}} \\
0 & \kappa_{22}^{Y, \mathbb{Q}} & \kappa_{23}^{Y, \mathbb{Q}} & \kappa_{24}^{Y, \mathbb{Q}} \\
0 & 0 & \kappa_{33}^{Y, \mathbb{Q}} & \kappa_{34}^{Y, \mathbb{Q}} \\
0 & 0 & 0 & \kappa_{44}^{Y, \mathbb{Q}}
\end{array}\right)\left(\begin{array}{c}
Y_{t}^{1} \\
Y_{t}^{2} \\
Y_{t}^{3} \\
Y_{t}^{4}
\end{array}\right) d t+\left(\begin{array}{cccc}
1 & 0 & 0 & 0 \\
0 & 1 & 0 & 0 \\
0 & 0 & 1 & 0 \\
0 & 0 & 0 & 1
\end{array}\right)\left(\begin{array}{c}
d W_{t}^{1, \mathbb{Q}} \\
d W_{t}^{2, \mathbb{Q}} \\
d W_{t}^{3, \mathbb{Q}} \\
d W_{t}^{4, \mathbb{Q}}
\end{array}\right),
$$

\footnotetext{
${ }^{7}$ Note that we follow Singleton $(2006)$ and impose the identifying restrictions on the $\mathbb{Q}$-dynamics, which contrasts with the approach of Dai and Singleton (2000) where they are imposed on the $\mathbb{P}$-dynamics.
} 
and the $\mathbb{P}$-dynamics are left unconstrained

$$
\left(\begin{array}{c}
d Y_{t}^{1} \\
d Y_{t}^{2} \\
d Y_{t}^{3} \\
d Y_{t}^{4}
\end{array}\right)=\left(\begin{array}{cccc}
\kappa_{11}^{Y, \mathbb{P}} & \kappa_{12}^{Y, \mathbb{P}} & \kappa_{13}^{Y, \mathbb{P}} & \kappa_{14}^{Y, \mathbb{P}} \\
\kappa_{21}^{Y, \mathbb{P}} & \kappa_{22}^{Y, \mathbb{P}} & \kappa_{23}^{Y, \mathbb{P}} & \kappa_{24}^{Y, \mathbb{P}} \\
\kappa_{31}^{Y, \mathbb{P}} & \kappa_{32}^{Y, \mathbb{P}} & \kappa_{33}^{Y, \mathbb{P}} & \kappa_{34}^{Y, \mathbb{P}} \\
\kappa_{41}^{Y, \mathbb{P}} & \kappa_{42}^{Y, \mathbb{P}} & \kappa_{43}^{Y, \mathbb{P}} & \kappa_{44}^{Y, \mathbb{P}}
\end{array}\right)\left[\left(\begin{array}{c}
\theta_{1}^{Y, \mathbb{P}} \\
\theta_{2}^{Y, \mathbb{P}} \\
\theta_{3}^{Y, \mathbb{P}} \\
\theta_{4}^{Y, \mathbb{P}}
\end{array}\right)-\left(\begin{array}{c}
Y_{t}^{1} \\
Y_{t}^{2} \\
Y_{t}^{3} \\
Y_{t}^{4}
\end{array}\right)\right] d t+\left(\begin{array}{cccc}
1 & 0 & 0 & 0 \\
0 & 1 & 0 & 0 \\
0 & 0 & 1 & 0 \\
0 & 0 & 0 & 1
\end{array}\right)\left(\begin{array}{c}
d W_{t}^{1, \mathbb{P}} \\
d W_{t}^{2, \mathbb{P}} \\
d W_{t}^{3, \mathbb{P}} \\
d W_{t}^{4, \mathbb{P}}
\end{array}\right) .
$$

Finally, the instantaneous risk-free rate is

$$
r_{t}=\delta_{0}^{Y}+\delta_{1,1}^{Y} Y_{t}^{1}+\delta_{1,2}^{Y} Y_{t}^{2}+\delta_{1,3}^{Y} Y_{t}^{3}+\delta_{1,4}^{Y} Y_{t}^{4}
$$

This equation shows that we will be considering two cases jointly: (1) The case of nominal yields discounted with the nominal risk-free rate $r_{t}^{N}$ and (2) the case of real yields discounted with the real risk-free rate $r_{t}^{R}$. Thus, the short rate processes in the canonical model are

$$
\begin{aligned}
& r_{t}^{N}=\delta_{0}^{N, Y}+\delta_{1,1}^{N, Y} Y_{t}^{1}+\delta_{1,2}^{N, Y} Y_{t}^{2}+\delta_{1,3}^{N, Y} Y_{t}^{3}+\delta_{1,4}^{N, Y} Y_{t}^{4}, \\
& r_{t}^{R}=\delta_{0}^{R, Y}+\delta_{1,1}^{R, Y} Y_{t}^{1}+\delta_{1,2}^{R, Y} Y_{t}^{2}+\delta_{1,3}^{R, Y} Y_{t}^{3}+\delta_{1,4}^{R, Y} Y_{t}^{4} .
\end{aligned}
$$

There are 35 parameters in this maximally flexible canonical representation of the $A_{0}(4)$ class of models for nominal and real yields separately. Once we join the information set and model $r_{t}^{N}$ and $r_{t}^{R}$ simultaneously, there are 40 parameters in the canonical $A_{0}(4)$ model and we now present the parameter restrictions needed to arrive at the CLR model of nominal and real yields with diagonal $\Sigma$ matrix analyzed in the paper.

To begin, let the state vector be denoted by $X_{t}=\left(L_{t}^{N}, S_{t}, C_{t}, L_{t}^{R}\right)$, where $L_{t}^{N}$ is the level factor for nominal yields, $S_{t}$ is the common slope factor, $C_{t}$ is the common curvature factor, and $L_{t}^{R}$ is the level factor for real yields.

The maximally flexible specification of the CLR model is

$$
\left(\begin{array}{c}
d L_{t}^{N} \\
d S_{t} \\
d C_{t} \\
d L_{t}^{R}
\end{array}\right)=\left(\begin{array}{cccc}
\kappa_{11}^{\mathbb{P}} & \kappa_{12}^{\mathbb{P}} & \kappa_{13}^{\mathbb{P}} & \kappa_{14}^{\mathbb{P}} \\
\kappa_{21}^{\mathbb{P}} & \kappa_{22}^{\mathbb{P}} & \kappa_{23}^{\mathbb{P}} & \kappa_{24}^{\mathbb{P}} \\
\kappa_{31}^{\mathbb{P}} & \kappa_{32}^{\mathbb{P}} & \kappa_{33}^{\mathbb{P}} & \kappa_{34}^{\mathbb{P}} \\
\kappa_{41}^{\mathbb{P}} & \kappa_{42}^{\mathbb{P}} & \kappa_{43}^{\mathbb{P}} & \kappa_{44}^{\mathbb{P}}
\end{array}\right)\left(\left(\begin{array}{c}
\theta_{1}^{\mathbb{P}} \\
\theta_{2}^{\mathbb{P}} \\
\theta_{3}^{\mathbb{P}} \\
\theta_{4}^{\mathbb{P}}
\end{array}\right)-\left(\begin{array}{c}
L_{t}^{N} \\
S_{t} \\
C_{t} \\
L_{t}^{R}
\end{array}\right)\right) d t+\Sigma\left(\begin{array}{c}
d W_{t}^{L^{N}, \mathbb{P}} \\
d W_{t}^{S, \mathbb{P}} \\
d W_{t}^{C, \mathbb{P}} \\
d W_{t}^{L^{R}, \mathbb{P}}
\end{array}\right),
$$


while its $\mathbb{Q}$-dynamics are given by

$$
\left(\begin{array}{c}
d L_{t}^{N} \\
d S_{t} \\
d C_{t} \\
d L_{t}^{R}
\end{array}\right)=\left(\begin{array}{cccc}
0 & 0 & 0 & 0 \\
0 & -\lambda & \lambda & 0 \\
0 & 0 & -\lambda & 0 \\
0 & 0 & 0 & 0
\end{array}\right)\left(\begin{array}{c}
L_{t}^{N} \\
S_{t} \\
C_{t} \\
L_{t}^{R}
\end{array}\right) d t+\Sigma\left(\begin{array}{c}
d W_{t}^{L^{N}, \mathbb{Q}} \\
d W_{t}^{S, \mathbb{Q}} \\
d W_{t}^{C, \mathbb{Q}} \\
d W_{t}^{L^{R}, \mathbb{Q}}
\end{array}\right)
$$

where $\Sigma$ is a diagonal matrix

$$
\Sigma=\left(\begin{array}{cccc}
\sigma_{L^{N}} & 0 & 0 & 0 \\
0 & \sigma_{S} & 0 & 0 \\
0 & 0 & \sigma_{C} & 0 \\
0 & 0 & 0 & \sigma_{L^{R}}
\end{array}\right)
$$

The instantaneous nominal and real risk-free rates are defined as:

$$
\begin{aligned}
& r_{t}^{N}=L_{t}^{N}+S_{t}, \\
& r_{t}^{R}=L_{t}^{R}+\alpha^{R} S_{t} .
\end{aligned}
$$

This model has a total of 26 parameters; thus, 14 parameter restrictions need to be imposed on the canonical $A_{0}(4)$ model with a joint representation of nominal and real yields.

It is easy to verify that the affine invariant transformation $\mathcal{T}_{A}\left(Y_{t}\right)=A Y_{t}+\eta$ with

$$
A=\left(\begin{array}{cccc}
\sigma_{L^{N}} & 0 & 0 & 0 \\
0 & \sigma_{S} & 0 & 0 \\
0 & 0 & \sigma_{C} & 0 \\
0 & 0 & 0 & \sigma_{L^{R}}
\end{array}\right) \text { and } \eta=\left(\begin{array}{c}
0 \\
0 \\
0 \\
0
\end{array}\right)
$$

will convert the canonical representation into the CLR model as described above. For the mean-reversion matrices, the relationship between the two representations is

$$
\begin{aligned}
K_{X}^{\mathbb{P}}=A K_{Y}^{\mathbb{P}} A^{-1} & \Longleftrightarrow K_{Y}^{\mathbb{P}}=A^{-1} K_{X}^{\mathbb{P}} A, \\
K_{X}^{\mathbb{Q}}=A K_{Y}^{\mathbb{Q}} A^{-1} & \Longleftrightarrow K_{Y}^{\mathbb{Q}}=A^{-1} K_{X}^{\mathbb{Q}} A .
\end{aligned}
$$


The equivalent mean-reversion matrix under the $\mathbb{Q}$-measure is then

$$
\begin{aligned}
K_{Y}^{\mathbb{Q}} & =\left(\begin{array}{cccc}
\frac{1}{\sigma_{L^{N}}} & 0 & 0 & 0 \\
0 & \frac{1}{\sigma_{S}} & 0 & 0 \\
0 & 0 & \frac{1}{\sigma_{C}} & 0 \\
0 & 0 & 0 & \frac{1}{\sigma_{L^{N}}}
\end{array}\right)\left(\begin{array}{cccc}
0 & 0 & 0 & 0 \\
0 & \lambda & -\lambda & 0 \\
0 & 0 & \lambda & 0 \\
0 & 0 & 0 & 0
\end{array}\right)\left(\begin{array}{cccc}
\sigma_{L^{N}} & 0 & 0 & 0 \\
0 & \sigma_{S} & 0 & 0 \\
0 & 0 & \sigma_{C} & 0 \\
0 & 0 & 0 & \sigma_{L^{R}}
\end{array}\right) \\
= & \left(\begin{array}{cccc}
0 & 0 & 0 & 0 \\
0 & \lambda & -\lambda \frac{\sigma_{C}}{\sigma_{S}} & 0 \\
0 & 0 & \lambda & 0 \\
0 & 0 & 0 & 0
\end{array}\right) .
\end{aligned}
$$

Thus, eight restrictions need to be imposed on the upper triangular mean-reversion matrix $K_{Y}^{\mathbb{Q}}$ :

$$
K_{11}^{Y, \mathbb{Q}}=K_{12}^{Y, \mathbb{Q}}=K_{13}^{Y, \mathbb{Q}}=K_{14}^{Y, \mathbb{Q}}=K_{24}^{Y, \mathbb{Q}}=K_{34}^{Y, \mathbb{Q}}=K_{44}^{Y, \mathbb{Q}}=0 \quad \text { and } \quad K_{33}^{Y, \mathbb{Q}}=K_{22}^{Y, \mathbb{Q}} .
$$

Furthermore, notice that $K_{23}^{Y, \mathbb{Q}}$ will always have the opposite sign of $K_{22}^{Y, \mathbb{Q}}$ and $K_{33}^{Y, \mathbb{Q}}$, but its absolute size can vary independently of these two parameters. Because $K_{X}^{\mathbb{P}}$ is an unconstrained $4 \times 4$ matrix, there are no restrictions on $K_{Y}^{\mathbb{P}}$.

Finally, we can study the factor loadings in the affine function for the short rate processes.

In the CLR model, the nominal risk-free rate is $r_{t}^{N}=L_{t}^{N}+S_{t}$, which is equivalent to fixing

$$
\delta_{0}^{N, X}=0, \quad \delta_{1}^{N, X}=\left(\begin{array}{c}
1 \\
1 \\
0 \\
0
\end{array}\right)
$$

From the relation $\left(\delta_{1}^{N, X}\right)^{\prime}=\left(\delta_{1}^{N, Y}\right)^{\prime} A^{-1}$ it follows that

$$
\left(\delta_{1}^{N, Y}\right)^{\prime}=\left(\delta_{1}^{N, X}\right)^{\prime} A=\left(\begin{array}{llll}
1 & 1 & 0 & 0
\end{array}\right)\left(\begin{array}{cccc}
\sigma_{L^{N}} & 0 & 0 & 0 \\
0 & \sigma_{S} & 0 & 0 \\
0 & 0 & \sigma_{C} & 0 \\
0 & 0 & 0 & \sigma_{L^{R}}
\end{array}\right)=\left(\begin{array}{llll}
\sigma_{L^{N}} & \sigma_{S} & 0 & 0
\end{array}\right)
$$


For the constant term it holds that

$$
\delta_{0}^{N, X}=\delta_{0}^{N, Y}-\left(\delta_{1}^{N, Y}\right)^{\prime} A^{-1} \eta \Longleftrightarrow \delta_{0}^{N, Y}=\delta_{0}^{N, X}=0 .
$$

Thus, we have obtained three additional parameter restrictions

$$
\delta_{0}^{N, Y}=0 \quad \text { and } \quad \delta_{1,3}^{N, Y}=\delta_{1,4}^{N, Y}=0 .
$$

In the CLR model, the real risk-free rate is $r_{t}^{R}=L_{t}^{R}+\alpha_{R} S_{t}$, which is equivalent to fixing

$$
\delta_{0}^{R, X}=0, \quad \delta_{1}^{R, X}=\left(\begin{array}{c}
0 \\
\alpha_{R} \\
0 \\
1
\end{array}\right)
$$

From the relation $\left(\delta_{1}^{R, X}\right)^{\prime}=\left(\delta_{1}^{R, Y}\right)^{\prime} A^{-1}$ it follows that

$$
\left(\delta_{1}^{R, Y}\right)^{\prime}=\left(\delta_{1}^{R, X}\right)^{\prime} A=\left(\begin{array}{llll}
0 & \alpha_{R} & 0 & 1
\end{array}\right)\left(\begin{array}{cccc}
\sigma_{L^{N}} & 0 & 0 & 0 \\
0 & \sigma_{S} & 0 & 0 \\
0 & 0 & \sigma_{C} & 0 \\
0 & 0 & 0 & \sigma_{L^{R}}
\end{array}\right)=\left(\begin{array}{llll}
0 & \alpha_{R} \sigma_{S} & 0 & \sigma_{L^{R}}
\end{array}\right) .
$$

For the constant term it holds that

$$
\delta_{0}^{R, X}=\delta_{0}^{R, Y}-\left(\delta_{1}^{R, Y}\right)^{\prime} A^{-1} \eta \Longleftrightarrow \delta_{0}^{R, Y}=\delta_{0}^{R, X}=0 .
$$

Thus, we have obtained another three additional parameter restrictions

$$
\delta_{0}^{R, Y}=0 \quad \text { and } \quad \delta_{1,1}^{R, Y}=\delta_{1,3}^{R, Y}=0,
$$

which brings the total to 14 parameter restrictions as required. 


\section{The RRB Liquidity Premium}

In this appendix, we analyze the RRB liquidity premium implied by the estimated CLR-L model. First, we formally define the RRB liquidity premium and study its historical evolution. We then assess its robustness by comparing it to other liquidity premium estimates before we end the section by relating the estimated liquidity premium to observable proxies of liquidity risk.

\section{C.1 The Estimated RRB Liquidity Premium}

To compute the liquidity premium in the RRB market, we first use the estimated parameters and the filtered states $\left\{X_{t \mid t}\right\}_{t=1}^{T}$ to calculate the fitted RRB prices $\left\{\hat{P}_{t}^{R R B, i}\right\}_{t=1}^{T}$ for all outstanding securities in our sample. These bond prices are then converted into yields to maturity $\left\{\hat{y}_{t}^{c, i}\right\}_{t=1}^{T}$ by solving the fixed-point problem

$$
\begin{aligned}
\hat{P}_{t=1}^{R R B, i}= & C\left(t_{1}-t\right) \exp \left\{-\left(t_{1}-t\right) \hat{y}_{t}^{c, i}\right\}+\sum_{k=2}^{n} \frac{C}{2} \exp \left\{-\left(t_{k}-t\right) \hat{y}_{t}^{c, i}\right\} \\
& +\exp \left\{-(T-t) \hat{y}_{t}^{c, i}\right\},
\end{aligned}
$$

for $i=1,2, \ldots, n_{R R B}$, meaning that $\left\{\hat{y}_{t}^{c, i}\right\}_{t=1}^{T}$ is approximately the real rate of return on the $i$ th RRB if held until maturity (see Sack and Elsasser 2004). To obtain the corresponding yields without correcting for liquidity risk, a new set of model-implied bond prices are computed from the estimated CLR-L model but using only its frictionless part, i.e., using the constraints that $X_{t \mid t}^{l i q}=0$ for all $t$ as well as $\sigma_{55}=0$ and $\theta_{\text {liq }}^{Q}=0$. These prices are denoted $\left\{\tilde{P}_{t}^{R R B, i}\right\}_{t=1}^{T}$ and converted into yields to maturity $\tilde{y}_{t}^{c, i}$ using (9). They represent estimates of the prices that would prevail in a world without any financial frictions. The liquidity premium for the $i$ th RRB is then defined as

$$
\Psi_{t}^{i} \equiv \hat{y}_{t}^{c, i}-\tilde{y}_{t}^{c, i}
$$

Figure 1 shows the average RRB liquidity premium $\bar{\Psi}_{t}$ across the outstanding RRB at a given point in time. The average estimated RRB liquidity premium clearly varies notably over time with a maximum of 39 basis points achieved at the peak of the financial crisis and a low of -22 basis points in the spring of 2013. For the entire period it has an average of -2.60 basis points with a standard deviation of 9.66 basis points. 


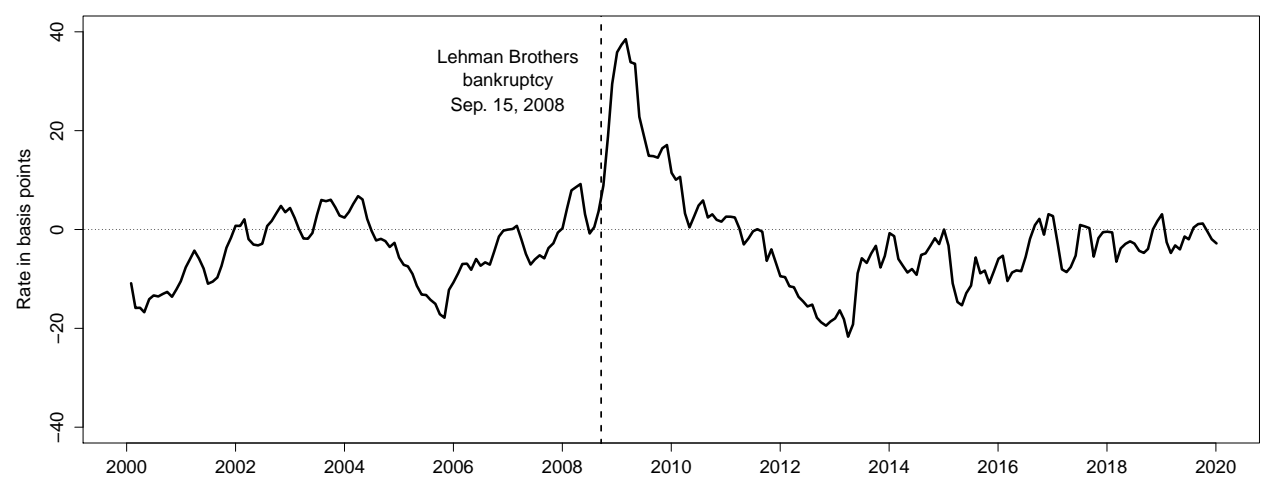

Figure 1: Average Estimated Real Bond Liquidity Premium

Illustration of the average estimated real return bond liquidity premium for each observation date implied by the CLR-L model. The real return bond liquidity premiums are measured as the estimated yield difference between the fitted yield-to-maturity of individual real return bonds and the corresponding frictionless yieldto-maturity with the liquidity risk factor turned off. The average real return liquidity premium is shown with a solid black horizontal line. The data cover the period from January 31, 2000, to December 31, 2019.

\section{C.2 Liquidity Premium Comparisons}

Our benchmark CLR-L model has a standard affine specification for the nominal short rate, which does not enforce the zero lower bound (ZLB). However, a large fraction of our sample (2009-2017) is near the ZLB, and we therefore briefly explore whether our estimated liquidity premium is robust to accounting for the ZLB through a shadow-rate extension of the CLR-L model. We adopt an approach inspired by Black (1995) and replace $r_{t}^{N}$ in equation (4) by $r_{t}^{N}=$ $\max \left(L_{t}^{N}+S_{t}, 0\right)$ and solve for nominal yields using the approximation in Christensen and Rudebusch (2015), but this B-CLR-L model is otherwise identical to the CLR-L model. We also consider the CLR model extension offered by Christensen et al. (2016), who incorporate stochastic volatility into the nominal and real level factors. We augment their model with a liquidity factor as before and refer to it as the CLR-L-SV model. Figure 2(a) shows that the estimated liquidity premiums from these two model alternatives are qualitatively similar to our benchmark estimate from the CLR-L model. Thus, neither the presence of the ZLB nor allowing for stochastic volatility seem to materially affect the estimated RRB liquidity premiums similar to what Andreasen et al. (2020, henceforth ACR) report in the context of U.S. Treasuries and TIPS.

Given the geographical proximity of Canada to the U.S., we next compare our average 


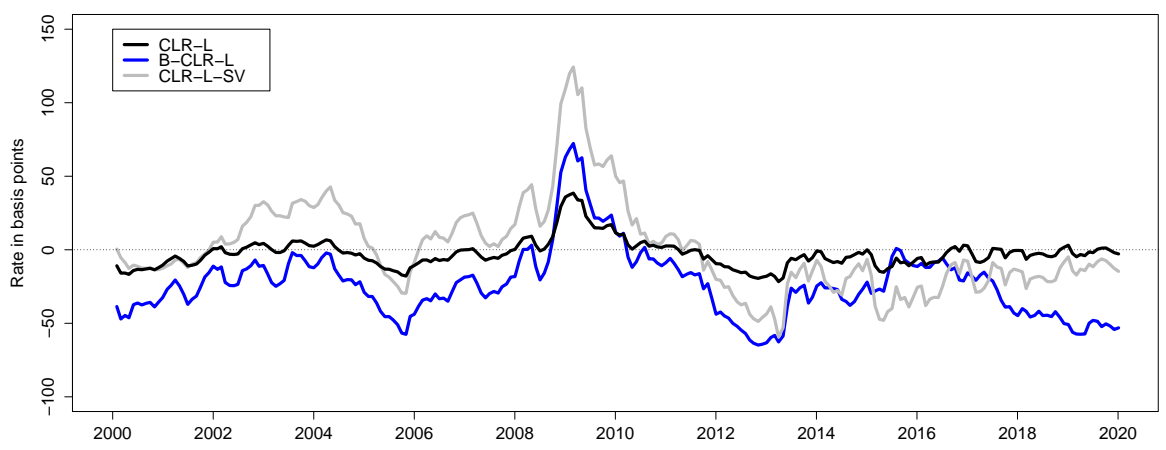

(a) Comparison with alternative models

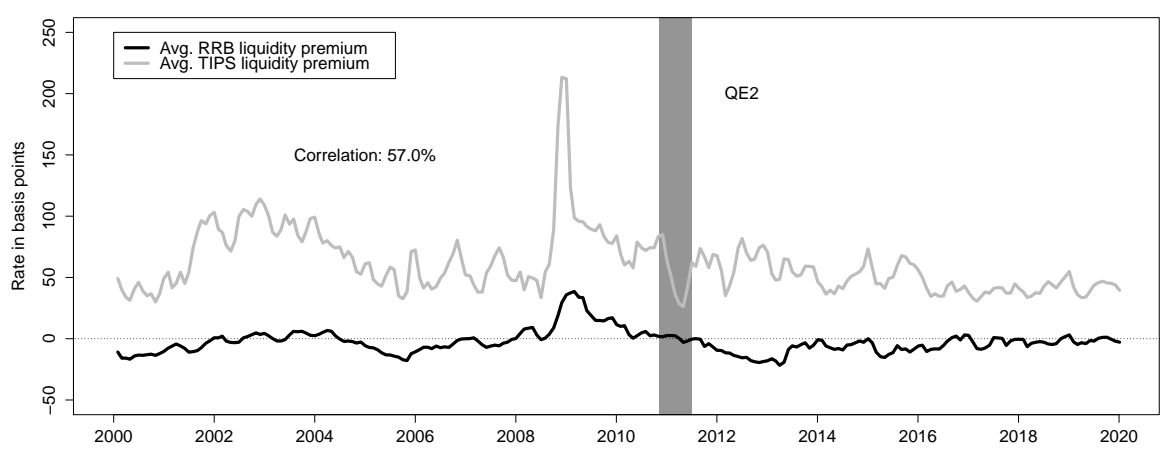

(b) Comparison with U.S. TIPS liquidity premium

\section{Figure 2: Comparisons of the RRB Liquidity Premium}

In panel (a) the average estimated real return bond liquidity premium implied by the CLR-L model is compared with the corresponding series implied by the shadow-rate B-CLR-L model. In panel (b) the average estimated real return bond liquidity premium implied by the CLR-L model is compared with the U.S. TIPS liquidity premium series implied by the CLR-L model applied to U.S. TIPS prices as described in ACR. The data cover the period from January 31, 2000, to December 31, 2019.

estimated RRB liquidity premium series with the average estimated U.S. TIPS liquidity premium from an update of the analysis in ACR. We make three changes relative to the estimation performed by ACR. First, we include all available TIPS and not just five- and tenyear TIPS as in ACR to make the sample more comparable to our RRB sample in terms of maturity composition. Second, we use monthly instead of weekly data to match our Canadian data. Third, we consider a sample with data through December 2019. The resulting average TIPS liquidity premium is shown with a solid grey line in Figure 2(b). We note that the two series share a number of broad trends. First, they both reach a peak in late 2002 followed by a steady decline with a trough in 2005. Both series spike sharply at the peak of the financial 
crisis in the fall of 2008 followed by a gradual reversal in the immediate years after the crisis. Finally, they are both close to their respective historical averages at the end of the sample. This broadly similar underlying trend implies a high positive correlation (57\%).

At the same time, it is also clear that each series has experienced a number of idiosyncratic shocks not shared by the other. For example, the U.S. TIPS liquidity premium series shows a clear dip during the Fed's second large-scale asset purchase program, commonly known as QE2, which included $\$ 26$ billion in TIPS purchases. This is consistent with analysis in Christensen and Gillan (2019). They argue that a central bank launching a large-scale asset purchase program acts as a large committed buyer with unusual preferences in that it trades strategically to raise asset prices. This temporarily increases the bargaining power of sellers and lowers the liquidity premiums in the targeted securities while the program is in operation, which explains the drop in the U.S. TIPS liquidity premiums during this period. As Canadian RRBs were naturally excluded from the set of securities targeted by the Fed, the logic of this QE liquidity transmission channel implies that the liquidity of RRBs should be practically unaffected by these purchases, and our results are consistent with this view as the estimated RRB liquidity premium does not respond to this shock to the U.S. TIPS market.

\section{C.3 Observable Proxies for Liquidity Risk}

We next show that the RRB liquidity premium is strongly related to observable proxies for liquidity risk as well as factors that are fundamental determinants of the cash flow of RRBs.

The first variable we consider is the VIX options-implied volatility index, which represents near-term uncertainty in the Standard \& Poor's 500 stock market index. Panel (a) of Figure 3 shows the expected positive correlation (55\%) between the VIX and the RRB liquidity premium, as high uncertainty tends to increase the risk attached to the future resale price of any security and therefore also the required liquidity premium. ${ }^{8}$ The second variable is the yield difference between the seasoned (off-the-run) ten-year U.S. Treasury as provided by Gürkaynak et al. (2007) and the most recently issued (on-the-run) U.S. Treasury of the same maturity from the H.15 series at the Federal Reserve Board of Governors. The onthe-run security is typically the most traded security and therefore penalized the least in terms of liquidity premiums, which explains the mostly positive spread. For our analysis, the important thing to note is that if there is a wide yield spread between liquid on-the-run and

\footnotetext{
${ }^{8}$ See also Duffie et al. (2007) for a model on the positive relationship between uncertainty and liquidity.
} 


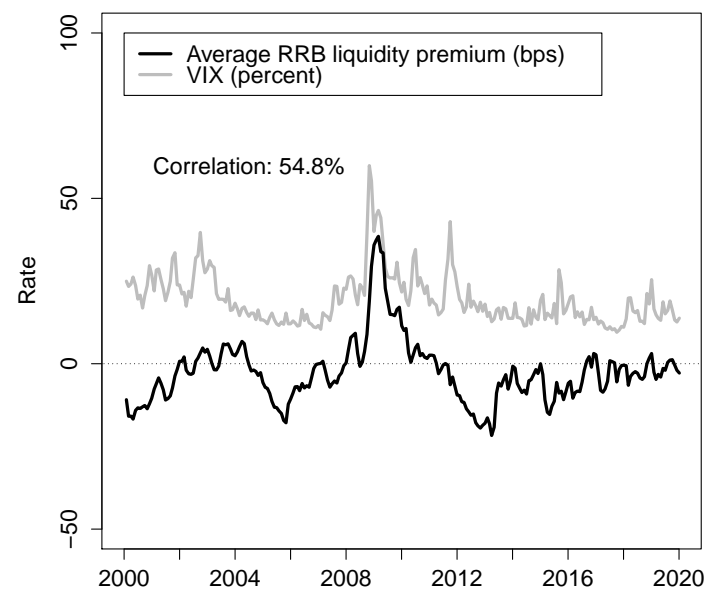

(a) The VIX options-implied volatility index

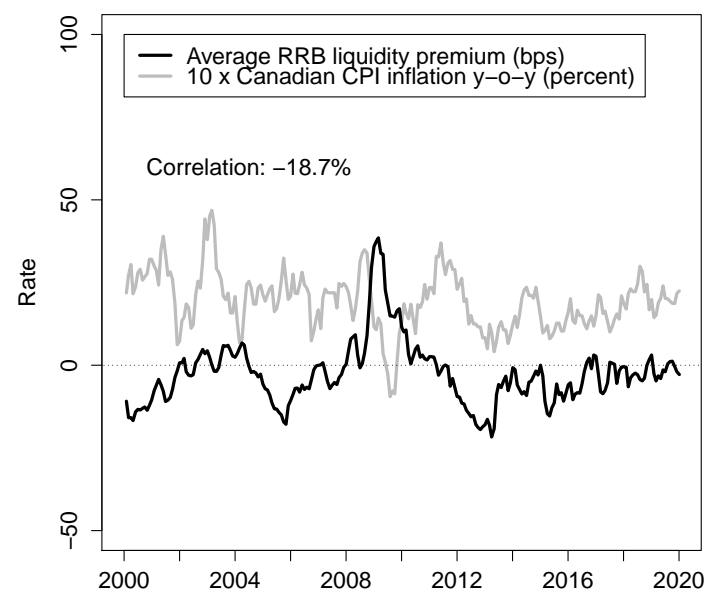

(c) Canadian CPI inflation

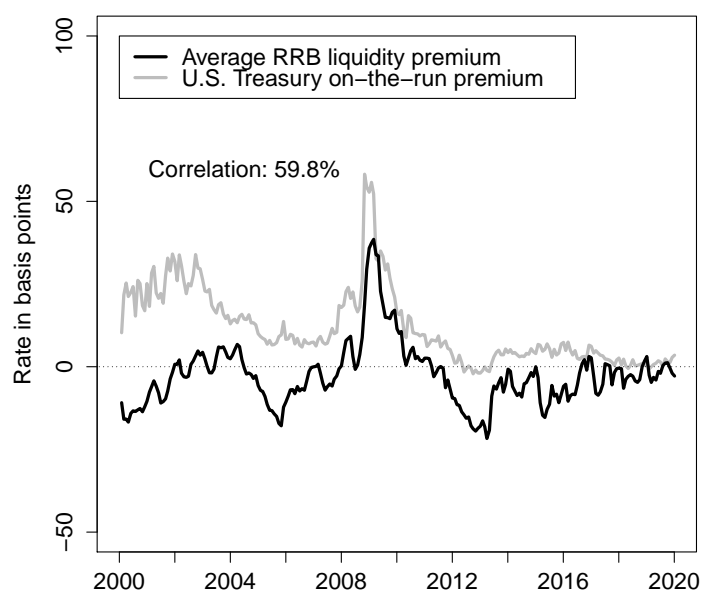

(b) The U.S. Treasury on-the-run par-yield spread

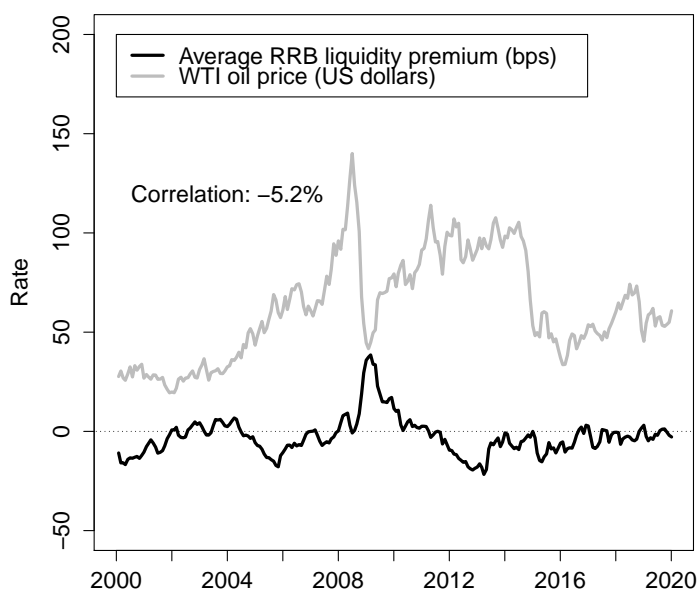

(d) WTI oil price

Figure 3: Variables Explaining the Average RRB Liquidity Premium

In panel (a) the VIX for the S\&P 500 is expressed in percentage, in panel (b) the yield spread is the difference between the ten-year off-the-run Treasury par yield from Gürkaynak et al. (2007) and the ten-year on-the-run Treasury par yield from the H.15 series at the Board of Governors, in panel (c) the year-over-year change in the Canadian consumer price index measured in percent, and in panel (d) the WTI spot oil price measured in U.S. dollars.

comparable seasoned U.S. Treasuries, we would expect liquidity premiums in the Canadian bond market to also be elevated. As seen in Figure 3(b), this view is supported by the data as the on-the-run liquidity premium in U.S. Treasuries is highly positively correlated (60\%) with the average RRB liquidity premium from our model. Our final two variables represent factors 


\begin{tabular}{lccccc}
\hline \hline & $(1)$ & $(2)$ & $(3)$ & $(4)$ & $(5)$ \\
\hline Intercept & $-15.692^{* *}$ & $-8.568^{* *}$ & 1.416 & -1.403 & $-11.034^{* *}$ \\
& $(3.038)$ & $(1.251)$ & $(3.736)$ & $(2.674)$ & $(2.694)$ \\
VIX & $0.672^{* *}$ & & & & $0.259^{*}$ \\
& $(0.173)$ & & & & $(0.131)$ \\
On the run premium & & $0.509^{* *}$ & & & $0.442^{* *}$ \\
& & $(0.122)$ & & & $(0.107)$ \\
Canadian CPI inflation & & & -2.079 & & $-2.779^{* *}$ \\
& & & $(1.558)$ & & $(0.925)$ \\
WTI oil price & & & -0.019 & $0.057^{*}$ \\
& & & & $(0.037)$ & $(0.027)$ \\
Adjusted $R^{2}$ & 0.298 & 0.355 & 0.031 & -0.001 & 0.457 \\
\hline \hline
\end{tabular}

Table 1: Regression Results

The table reports the results of regressions with the average estimated RRB liquidity premium as the dependent variable and four explanatory variables that represent measures of financial market uncertainty, financial market functioning, Canadian consumer price inflation, and energy prices, respectively. Standard errors computed by the Newey-West estimator (with 3 lags) are reported in parentheses. Asterisks ${ }^{*}$ and ${ }^{* *}$ indicate significance at the 5 percent and 1 percent levels, respectively.

that are fundamental to the cash flow of RRBs, namely Canadian CPI inflation and energy prices as reflected in the WTI spot oil price. Still, we only see a modest negative correlation between the estimated RRB liquidity premium and these two important variables. This means that when energy prices go up and inflation is boosted as a result, the RRB liquidity premiums tend to fall, likely because RRBs are desirable assets under those circumstances.

We now run standard linear regressions to more formally assess the relative importance of each of these four variables. First, we run regressions with each explanatory variable in isolation. The results reported in columns (1)-(4) of Table 1 confirm the characterizations above about the ties between our RRB liquidity premium series and the four explanatory variables. In particular, the on-the-run premium has the largest explanatory power, while the RRB liquidity premium indeed only has a weak link with Canadian CPI inflation and the WTI oil price.

The final column of Table 1 reports the results of regressing the average RRB liquidity premium from our model on all four explanatory variables jointly. We find a significant effect from the on-the-run premium that has the expected positive sign. On the other hand, the VIX and WTI oil price coefficients are insignificant at the $5 \%$ level and hardly affect the adjusted $R^{2}$ of 0.46 . While Canadian CPI inflation is significant when included in the multivariate regression, we note that it has a lower significance than the on the run premium and the 


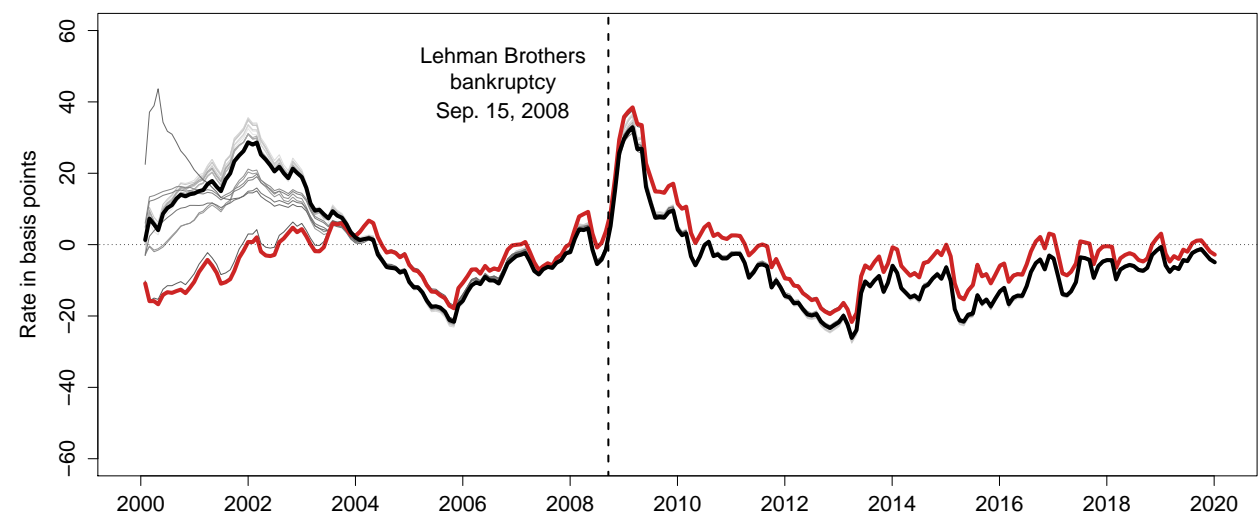

Figure 4: Sensitivity of Real Bond Liquidity Premium to Model Specification

Illustration of the average estimated real return bond liquidity premium for each observation date implied by the CLR-L model estimated with the 21 different specifications of $K^{\mathbb{P}}$ considered in Table 5 in the paper. Note that $\Sigma$ has a diagonal specification in all estimations. The real return bond liquidity premiums are measured as the estimated yield difference between the fitted yield to maturity of individual real return bonds and the corresponding frictionless yield to maturity with the liquidity risk factor turned off. The data cover the period from January 31, 2000, to December 31, 2019.

univariate regression has limited explanatory power of the liquidity premium as measured by the adjusted $R^{2}$. These regressions show that our model-implied measure of liquidity risk has a robust correlation with the on the run premium, which is commonly used proxy for liquidity risk. We interpret this result as confirming that the strategy for identification of liquidity risk proposed by ACR works well in the context of Canadian RRBs.

\section{C.4 Sensitivity of the RRB Liquidity Premium to Model Specifications}

In this appendix, we study the sensitivity of the estimated RRB liquidity premiums to the choice of dynamic specification within the CLR-L model. To do so, we compare the different RRB liquidity premium series we get from the model specifications considered as part of the model selection procedure described in the paper.

We are interested in the variation in the average estimated RRB liquidity premium calculated as described earlier for each of the specifications considered in Table 5 in the paper. These 21 different liquidity premium series are shown in Figure 4 with the one generated by the most parsimonious CLR-L model with diagonal $K^{\mathbb{P}}$ and $\Sigma$ matrices analyzed in this appendix and highlighted with a thick solid red line and the one generated by the preferred 


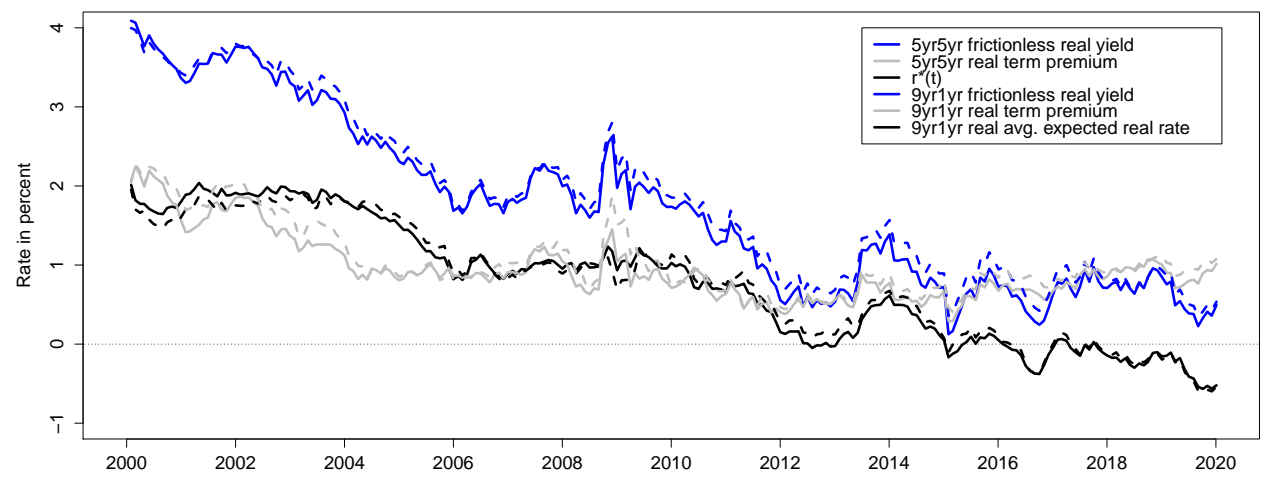

Figure 5: CLR-L Model 9yr1yr Real Yield Decomposition

CLR-L model studied in Section 4 of the paper highlighted with a thick solid black line.

We note a fairly large dispersion across specifications early in our sample period when we observe prices for only a small set of RRB. However, since 2004 the estimated RRB liquidity premiums are practically indistinguishable across specifications. Overall, our results confirm the findings of ACR, namely that liquidity premiums estimated with their approach are extracted primarily from the cross sectional information on each observation date with relatively little sensitivity to the specification of the time series dynamics. As a consequence, we limit the earlier regression analysis to the average RRB liquidity premium estimated by the most parsimonious specification of the CLR-L model with diagonal $K^{\mathbb{P}}$ and $\Sigma$ matrices as it is - with few exceptions - clearly representative of the liquidity premiums one would estimate with other more flexible specifications.

\section{Alternative Definitions of $r^{*}(t)$}

In this appendix, we consider an alternative definition of $r_{t}^{*}$ as the average expected real short rate over a one-year period starting nine years ahead, i.e.,

$$
\bar{r}_{t}^{*}=\int_{t+9}^{t+10} E_{t}^{\mathbb{P}}\left[r_{t+s}^{R}\right] d s
$$

Figure 5 shows the preferred CLR-L model decomposition of the 9yr1yr forward frictionless real yield based on the equation above and compares it to our existing results. As can be seen from the figure, this alternative definition of $r_{t}^{*}$ generates results, which that are very close 


\begin{tabular}{|l|c|c|c|c|}
\hline \multirow{2}{*}{$\begin{array}{l}\text { Alternative } \\
\text { Specifications }\end{array}$} & \multicolumn{4}{|c|}{ Goodness of fit statistics } \\
\cline { 2 - 5 } & $\log L$ & $k$ & $p$-value & BIC \\
\hline$(1)$ Unrestricted $K^{\mathbb{P}}$ & $25,765.64$ & 28 & .a. & $-51,367.42$ \\
$(2) \kappa_{43}^{\mathbb{P}}=0$ & $25,765.63$ & 27 & 0.89 & $-51,373.25$ \\
$(3) \kappa_{43}^{\mathbb{P}}=\kappa_{41}^{\mathbb{P}}=0$ & $25,765.63$ & 26 & 1.00 & $-51,379.10$ \\
$(4) \kappa_{43}^{\mathbb{P}}=\kappa_{41}^{\mathbb{P}}=\kappa_{31}^{\mathbb{P}}=0$ & $25,765.29$ & 25 & 0.41 & $-51,384.27$ \\
$(5) \kappa_{43}^{\mathbb{P}}=\ldots=\kappa_{12}^{\mathbb{P}}=0$ & $25,764.84$ & 24 & 0.34 & $-51,389.23$ \\
$(6) \kappa_{43}^{\mathbb{P}}=\ldots=\kappa_{32}^{\mathbb{P}}=0$ & $25,764.39$ & 23 & 0.34 & $-51,394.18$ \\
$(7) \kappa_{43}^{\mathbb{P}}=\ldots=\kappa_{21}^{\mathbb{P}}=0$ & $25,761.69$ & 22 & 0.02 & $-51,394.63$ \\
$(8) \kappa_{43}^{\mathbb{P}}=\ldots=\kappa_{13}^{\mathbb{P}}=0$ & $25,761.21$ & 21 & 0.33 & $-51,399.52$ \\
$(9) \kappa_{43}^{\mathbb{P}}=\ldots=\kappa_{24}^{\mathbb{P}}=0$ & $25,760.17$ & 20 & 0.15 & $-51,403.30$ \\
$(10) \kappa_{43}^{\mathbb{P}}=\ldots=\kappa_{23}^{\mathbb{P}}=0$ & $25,760.15$ & 19 & 0.84 & $-51,409.11$ \\
$(11) \kappa_{43}^{\mathbb{P}}=\ldots=\kappa_{34}^{\mathbb{P}}=0$ & $25,754.99$ & 18 & $<0.01$ & $-51,404.64$ \\
$(12) \kappa_{43}^{\mathbb{P}}=\ldots=\kappa_{14}^{\mathbb{P}}=0$ & $25,750.15$ & 17 & $<0.01$ & $-51,400.81$ \\
$(13) \kappa_{43}^{\mathbb{P}}=\ldots=\kappa_{42}^{\mathbb{P}}=0$ & $25,747.17$ & 16 & $<0.01$ & $-51,400.70$ \\
\hline
\end{tabular}

Table 2: Evaluation of Alternative Specifications of the CLR Model

There are thirteen alternative estimated specifications of the CLR model. Each specification is listed with its maximum $\log$ likelihood $(\log L)$, number of parameters $(k)$, the $p$-value from a likelihood ratio test of the hypothesis that it differs from the specification above with one more free parameter, and the Bayesian information criterion (BIC). The period analyzed covers monthly data from January 31, 1991, to December $31,2019$.

to those obtained based on our adopted definition. Thus, the reported results are robust to using alternative definitions of $r_{t}^{*}$ of this kind.

\section{E Model Selection in the CLR Model}

In this appendix, we go through a careful model selection procedure for the CLR model similar to the one described in the main text for the CLR-L model.

For estimates of $r_{t}^{*}$ based on our definition, the specification of the mean-reversion matrix $K^{\mathbb{P}}$ is critical. To select the best fitting specification of the CLR model's real-world dynamics, we use a general-to-specific modeling strategy in which the least significant off-diagonal parameter of $K^{\mathbb{P}}$ is restricted to zero and the model is re-estimated. This strategy of eliminating the least significant coefficient is carried out down to the most parsimonious specification, which has a diagonal $K^{\mathbb{P}}$ matrix. As in the main text, the final specification choice is based on the value of the Bayesian information criterion (BIC).

The summary statistics of the model selection process are reported in Table 2. The BIC 


\begin{tabular}{|c|cccc||c||c|c|}
\hline$K^{\mathbb{P}}$ & $K_{\cdot, 1}^{\mathbb{P}}$ & $K_{\cdot, 2}^{\mathbb{P}}$ & $K_{\cdot, 3}^{\mathbb{P}}$ & $K_{\cdot, 4}^{\mathbb{P}}$ & $\theta^{\mathbb{P}}$ & & $\Sigma$ \\
\hline$K_{1, \cdot}^{\mathbb{P}}$ & 0.0652 & 0 & 0 & 0.0820 & -0.0092 & $\Sigma_{1,1}$ & 0.0059 \\
& $(0.0812)$ & & & $(0.0836)$ & $(0.1182)$ & & $(0.0001)$ \\
$K_{2, \cdot}^{\mathbb{P}}$ & 0 & 0.2777 & 0 & 0 & -0.0233 & $\Sigma_{2,2}$ & 0.0115 \\
& & $(0.1632)$ & & & $(0.0068)$ & & $(0.0003)$ \\
$K_{3, \cdot}^{\mathbb{P}}$ & 0 & 0 & 0.9711 & -0.6461 & 0.0012 & $\Sigma_{3,3}$ & 0.0214 \\
& & & $(0.2386)$ & $(0.3013)$ & $(0.0059)$ & & $(0.0008)$ \\
$K_{4, \cdot}^{\mathbb{P}}$ & 0 & -0.1530 & 0 & 0.0045 & 0.0527 & $\Sigma_{4,4}$ & 0.0040 \\
& & $(0.0700)$ & & $(0.0105)$ & $(0.0091)$ & & $(0.0000)$ \\
\hline
\end{tabular}

Table 3: Estimated Parameters in the Preferred CLR Model

The estimated parameters for the mean-reversion matrix $K^{\mathbb{P}}$, the mean vector $\theta^{\mathbb{P}}$, and the volatility matrix $\Sigma$ in the CLR model preferred according to the BIC. The $Q$-related parameter is estimated at $\lambda=0.2902(0.0029)$ and $\alpha^{R}=0.6227$ (0.0069). The maximum log likelihood value is $25,760.15$. The numbers in parentheses are the estimated standard deviations.

is minimized by specification (10), which has a $K^{\mathbb{P}}$ matrix given by

$$
K_{B I C}^{\mathbb{P}}=\left(\begin{array}{cccc}
\kappa_{11}^{\mathbb{P}} & 0 & 0 & \kappa_{14}^{\mathbb{P}} \\
0 & \kappa_{22}^{\mathbb{P}} & 0 & 0 \\
0 & 0 & \kappa_{33}^{\mathbb{P}} & \kappa_{34}^{\mathbb{P}} \\
0 & \kappa_{42}^{\mathbb{P}} & 0 & \kappa_{44}^{\mathbb{P}}
\end{array}\right)
$$

The estimated parameters of this preferred specification are reported in Table 3 . We note that the nominal and real level factors are very persistent processes with near-unit root dynamics. On the other hand, the common curvature factor is a volatile process that reverts to mean fairly quickly, while the common slope factor has dynamic properties in between the two extremes.

In Figure 6, we compare the estimate of the natural real rate from the preferred CLR model to those derived from the estimated CLR model with unrestricted and diagonal $K^{\mathbb{P}}$ matrix, respectively. We note the great variability of the $r_{t}^{*}$ estimates across different specifications of the CLR model. This shows that, when RRB liquidity risk is not accounted for, some of this variation will make its way into the model's fundamental factors and affect estimates of important model output such as the outlook for real rates. This underscores that accounting for liquidity risk can be of first-order importance even when the average size of the estimated liquidity premiums is small as in our case.

A well-known criticism of macro-based estimates of both expected inflation and the natural real rate is that they can exhibit significant variation as additional and revised data become 


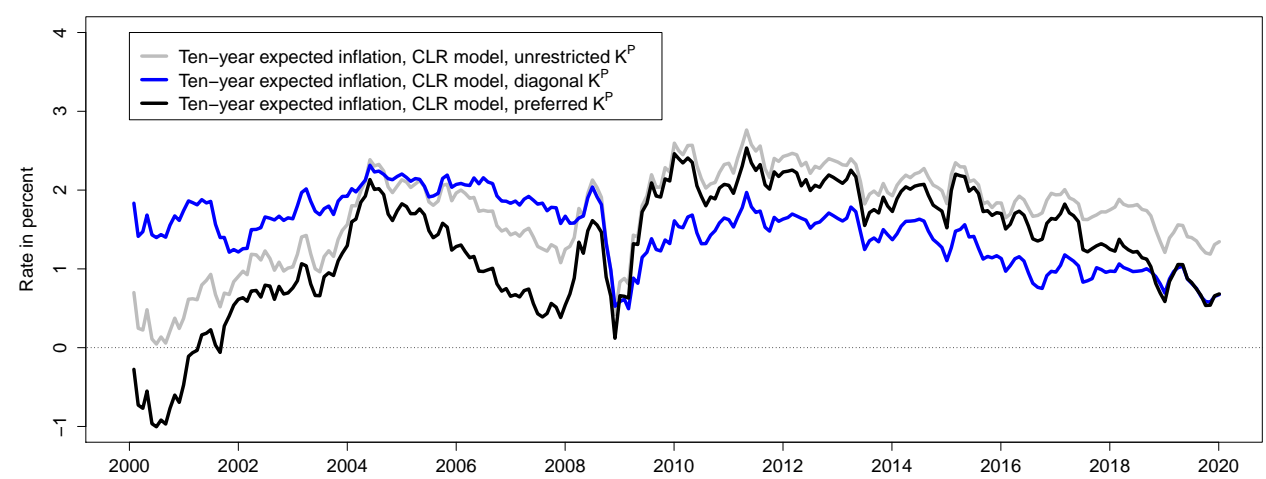

(a) Ten-year expected inflation

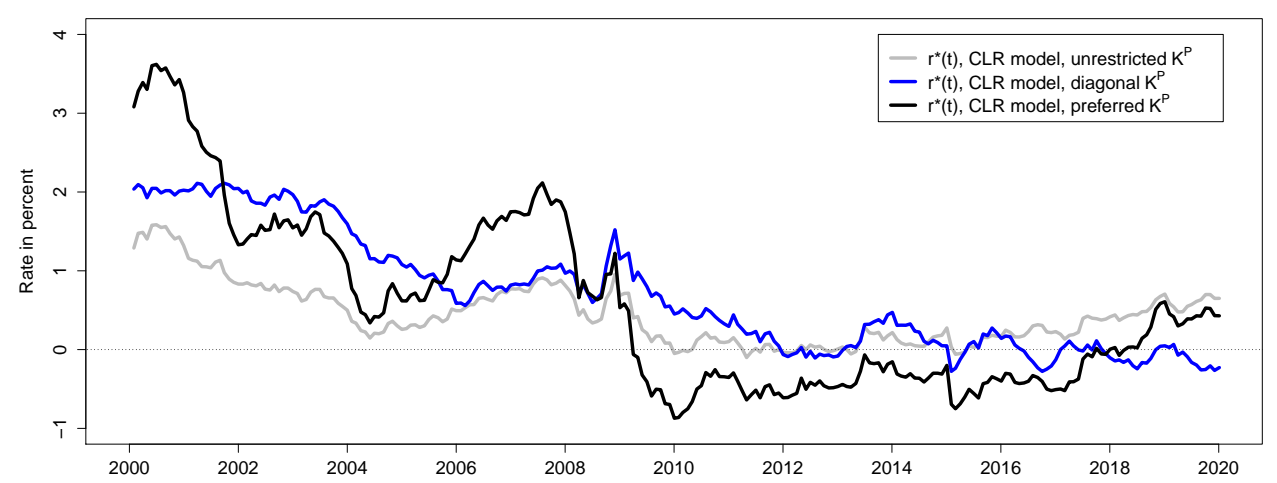

(b) $r_{t}^{*}$

Figure 6: The Sensitivity of Estimates of Ten-Year Expected Inflation and $\mathbf{r}^{*}$ to CLR Model Specification

available, although Laubach and Williams (2016) demonstrate that the Laubach and Williams (2003) estimate of the natural real rate has been robust in real time at least since 2005.

All else equal, finance-based estimates should be less subject to this line of criticism as the key model input, namely the observed bond prices, are available in real time and not subject to any revisions. However, finance-based estimates could still vary as the sample length increases, for example the estimated persistence of the state variables may change, and this could be particularly relevant in the current environment where the general level of interest rates has been declining for the past two decades. To dispel such concerns, we estimate the preferred CLR model in real time starting in 2011 through December 2019. This allows us to generate real-time estimates of the ten-year expected inflation and $r_{t}^{*}$ and compare them to the corresponding full sample "look back" estimates, which is done in Figure 7. Although we 


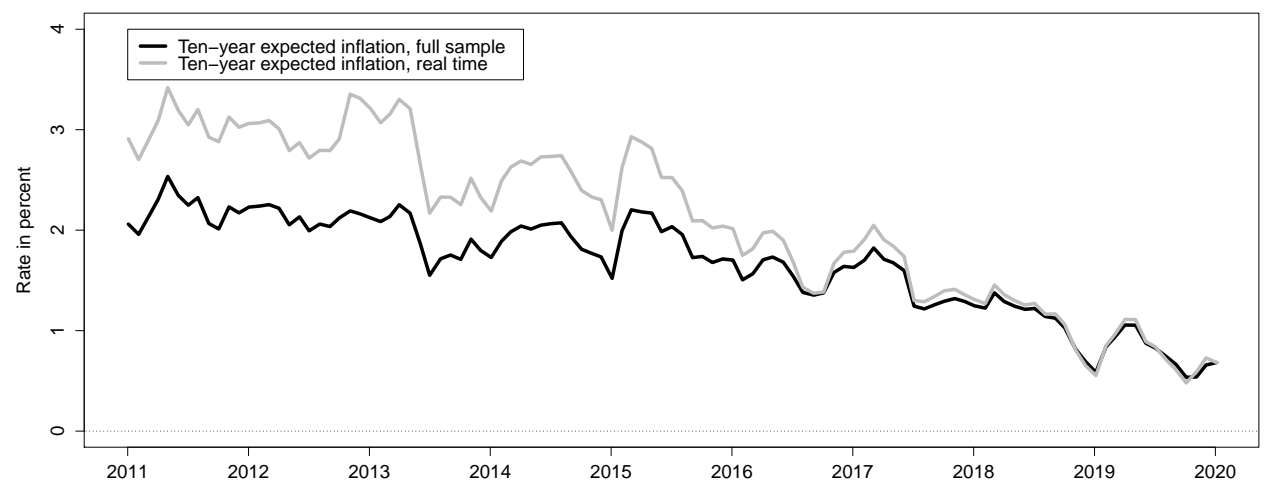

(a) Ten-year expected inflation

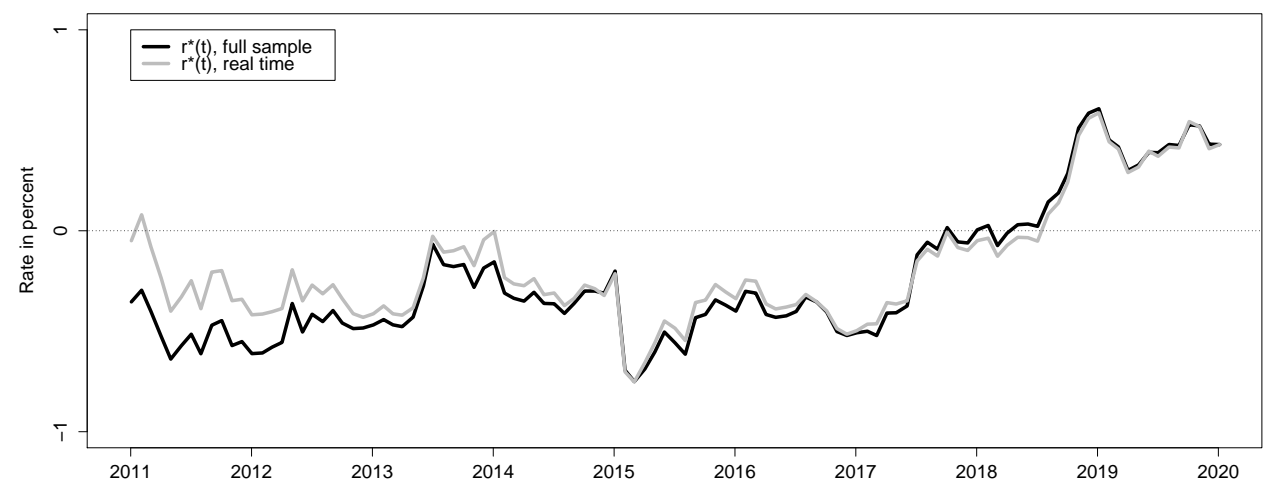

(b) $r_{t}^{*}$

Figure 7: Accuracy of Real-Time Estimates of Ten-Year Expected Inflation and $\mathbf{r}^{*}$

do see some discrepancies between the estimates as we go back through time, these results show that both the ten-year expected inflation and the $r_{t}^{*}$ estimates from our preferred CLR model are reliable in real time similar to what we find for the preferred CLR-L model.

\section{F Nominal Yield Forecast Exercise}

In this appendix, we evaluate the ability of our preferred CLR-L model to forecast nominal yields in the Canadian government bond market. To do so, we replicate the forecast exercise implemented by Andreasen et al. (2019) and described in the following. 


\section{F.1 Models}

To make their forecasting exercise comprehensive, Andreasen et al. (2019) include three nominal yield models: a standard three-factor arbitrage-free Nelson-Siegel (AFNS) model, a shadow-rate specification to accommodate the zero lower bound (ZLB), and a five-factor generalized AFNS model to better fit the entire yield curve, including long-term bonds.

\section{F.1.1 The Three-Factor Model}

In the three-factor AFNS model, the state vector is denoted by $X_{t}=\left(L_{t}, S_{t}, C_{t}\right)$, where $L_{t}$, $S_{t}$, and $C_{t}$ are the level, slope, and curvature factors. The instantaneous risk-free rate is defined as $r_{t}=L_{t}+S_{t}$, and the risk-neutral (or $\mathbb{Q}$-) dynamics of the state variables are given by

$$
\left(\begin{array}{l}
d L_{t} \\
d S_{t} \\
d C_{t}
\end{array}\right)=\left(\begin{array}{ccc}
0 & 0 & 0 \\
0 & -\lambda & \lambda \\
0 & 0 & -\lambda
\end{array}\right)\left(\begin{array}{c}
L_{t} \\
S_{t} \\
C_{t}
\end{array}\right) d t+\Sigma\left(\begin{array}{c}
d W_{t}^{L, \mathbb{Q}} \\
d W_{t}^{S, \mathbb{Q}} \\
d W_{t}^{C, \mathbb{Q}}
\end{array}\right) .
$$

Here, $d W^{i, \mathbb{Q}}$ for $i=\{L, S, C\}$ denotes independent Wiener processes and $\Sigma$ is a constant covariance matrix with dimensions $3 \times 3 .{ }^{9}$ The zero-coupon bond yield at maturity $\tau$ is

$$
y_{t}(\tau)=L_{t}+\left(\frac{1-e^{-\lambda \tau}}{\lambda \tau}\right) S_{t}+\left(\frac{1-e^{-\lambda \tau}}{\lambda \tau}-e^{-\lambda \tau}\right) C_{t}-\frac{A(\tau)}{\tau}
$$

where $A(\tau)$ is a convexity term that adjusts the functional form in Nelson and Siegel (1987) to ensure absence of arbitrage (see Christensen et al. (2011)).

The model is closed by adopting the essentially affine specification for the market price of risk $\Gamma_{t}$ from Duffee (2002). That is, we let $\Gamma_{t}=\gamma^{0}+\gamma^{1} X_{t}$, where $\gamma^{0} \in \mathbf{R}^{3}$ and $\gamma^{1} \in \mathbf{R}^{3 \times 3}$ contain unrestricted parameters. The physical (or $\mathbb{P}_{-}$) dynamics of the three factors in the AFNS model are therefore

$$
d X_{t}=K^{\mathbb{P}}\left(\theta^{\mathbb{P}}-X_{t}\right) d t+\Sigma d W_{t}^{\mathbb{P}}
$$

where $K^{\mathbb{P}}$ and $\theta^{\mathbb{P}}$ contain free parameters, subject to $X_{t}$ being stationary under the $\mathbb{P}$-measure.

\footnotetext{
${ }^{9}$ As discussed in Christensen et al. (2011), the unit root in the level factor implies that the model is only free of arbitrage for bonds with a finite horizon. For our sample of Canadian nominal bond yields, and most other sovereign bond markets, this restriction is not binding and therefore of no practical relevance.
} 


\section{F.1.2 The Shadow-Rate Model}

Given the very low policy rates in many economies during the recent financial crisis and its aftermath, it has become popular to account for the ZLB in dynamic term structure models. Although relative to other developed economies, Canadian short rates were close to zero for only a limited period in our sample, it is still possible that the ZLB may affect the shape and dynamics of the yield curve. To enforce the ZLB in the AFNS model, we introduce the shadow rate $s_{t}=L_{t}+S_{t}$ and let $r_{t}=\max \left\{0, s_{t}\right\}$, as in Christensen and Rudebusch (2015). All other aspects of this B-AFNS model remain as described above for the AFNS model. ${ }^{10}$ The expression for zero-coupon yields in the B-AFNS model is not available in closed form but approximated numerically using the accurate method of Krippner (2013). ${ }^{11}$

\section{F.1.3 The Five-Factor Model}

To explore whether the performance of the AFNS model on our Canadian sample may be improved further, we consider the arbitrage-free generalized Nelson-Siegel (AFGNS) model of Christensen et al. (2009), which includes an additional pair of slope and curvature factors that help to fit long-term bonds. In this AFGNS model, the short rate is $r_{t}=L_{t}+S_{t}+\tilde{S}_{t}$, where $\tilde{S}_{t}$ is an additional (long-term) slope factor. The state dynamics under the risk-neutral $\mathbb{Q}$-measure is

$$
\left(\begin{array}{c}
d L_{t} \\
d S_{t} \\
d \tilde{S}_{t} \\
d C_{t} \\
d \tilde{C}_{t}
\end{array}\right)=\left(\begin{array}{ccccc}
0 & 0 & 0 & 0 & 0 \\
0 & -\lambda & 0 & \lambda & 0 \\
0 & 0 & -\tilde{\lambda} & 0 & \tilde{\lambda} \\
0 & 0 & 0 & -\lambda & 0 \\
0 & 0 & 0 & 0 & -\tilde{\lambda}
\end{array}\right)\left(\begin{array}{c}
L_{t} \\
S_{t} \\
\tilde{S}_{t} \\
C_{t} \\
\tilde{C}_{t}
\end{array}\right) d t+\Sigma d \tilde{W}_{t}^{\mathbb{Q}}
$$

\footnotetext{
${ }^{10}$ Following Kim and Singleton (2012), the prefix "B-" refers to a shadow-rate model in the spirit of Black (1995).

${ }^{11}$ See also Christensen and Rudebusch $(2015,2016)$ for further details on this approximation and its accuracy.
} 
where $\lambda>\tilde{\lambda}>0$ and $\tilde{C}_{t}$ is an additional (long-term) curvature factor. Zero-coupon yields are then given by

$$
\begin{aligned}
y_{t}(\tau)= & L_{t}+\frac{1-e^{-\lambda \tau}}{\lambda \tau} S_{t}+\left[\frac{1-e^{-\lambda \tau}}{\lambda \tau}-e^{-\lambda \tau}\right] C_{t} \\
& +\frac{1-e^{-\tilde{\lambda} \tau}}{\tilde{\lambda} \tau} \tilde{S}_{t}+\left[\frac{1-e^{-\tilde{\lambda} \tau}}{\tilde{\lambda} \tau}-e^{-\tilde{\lambda} \tau}\right] \tilde{C}_{t}-\frac{\tilde{A}(\tau)}{\tau},
\end{aligned}
$$

where the yield-adjustment term $\tilde{A}(\tau)$ is derived in Christensen et al. (2009). The $\mathbb{P}$-dynamics for this five-factor model is obtained in a standard fashion by adopting an essential affine specification for the market price of risk, as in the AFNS model.

Finally, as in Andreasen et al. (2019), all three models described above are implemented using the most parsimonious specification where both the mean-reversion matrix $K^{\mathbb{P}}$ and the volatility matrix $\Sigma$ are diagonal. This contrasts with our preferred CLR-L model, which also has a diagonal volatility matrix, but a more flexible specification of its $5 \times 5 K^{\mathbb{P}}$ matrix. We view this added flexibility as slightly unfavorable to the CLR-L model given that parsimony typically trumps flexibility in real-time forecast exercises like ours, see Christensen et al. (2011) for an example.

\section{F.2 The Consensus Forecasts}

As in Andreasen et al. (2019), we use the Consensus Forecasts survey as the benchmark in our forecast exercise for at least three reasons. First and most importantly, it offers a long history of forecasts of Canadian bond yields. Second, the fixed structure of its survey questions is particularly suitable for a real-time forecast exercise like ours as we explain below. Finally, we note that it tracks a panel of very qualified economic forecasters despite the potential shortcomings listed in Sections 4.3 and 5.2 in the paper. To give an example, the May 2016 survey, which is the last survey used in our exercise, included interest rate projections from a total of 15 participating institutions. Thus, we consider these forecasts to be reliable and of high quality. As a consequence, they serve as a good yardstick for validating the performance of the various models we consider.

The survey is performed once a month, and participants are asked to submit forecasts for two Canadian interest rates, the three-month Treasury bill rate and ten-year government bond yield, at two forecast horizons, namely at the end of the third month after the survey month 
and at the end of the survey month the following year. Since the survey dates are typically the second Monday of the survey month, this structure implies that the effective forecast horizons are roughly three and a half months and twelve and a half months. However, for convenience we refer to them as three- and twelve-month forecasts, respectively, although we stress that we generate the model-implied forecast to match exactly the future dates indicated in each survey. It is this repeated regular pattern to the survey questions that makes it well-suited as a benchmark in a real-time forecast exercise.

Since Andreasen et al. (2019) only consider Canadian government bond price data back to January 2000, they start the forecast exercise at the end of December 2006 for the real-time model estimations. This choice implies that the first survey forecasts we consider are from the Consensus Forecasts survey dated January 8, 2007, and we focus on the consensus forecasts, i.e., the mean of the individual forecasts for the four (yield, forecast horizon)-pairs available in each survey.

\section{F.3 Yield Forecast Generation}

To explain the matching yield forecast generation from the estimated models, consider the $i$ th survey dated $t_{0}^{i}$ with the two forecast dates $T_{1}^{i}$ and $T_{2}^{i}$. To map this to our models, we use the estimated model parameters from the bond yield data up until the end of the month before the survey month, denoted $t^{i}$ with $t^{i}<t_{0}^{i}$. This means that the model forecasts are lagged by about 10 days relative to the survey date of the economic forecasters. This makes our forecast performance assessment conservative relative to the survey panel. This also implies that the two effective forecast horizons for the model forecasts are $\Delta_{1}^{i}=T_{1}^{i}-t^{i}$ and $\Delta_{2}^{i}=T_{2}^{i}-t^{i}$.

For the forecasts of the three-month Treasury bill rate, we treat them as forecasts of three-month zero-coupon yields.

In the AFNS, AFGNS, and CLR-L models, yields are affine in the state variables, i.e.

$$
y_{t}(3 m)=A(3 m)+B(3 m)^{\prime} X_{t}
$$

The conditional expectation of the state variables is easily calculated as

$$
E_{t^{i}}^{\mathbb{P}}\left[X_{t^{i}+\Delta_{j}^{i}}\right]=\left(I-\exp \left(-\widehat{\mathcal{K}}_{t^{i}}^{\mathbb{P}} \Delta_{j}^{i}\right)\right) \widehat{\theta}_{t^{i}}^{\mathbb{P}}+\exp \left(-\mathcal{K}^{\mathbb{P}} \Delta_{j}^{i}\right) X_{t^{i}} \quad \text { for } \quad j=1,2,
$$

where $\widehat{\mathcal{K}}_{t^{i}}^{\mathbb{P}}$ and $\widehat{\theta}_{t^{i}}^{\mathbb{P}}$ are the estimated model parameters using bond price data up until date $t^{i}$. 
Hence, the forecasts from these two models for the three-month yield corresponding to the $i$ th survey are given by

$$
E_{t^{i}}^{\mathbb{P}}\left[y_{t^{i}+\Delta_{j}^{i}}(3 m)\right]=A(3 m)+B(3 m)^{\prime} E_{t^{i}}^{\mathbb{P}}\left[X_{t^{i}+\Delta_{j}^{i}}\right] \quad \text { for } \quad j=1,2 .
$$

In the B-AFNS model, even zero-coupon yields are not linear functions of the state variables. As a consequence, we have to resort to Monte Carlo simulations to generate the forecasts for the three-month yields from this model.

To do so, we first calculate the estimated conditional covariance matrix of the state variables

$$
\widehat{Q}_{j}^{i}=\int_{0}^{\Delta_{j}^{i}} e^{-\widehat{\mathcal{K}}_{t^{i}}^{\mathbb{P}} s} \widehat{\Sigma}_{t^{i}} \widehat{\Sigma}_{t^{i}}^{\prime} e^{-\left(\widehat{\mathcal{K}}_{t^{i}}^{\mathbb{P}}\right)^{\prime} s} d s \quad \text { for } \quad j=1,2
$$

using the estimated $\widehat{\mathcal{K}}_{t^{i}}^{\mathbb{P}}$ and $\widehat{\Sigma}_{t^{i}}$ matrices as of date $t^{i}$.

Now, let $\widehat{\Sigma}_{j}^{i}$ be the Cholesky decomposition of $\widehat{Q}_{j}^{i}$ and let $Z(\omega)$ be a vector of random variables that are each $\mathcal{N}(0,1)$ distributed with dimension equal to the number of state variables in the model. Then

$$
X_{t^{i}+\Delta_{j}^{i}}(\omega)=\left(I-\exp \left(-\widehat{\mathcal{K}}_{t^{i}}^{\mathbb{P}} \Delta_{j}^{i}\right)\right) \widehat{\theta}_{t^{i}}^{\mathbb{P}}+\exp \left(-\mathcal{K}^{\mathbb{P}} \Delta_{j}^{i}\right) X_{t^{i}}+\widehat{\Sigma}_{j}^{i} Z(\omega)
$$

represents a random draw of the state variables at time $T_{j}^{i}$ for $j=1,2$.

Next, we repeat this $N=5,000$ times to get draws $X_{t^{i}+\Delta_{j}^{i}}\left(\omega^{n}\right)$ for $n=1, \ldots, N$. The yield forecast is then given by the mean of the value of the nonlinear yield function $g\left(X_{t}\right)$ evaluated at each of the draws:

$$
E_{t^{i}}^{\mathbb{P}}\left[y_{t^{i}+\Delta_{j}^{i}}(3 m)\right]=\frac{1}{N} \sum_{n=1}^{N} g\left(X_{t^{i}+\Delta_{j}^{i}}\left(\omega^{n}\right)\right) \quad \text { for } \quad j=1,2 .
$$

For the forecasts of the ten-year government bond yield, we note that the Bank of Canada (just like the U.S. Treasury) tends to issue new bonds as close to par as possible (subject to minimum increments of 12.5 basis points in the stated coupon rate). We take this to mean that the survey participants are projecting ten-year par-coupon yields even though the Bank of Canada only issues new ten-year bonds roughly once a year. Thus, at times it may be known in advance (in particular for the three-month forecasts) that there may not be any new ten-year bonds trading, but only old seasoned bonds that could be trading some distance away from par. Even under those circumstances we take the submitted forecasts to represent 
forecasts of ten-year par-coupon yields. By implication, we must generate forecasts of ten-year par-coupon yields from the models.

To begin, we note that synthetic ten-year par-coupon yields are calculated by adjusting the coupon rate $C$ in the following equation

$$
1=\sum_{j=1}^{20} \frac{C}{2} \exp \left\{-\widehat{y}_{t^{i}}\left(t_{j}-t\right)\right\}+\exp \left\{-\widehat{y}_{t^{i}}(10)\right\},
$$

where $\widehat{y}_{t^{i}}(\tau)$ is the fitted $\tau$-year zero-coupon yield implied by the considered model estimated as of time $t^{i}$.

Since this is a nonlinear function in the state variables, we again have to resort to Monte Carlo simulation of the state variables identical to the algorithm described above. For each

survey date $t^{i}$ and forecast horizon $T_{j}^{i}$, this gives us $N$ estimated ten-year par-coupon rates denoted $C_{j}^{i}\left(\omega^{n}\right), n=1, \ldots, N$.

The forecast of the ten-year par-coupon yield is then the average of the individual projected par-coupon values:

$$
E_{t^{i}}^{\mathbb{P}}\left[C_{j}^{i}\right]=\frac{1}{N} \sum_{n=1}^{N} C_{j}^{i}\left(\omega^{n}\right) \quad \text { for } \quad j=1,2 .
$$

Finally, this is repeated for all models and all $i=1, \ldots, I$ survey dates, where $I=113$ since we cover the period from end of December 2006 to end of April 2016 with the matching Consensus forecasts covering the period from January 8, 2007, to May 9, 2016.

\section{F.4 Yield Realizations}

When it comes to the yield realizations, the available data forces us to use two different approaches.

For the three-month Treasury bill rates, we linearly interpolate between the end of the month readings of the rates of the two Treasury bills whose remaining times to maturity provide the tightest bracket around the three-month maturity point that we use in the generation of the model forecasts and that the participants in the Consensus Forecasts survey panel are assumed to be predicting.

As for the ten-year government bond yields, we base the generated forecast on par-coupon yields as explained in the previous section. Unfortunately, as already noted, the Bank of Canada only issues new ten-year bonds that would be trading close to par rather infrequently 


\begin{tabular}{c|cc}
\hline \hline \multirow{2}{*}{ Par. } & \multicolumn{2}{|c}{ One-step approach } \\
\cline { 2 - 3 } & Est & SE \\
\hline$\kappa_{11}^{\mathbb{P}}$ & 0.0445 & 0.0467 \\
$\kappa_{22}^{\mathbb{P}}$ & 0.2129 & 0.1508 \\
$\kappa_{33}^{\mathbb{P}}$ & 0.2618 & 0.2123 \\
$\kappa_{44}^{\mathbb{P}}$ & 0.7314 & 0.3037 \\
$\kappa_{55}^{\mathbb{P}}$ & 0.2024 & 0.1398 \\
\hline$\sigma_{11}$ & 0.0028 & 0.0005 \\
$\sigma_{22}$ & 0.0123 & 0.0009 \\
$\sigma_{33}$ & 0.0106 & 0.0009 \\
$\sigma_{44}$ & 0.0225 & 0.0019 \\
$\sigma_{55}$ & 0.0208 & 0.0012 \\
\hline$\theta_{1}^{\mathbb{P}}$ & 0.0517 & 0.0049 \\
$\theta_{2}^{\mathbb{P}}$ & 0.0137 & 0.0133 \\
$\theta_{3}^{\mathbb{P}}$ & -0.0417 & 0.0104 \\
$\theta_{4}^{\mathbb{P}}$ & 0.0079 & 0.0079 \\
$\theta_{5}^{\mathbb{P}}$ & 0.0396 & 0.0157 \\
\hline$\lambda$ & 0.6594 & 0.0272 \\
$\tilde{\lambda}$ & 0.1202 & 0.0070 \\
\hline \hline
\end{tabular}

Table 4: Parameter Estimates in the Updated AFGNS Model

This table reports the estimated parameters (Est) in the AFGNS model with independent factors and their standard errors (SE) using either the one-step. The SE approach are computed by pre- and post-multiplying the variance of the score by the inverse of the Hessian matrix, as outlined in Harvey (1989). The data are monthly and cover the period from January 31, 2000, to December 29, 2017.

(roughly once a year). As a consequence, we have to estimate what the coupon rate would be on a hypothetical new ten-year bond issued at par at the end of each month included in our forecast exercise.

To generate these realizations, Andreasen et al. (2019) exploit the fact that the AFGNS model delivers an accurate fit to the universe of Canadian government bonds. They therefore estimate the AFGNS model on an updated sample of Canadian government bond prices that contain data through the end of December 2017. Table 4 reports the estimated parameters for the AFGNS model using the updated sample of bond prices through December 2017.

They next combine the estimated parameters and state variables to calculate synthetic ten-year par-coupon yields based on equation (14) starting a the end of December 2006. This produces the time series shown in Figure 8, which are the values we use as the realizations in calculating the errors for the ten-year par-coupon yield forecasts.

To validate the accuracy of the series, Andreasen et al. (2019) compare them to the ten-year yields on the survey dates as reported in the Consensus Forecasts surveys and also 


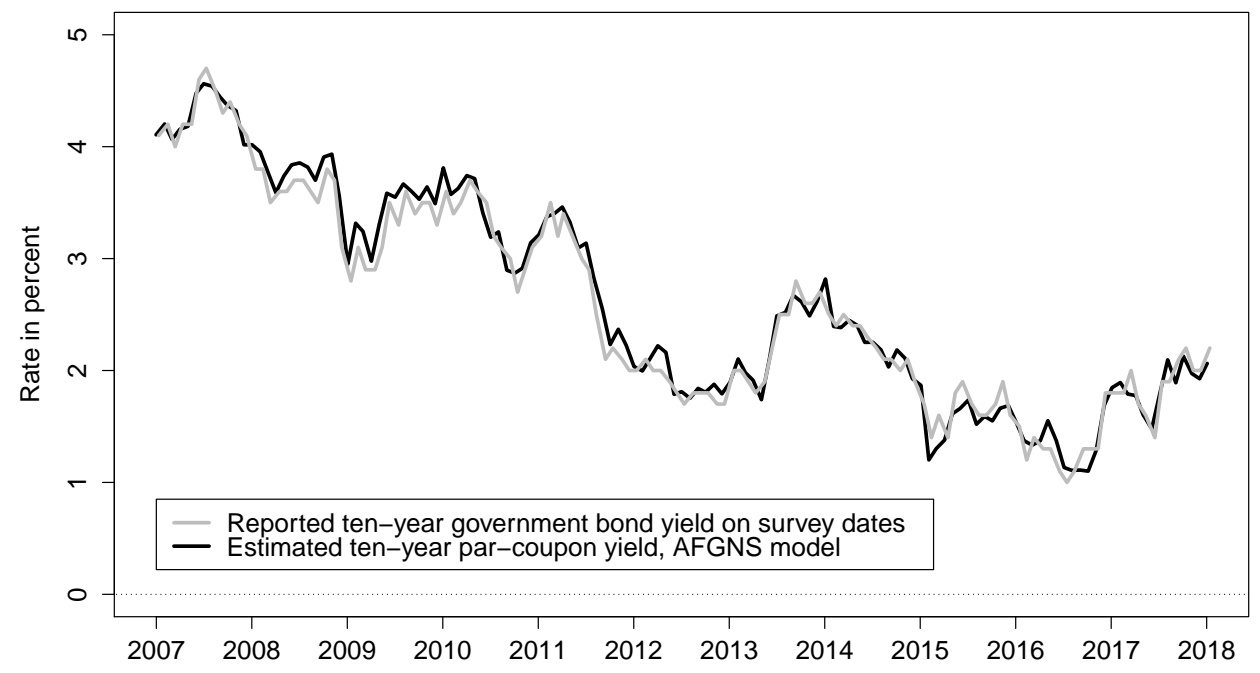

Figure 8: Estimated Ten-Year Par-Coupon Bond Yield

shown in Figure 8. Note the closeness of the two yield series, which offers support for this approach. There are two main reasons why the series are not perfectly aligned. First and most importantly, they are observed on two different dates each month (last day of the month versus the Consensus Forecasts survey date). Second, the numbers reported in the surveys are rounded to the first decimal, whereas our model-implied series are reported with 7 decimals accuracy. Both of these differences are likely to contribute to the time-varying wedges between the two series.

\section{F.5 Results}

Starting with the forecasts of the three-month yield reported in Table 5, the first set of results for the AFNS, B-AFNS, AFGNS models, labeled sample start: Jan. 2000, are taken from Andreasen et al. (2019) and refer to their results based on Bank of Canada yields. These are not identical to the nominal yields used in the implementation of our CLR-L model for two reasons. First, their data start in January 2000, while our sample of nominal yields includes data back to 1991. Second, their sample does not include the 15-year nominal yield and hence only contains ten constant yield maturities. Therefore, we also estimate their three models on our sample to have a direct apples-to-apples comparison. This produces the second set of results reported for the AFNS, B-AFNS, and AFGNS models in addition to the results 


\begin{tabular}{|c|c|c|c|c|c|c|}
\hline \multirow{2}{*}{ Model } & \multicolumn{3}{|c|}{ Three-month forecasts } & \multicolumn{3}{|c|}{ Twelve-month forecasts } \\
\hline & Mean & RMSE & MAE & Mean & RMSE & MAE \\
\hline Consensus Forecasts & -18.47 & 41.50 & 24.18 & -84.97 & 122.25 & 85.07 \\
\hline \multicolumn{7}{|c|}{ Sample start: Jan. 2000} \\
\hline AFNS model & -33.36 & 52.52 & 36.57 & -91.75 & 126.53 & 96.11 \\
\hline B-AFNS model & -33.52 & 52.63 & 36.59 & -90.66 & 128.83 & 96.17 \\
\hline AFGNS model & -20.71 & 43.71 & 28.83 & -61.21 & 88.19 & 64.12 \\
\hline \multicolumn{7}{|c|}{ Sample start: Jan. 1991} \\
\hline$\overline{\mathrm{AFNS} \text { model }}$ & -24.89 & 45.95 & 29.73 & -64.06 & 97.86 & 64.97 \\
\hline B-AFNS model & -25.13 & 45.79 & 29.85 & -65.59 & 98.20 & 67.75 \\
\hline AFGNS model & -19.44 & 43.89 & 28.17 & -52.96 & 99.29 & 66.45 \\
\hline CLR-L model & -29.06 & 51.54 & 39.62 & -86.48 & 122.64 & 101.75 \\
\hline
\end{tabular}

Table 5: Summary Statistics of Three-Month Yield Forecast Errors

This table reports the mean forecasting errors (Mean), the root mean squared forecasting errors (RMSE), and the mean absolute forecasting errors (MAE). All forecasts are computed from DTSMs that are estimated recursively. The forecast errors are reported as the true value minus the model-implied prediction, and all numbers are reported in annual basis points.

reported for our preferred CLR-L model, all shown under the heading sample start: Jan. 1991.

First, we note that the mean forecast errors are negative for all models in all exercises. We take this as evidence that Canadian yields in the 2007-2016 period examined here have been systematically running below expected levels, in part thanks to the persistent secular decline in the Canadian natural real rate $r_{t}^{*}$ we document in the paper.

Our second finding is that the forecasts from the AFNS model are generally not improved by accounting for the ZLB via the B-AFNS model, which is likely explained by the relatively brief period that the Canadian short rate stayed at the ZLB during our sample. Furthermore, this conclusion is robust to altering the sample start date. Instead, the forecasts from the AFNS model are generally improved by using the more flexible AFGNS model, and more so when the sample is short.

Regarding the importance of the sample length, the results are clear and uniform. To have a long sample with at least 15 years of data improves forecast accuracy, in particular for longer-term forecasts, relative to performing the same forecast exercise, but using shorter yield samples with 9 years less of data. As discussed in Bauer et al. (2012), long samples help mitigate finite-sample bias in the estimated parameters of the mean-reversion matrix 


\begin{tabular}{lccccccc}
\hline \hline \multirow{2}{*}{ Model } & \multicolumn{3}{c}{ Three-month forecasts } & & \multicolumn{3}{c}{ Twelve-month forecasts } \\
\cline { 2 - 3 } & Mean & RMSE & MAE & & Mean & RMSE & MAE \\
\hline Consensus Forecasts & -15.00 & 47.34 & 38.62 & & -78.69 & 101.77 & 87.44 \\
Sample start: Jan. 2000 & & & & & & \\
\cline { 1 - 1 } & & & & & & & \\
AFNS model & -29.34 & 46.88 & 38.54 & & -86.63 & 100.09 & 87.73 \\
AFGNS model & -26.56 & 45.40 & 37.11 & & -81.41 & 97.07 & 84.45 \\
& -14.02 & 41.42 & 33.33 & & -58.80 & 84.23 & 67.50 \\
Sample start: Jan. 1991 & & & & & & \\
AFNS model & -22.27 & 41.78 & 34.18 & & -60.18 & 78.18 & 65.97 \\
B-AFNS model & -18.73 & 39.92 & 32.31 & & -54.60 & 74.08 & 62.15 \\
AFGNS model & -9.44 & 37.23 & 29.98 & & -41.70 & 66.98 & 55.83 \\
CLR-L model & -25.33 & 45.71 & 38.76 & & -70.16 & 87.80 & 76.98 \\
\hline \hline
\end{tabular}

Table 6: Summary Statistics of Ten-Year Yield Forecast Errors

This table reports the mean forecasting errors (Mean), the root mean squared forecasting errors (RMSE), and the mean absolute forecasting errors (MAE). All forecasts are computed from DTSMs that are estimated recursively. The forecast errors are reported as the true value minus the model-implied prediction, and all numbers are reported in annual basis points.

$K^{\mathbb{P}}$, which can otherwise cause the estimated model dynamics to have inadequate persistence and make yield forecasts revert to mean too fast.

Now, focusing on the estimations with the sample starting in 1991, we note that the three standard models are able to outperform the Consensus Forecasts when forecasting twelve months ahead. In contrast, our preferred CLR-L model produces less accurate forecasts of three-month yields than both the standard models and the Consensus Forecasts. This may be tied to the fact that the sample of nominal yields and RRB prices used in the estimation of the CLR-L model is dominated by medium- and long-term maturities. Still, we stress that, by the conventional mean and RMSE measures, the CLR-L model is very close to the Consensus Forecasts at the twelve-month forecast horizon. Given the higher degree of complexity of the CLR-L model, we find these results encouraging.

The corresponding forecasts for the ten-year bond yield are summarized in Table 6. Here, we note a slight improvement in forecast accuracy from accounting for the ZLB as done in the B-AFNS model. We also note that the flexible five-factor AFGNS model also delivers the best forecasts for the ten-year bond yield among the three standard models. Overall, the patterns are very similar to what we observed for the three-month yield forecasts.

For the key comparison to the Consensus Forecasts survey, we note that our preferred 
CLR-L model is competitive at forecasting ten-year nominal yields at both the three- and twelve-month horizon. We speculate that this relative improvement in the forecast performance of the CLR-L model vis-à-vis the Consensus Forecasts may be a function of the greater concentration of medium- and long-term maturities used in its estimation. In addition, it remains the case that the CLR-L model underperforms the standard models when they are estimated with a matching sample of nominal yield data starting in 1991.

Overall, we can confirm the results of Andreasen et al. (2019) in that the three standard models are competitive at forecasting Canadian nominal bond yields, and their results and conclusions are strengthened when we use our longer sample with data starting in 1991. In that case, the flexible AFGNS model in particular stands out by easily beating the Consensus Forecasts in three out of the four races independent of the evaluation measure used (mean error, RMSE, or MAE). Furthermore, given the good performance of the CLR-L model, in particular relative to the Consensus Forecasts, we feel comfortable concluding that the model is able to capture nominal yield dynamics during this challenging 2007-2016 period despite the proximity of Canadian nominal yields to the ZLB. 


\section{References}

Andreasen, Martin M., Jens H. E. Christensen, and Simon Riddell, 2020, "The TIPS Liquidity Premium," Working Paper 2017-11, Federal Reserve Bank of San Francisco.

Andreasen, Martin M., Jens H. E. Christensen, and Glenn D. Rudebusch, 2019, "Term Structure Analysis with Big Data: One-Step Estimation Using Bond Prices," Journal of Econometrics, Vol. 212, 26-46.

Bauer, Michael D., Glenn D. Rudebusch, and Jing (Cynthia) Wu, 2012, "Correcting Estimation Bias in Dynamic Term Structure Models," Journal of Business and Economic Statistics, Vol. 30, No. 3, 454-467.

Black, Fisher, 1995, "Interest Rates as Options," Journal of Finance, Vol. 50, No. 7, 1371-1376.

Cheridito, Patrick, Damir Filipović, and Robert L. Kimmel, 2007, "Market Price of Risk Specifications for Affine Models: Theory and Evidence," Journal of Financial Economics, Vol. 83, No. 1, 123-170.

Chernov, Mikhail and Philippe Mueller, 2012, "The Term Structure of Inflation Expectations," Journal of Financial Economics, Vol. 106, No. 2, 367-394.

Christensen, Jens H. E., Francis X. Diebold, and Glenn D. Rudebusch, 2009, “An ArbitrageFree Generalized Nelson-Siegel Term Structure Model," Econometrics Journal, Vol. 12, No. 3, C33-C64.

Christensen, Jens H. E., Francis X. Diebold, and Glenn D. Rudebusch, 2011, "The Affine Arbitrage-Free Class of Nelson-Siegel Term Structure Models," Journal of Econometrics, Vol. 164, No. 1, 4-20.

Christensen, Jens H. E. and James M. Gillan, 2019, "Does Quantitative Easing Affect Market Liquidity?," Working Paper 2013-26, Federal Reserve Bank of San Francisco.

Christensen, Jens H. E., Jose A. Lopez, and Glenn D. Rudebusch, 2010, "Inflation Expectations and Risk Premiums in an Arbitrage-Free Model of Nominal and Real Bond Yields," Journal of Money, Credit and Banking, Supplement to Vol. 42, No. 6, 143-178. 
Christensen, Jens H. E., Jose A. Lopez, and Glenn D. Rudebusch, 2016, "Pricing Deflation Risk with U.S. Treasury Yields," Review of Finance, Vol. 20, No. 3, 1107-1152.

Christensen, Jens H. E. and Glenn D. Rudebusch, 2015, "Estimating Shadow-Rate Term Structure Models with Near-Zero Yields," Journal of Financial Econometrics, Vol. 13, No. 2, 226-259.

Christensen, Jens H. E. and Glenn D. Rudebusch, 2016, "Modeling Yields at the Zero Lower Bound: Are Shadow Rates the Solution?," in Eric Hillebrand, Siem Jan Koopman (ed.) Dynamic Factor Models (Advances in Econometrics, Volume 35) Emerald Group Publishing Limited, 75-125.

Dai, Qiang and Kenneth J. Singleton, 2000, "Specification Analysis of Affine Term Structure Models," Journal of Finance, Vol. 55, No. 5, 1943-1978.

Duffee, Gregory R., 2002, "Term Premia and Interest Rate Forecasts in Affine Models," Journal of Finance, Vol. 57, No. 1, 405-443.

Duffie, Darrell, Nicolae Gârleanu, and Lasse Heje Pedersen, 2007, "Valuation in Over-theCounter Markets," Review of Financial Studies, Vol 20, No. 5, 1865-1900.

Duffie, Darrell and Rui Kan, 1996, "A Yield-Factor Model of Interest Rates," Mathematical Finance, Vol. 6, No. 4, 379-406.

Gürkaynak, Refet S., Brian Sack, and Jonathan H. Wright, 2007, "The U.S. Treasury Yield Curve: 1961 to the Present," Journal of Monetary Economics, Vol. 54, No. 8, 22912304 .

Kim, Don H. and Kenneth J. Singleton, 2012, "Term Structure Models and the Zero Bound: An Empirical Investigation of Japanese Yields," Journal of Econometrics, Vol. 170, No. $1,32-49$.

Krippner, Leo, 2013, “A Tractable Framework for Zero Lower Bound Gaussian Term Structure Models," Discussion Paper 2013-02, Reserve Bank of New Zealand.

Laubach, Thomas and John C. Williams, 2003, "Measuring the Natural Rate of Interest," Review of Economics and Statistics, Vol. 85, No. 4, 1063-1070. 
Laubach, Thomas and John C. Williams, 2016, "Measuring the Natural Rate of Interest Redux," Business Economics, Vol. 51, No. 2, 57-67.

Merton, Robert C., 1974, "On the Pricing of Corporate Debt: The Risk Structure of Interest Rates," Journal of Finance, Vol. 29, No. 2, 449-470.

Nelson, Charles R. and Andrew F. Siegel, 1987, "Parsimonious Modeling of Yield Curves," Journal of Business, Vol. 60, No. 4, 473-489.

Rudebusch, Glenn D. and Eric Swanson, 2011, "The Bond Premium in a DSGE Model with Long-Run Real and Nominal Risks," American Economic Journals: Macroeconomics, Vol. 4, No. 1, 105-43.

Sack, Brian and Robert Elsasser, 2004, "Treasury Inflation-Indexed Debt: A Review of the U.S. Experience," Federal Reserve Bank of New York Economic Policy Review, Vol. 10, No. 1, 47-63.

Singleton, Kenneth J., 2006, Empirical Dynamic Asset Pricing, Princeton University Press. 